\title{
Organic electronic materials for hydrogen peroxide production
}

Maciej Gryszel

$$
\mathrm{O}_{2}+2 \mathrm{H}_{2} \mathrm{O} \underset{\text { energy }(\mathrm{h} v \text { or } \Delta \mathrm{E})}{\stackrel{\text { catalyst }}{\longrightarrow}} 2 \mathrm{H}_{2} \mathrm{O}_{2}
$$


Linköping Studies in Science and Technology, Dissertation No. 2037

\section{Organic electronic \\ materials for hydrogen peroxide production \\ Maciej Gryszel}

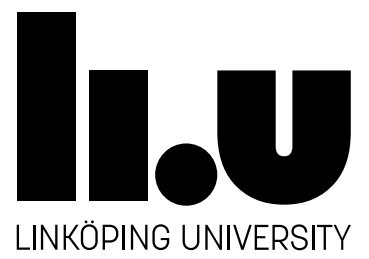

Department of Science and Technology

Linköping University, Sweden

Linköping 2020 


\section{Description of the cover image:}

Chemical equation of hydrogen peroxide synthesis from oxygen and water, investigated in this thesis. The reaction requires a catalyst and an external energy source, in the form of light or electricity.

Organic electronic materials for hydrogen peroxide production Copyright (C) Maciej Gryszel, 2020

During the course of research underlying this thesis, Maciej Gryszel was enrolled in Forum Scientium, a multidisciplinary graduate school at Linköping University, Sweden.

Printed by LiU-Tryck, Linköping, Sweden, 2020

Electronic Publication: www.ep.liu.se

ISBN 978-91-7929-939-2

ISNN 0345-7524 


\begin{abstract}
Hydrogen peroxide $\left(\mathrm{H}_{2} \mathrm{O}_{2}\right)$ is an important oxidant, used in various fields of industry, such as paper manufacturing, production of polymers, detergents, and cosmetics. Considering that the molecule degrades only to $\mathrm{H}_{2} \mathrm{O}$ and $\mathrm{O}_{2}$, it is regarded as a green chemical. Unfortunately, the incumbent method of $\mathrm{H}_{2} \mathrm{O}_{2}$ synthesis, based on anthraquinone oxidation, although efficient, is not environmentally friendly, as it requires fossil fuels and significant energy input. Therefore, there are efforts underway to reduce the ecological impact of hydrogen peroxide production. Some of the most promising approaches involve catalytic reduction of $\mathrm{O}_{2}$ to $\mathrm{H}_{2} \mathrm{O}_{2}$ in an aqueous environment. This can be coupled with water oxidation. As the required energy could be delivered in different ways, hydrogen peroxide synthesis can be achieved by electrocatalysis, photoelectrocatalysis, or photocatalysis.

This thesis explores the possibility of using organic electronic materials as catalysts for $\mathrm{H}_{2} \mathrm{O}_{2}$ evolution in oxygenated water solutions. Organic electronics is a field of materials science focused on conducting and semiconducting organic molecules. These materials offer many possible advantages, related to low cost, flexibility, and good optoelectronic properties. Huge progress in the field over the last years led to their commercial applications in e.g. organic light emitting diodes and photovoltaics. Only very recently have organic electronics begun to be considered from the point of view of catalysis.

In the first two papers, we investigate electrocatalytic activity of an organic pigment (PTCDI) and a conducting polymer (PEDOT) towards oxygen reduction to hydrogen peroxide. Both types of catalysts are chemically stable and able to operate in a wide $\mathrm{pH}$ range. In paper 3, we demonstrate that $\mathrm{H}_{2} \mathrm{O}_{2}$-evolving photocathodes can be based on an organic PN heterojunction, giving devices of a record-breaking performance. In the first part of paper 4, the same concept was tested for a naturally-occurring semiconductor, eumelanin, leading to a first report of photoelectrocatalytic properties of this material. In the second part of paper 4, as well as in papers 5 and 6 , we explore, respectively, photochemical hydrogen peroxide synthesis with eumelanin, organic semiconductors, and organic dyes. We show that the photostability of catalysts is higher for materials with low-lying HOMO level and it can be increased by an addition of a reducing agent to the reaction system. Our findings prove that already existing organic electronic materials can be successfully applied in $\mathrm{H}_{2} \mathrm{O}_{2}$ evolution for environmentally friendly chemical synthesis, suggesting their use in harvesting of solar energy and in situ generation of hydrogen peroxide for biomedical applications.
\end{abstract}





\section{Sammanfattning}

Väteperoxid $\left(\mathrm{H}_{2} \mathrm{O}_{2}\right)$ är en viktig oxidant som används inom olika industrier, såsom papperstillverkning och produktion av polymerer, tvättmedel och kosmetika. Med tanke på att molekylen bryts ner till vatten $\left(\mathrm{H}_{2} \mathrm{O}\right)$ och syre $\left(\mathrm{O}_{2}\right)$ betraktas den som en grön kemikalie. Tyvärr är den befintliga metoden för framställning av $\mathrm{H}_{2} \mathrm{O}_{2}$ baserad på oxidation av en antrakinon, en metod som är effektiv, men inte miljövänlig eftersom den kräver fossila bränslen och betydande energitillförsel. Det pågår därför ansträngningar för att minska den ekologiska effekten av väteperoxidproduktionen. Några av de mest lovande metoderna involverar katalytisk $\mathrm{O}_{2}$ till $\mathrm{H}_{2} \mathrm{O}_{2}$-reduktion i vattenlösning, kombinerat med vattenoxidation. Eftersom den nödvändiga energin kan levereras på olika sätt kan väteperoxidsyntesen uppnås genom elektrokatalys, fotoelektrokatalys eller fotokatalys.

Denna avhandling undersöker möjligheten att använda organiska elektroniska material som katalysatorer för framställning av $\mathrm{H}_{2} \mathrm{O}_{2}$ i syresatta vattenlösningar. Organisk elektronik är ett område inom materialvetenskap med fokus på ledande och halvledande organiska molekyler. Dessa material erbjuder många fördelar, såsom låg kostnad, flexibilitet och goda optoelektroniska egenskaper. Enorma framsteg på området har under de senaste åren lett till deras kommersiella tillämpningar i till exempel organiska ljusemitterande dioder och fotovoltaik. Nyligen har också organisk elektronik börjat övervägas ur katalysens synvinkel.

I de två första artiklarna undersöker vi en elektrokatalytisk aktivitet av ett organiskt pigment (PTCDI) och en ledande polymer (PEDOT) i respekt till syrereduktion och väteperoxidproduktion. Båda typerna av katalysatorer är kemiskt stabila och kan arbeta inom ett brett pH-område. I artikel 3 visar vi att $\mathrm{H}_{2} \mathrm{O}_{2}$-producerande fotokatoder kan baseras på en organisk PN-gränsyta, vilket ger enheter med en rekordbrytande kapacitet. I den första delen av artikel 4 testades samma koncept för en naturligt förekommande halvledare, eumelanin, vilket ledde till en första rapport om fotoelektrokatalytiska egenskaper hos detta material. I den andra delen av artikel 4, samt i artikel 5 och 6, undersöker vi fotokemisk väteperoxidsyntes med eumelanin, organiska halvledare och organiska färgämnen. Vi visar att fotostabiliteten hos katalysatorer är högre för material med lågt liggande HOMO-nivå och att den kan ökas genom en tillsats av ett reduktionsmedel till reaktionssystemet. Våra fynd visar att redan befintliga organiska elektroniska material framgångsrikt kan tillämpas i $\mathrm{H}_{2} \mathrm{O}_{2}$-utvecklingen för miljövänlig kemisk syntes, vilket antyder att de kan användas för att ta tillvara på solenergi och för produktion av väteperoxid inom biomedicin. 



\section{Acknowledgments}

I would like to express my sincere gratitude to all those who made this thesis possible, especially:

Eric Glowacki, for offering me a great work and life opportunity, being my main supervisor and help with writing the papers and this thesis. Thanks to for his time, patience and devotion I learned many new techniques and gained invaluable knowledge. If it weren't for his great scientific ideas and courage to explore new paths, we wouldn't have achieved so much.

Magnus Berggren, for founding and leading Laboratory of Organic Electronics, the amazing place where I performed the research.

Magnus Jonsson, for being my co-supervisor, always ready to help with problems of any nature.

Xavier Crispin, Vedran Đerek, Marie Jakešová, Aleksandr Markov, Eva Miglbauer, Ludovico Migliaccio, Evangelia Mitraka, Renata Rybakiewicz, Malin Silverå Ejneby, Mykhailo Sytnyk, Mikhail Vagin, and Magdalena Warczak, for nice and smooth collaborations, resulting in the papers we had an honor to publish together.

All other LOE and RISE members, former and current, for creating the wonderful environment and cheerful atmosphere for scientific work.

Wolfgang Heiss, for hosting me during my stay in the i-MEET Laboratory at FriedrichAlexander University in Erlangen.

Lars Gustavsson, Meysam Karami Rad, Thomas Karlsson, and Anna Malmström, for maintaining the laboratory.

The administrative team and the human resources department, for taking care of all important matters, allowing me to focus on the research.

Stefan Klintström, for leading Forum Scientium, the graduate school I was member of working on my thesis.

Pawel Wójcik and Redox.me, for supplying the electrochemical equipment used in our work. Knut and Alice Wallenberg Foundation, for financing all the research and my $\mathrm{PhD}$ student position. 



\section{List of included papers}

\section{Paper 1:}

Organic semiconductor perylenetetracarboxylic diimide (PTCDI) electrodes for electrocatalytic reduction of oxygen to hydrogen peroxide

Magdalena Warczak, Maciej Gryszel, Marie Jakešová, Vedran Đerek and Eric Daniel Głowacki Chemical communications, 2018, 54, 1960 - 1963

Contribution: I contributed to the experiment design, performed some of the experimental work, and took part in the editing of the final manuscript.

\section{Paper 2:}

Electrocatalytic Production of Hydrogen Peroxide with Poly(3,4-ethylenedioxythiophene) Electrodes

Evangelia Mitraka, Maciej Gryszel, Mikhail Vagin, Mohammad Javad Jafari, Amritpal Singh, Magdalena Warczak, Manassis Mitrakas, Magnus Berggren, Thomas Ederth, Igor Zozoulenko, Xavier Crispin, and Eric Daniel Głowacki

Advanced Sustainable Systems, 2019, 3, 1800110

Contribution: I contributed to the experiment design, performed some of the experimental work, processed part of the experimental data, and took part in the editing of the final manuscript.

\section{Paper 3:}

Organic heterojunction photocathodes for optimized photoelectrochemical hydrogen peroxide production

Maciej Gryszel, Aleksandr Markov, Mikhail Vagin and Eric Daniel Głowacki

Journal of Materials Chemistry A, 2018, 6, 24709 - 24716

Contribution: I came up with the project concept, performed most of the experimental work, processed the experimental data, wrote and submitted the final manuscript. 


\section{Paper 4:}

\section{Aqueous photo(electro)catalysis with eumelanin thin films}

Ludovico Migliaccio, Maciej Gryszel, Vedran Đerek, Alessandro Pezzella and Eric Daniel Głowacki

Materials Horizons, 2018, 5, 984 - 990

Contribution: I contributed to the experiment design, performed some of the experimental work, processed part of the experimental data, contributed to writing of the experimental part of the paper and took part in the editing of the final manuscript.

\section{Paper 5:}

General Observation of Photocatalytic Oxygen Reduction to Hydrogen Peroxide by Organic Semiconductor Thin Films and Colloidal Crystals

Maciej Gryszel, Mykhailo Sytnyk, Marie Jakešová, Giuseppe Romanazzi, Roger Gabrielsson, Wolfgang Heiss and Eric Daniel Głowacki

ACS Applied Materials \& Interfaces, 2018, 10, 13253 - 13257

Contribution: I came up with the experiment design, performed the experimental work, processed the experimental data, wrote a draft of the experimental part of the paper and took part in the editing of the final manuscript.

\section{Paper 6:}

\section{Water-Soluble Organic Dyes as Molecular Photocatalysts for $\mathrm{H}_{2} \mathrm{O}_{2}$ Evolution}

Maciej Gryszel, Renata Rybakiewicz and Eric Daniel Głowacki

Advanced Sustainable Systems, 2019, 3, 1900027

Contribution: I came up with the experiment design, performed most of the experimental work, processed the experimental data, wrote a first draft of the paper and took part in the editing of the final manuscript. 


\section{Table of contents}

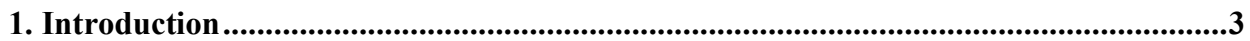

1.1. Motivation and research background ......................................................................

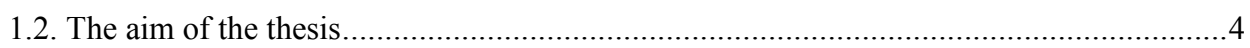

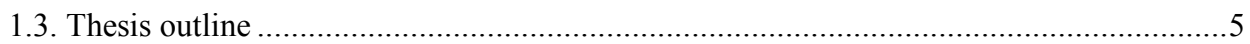

2. Electro-, photoelectro-, and photocatalysis for chemical synthesis ..................................7

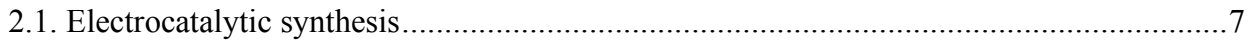

2.1.1. General characteristic of electrocatalytic synthesis ........................................... 7

2.1.2. Properties of a good electrocatalyst ...............................................................

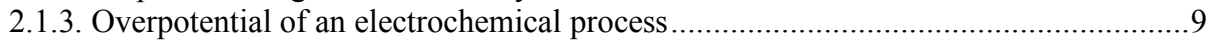

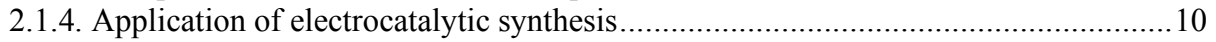

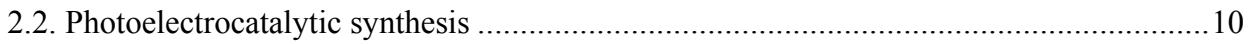

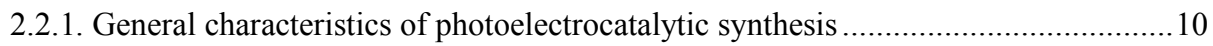

2.2.2. Comparison of photoelectrodes and photovoltaic cells....................................... 12

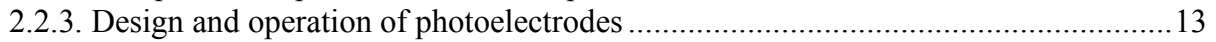

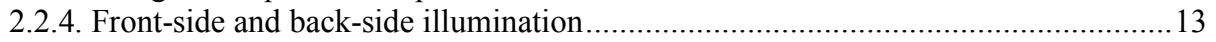

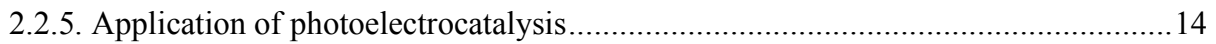

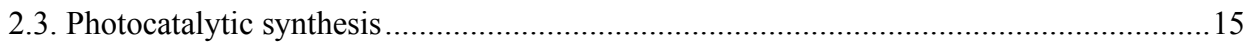

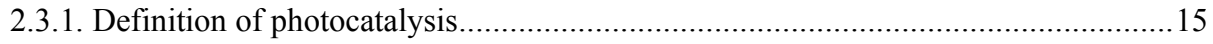

2.3.2. General characteristic of photocatalysis with semiconductors ................................15

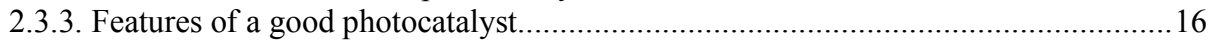

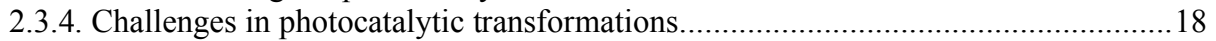

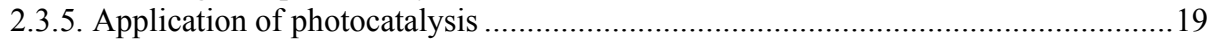

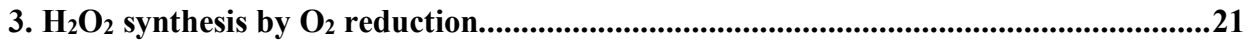

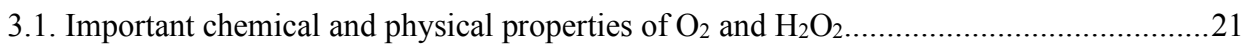

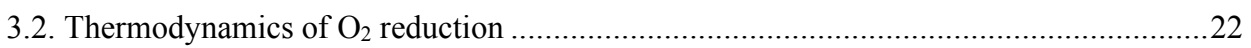

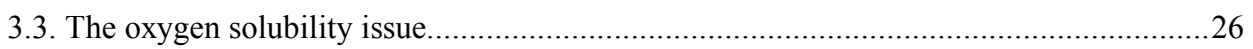

4. Organic electronic materials as catalysts for $\mathrm{H}_{2} \mathrm{O}_{2}$ synthesis.....................................29

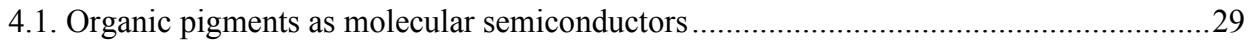

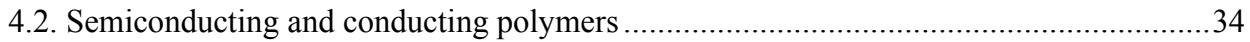

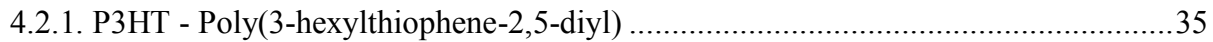

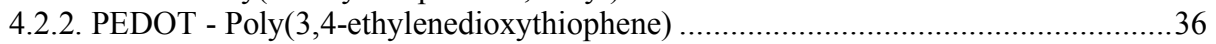

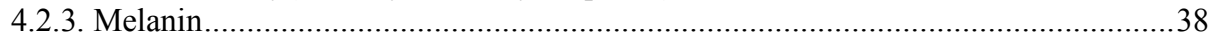


5. Fabrication...................................................................................................................41

5.1. Preparation of thin films by physical vapor deposition (PVD) ...................................... 41

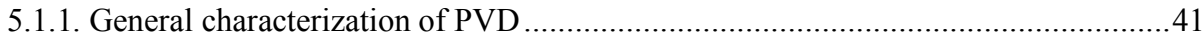

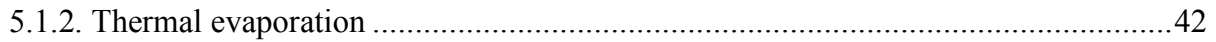

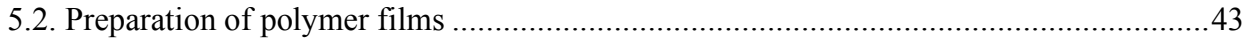

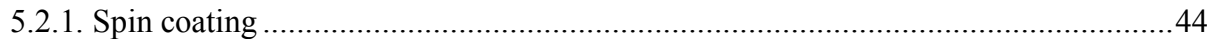

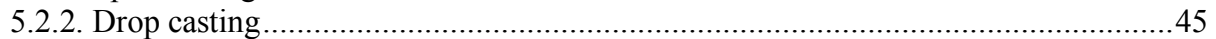

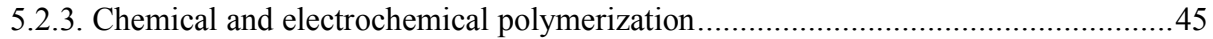

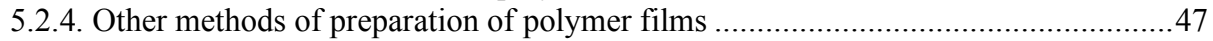

5.3. Other processes in manufacturing of thin layer devices.............................................47

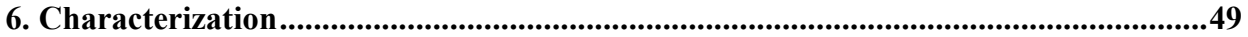

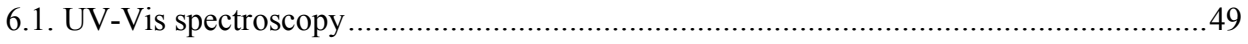

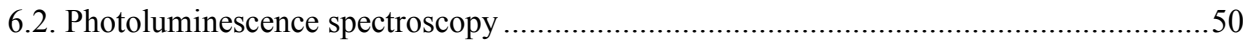

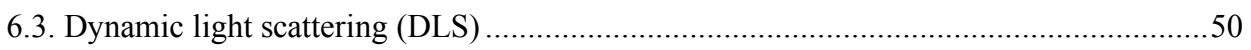

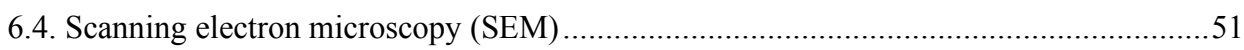

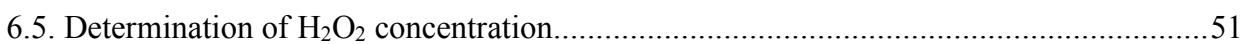

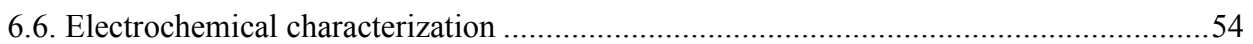

6.6.1. General information on electrochemical measurements ......................................54

6.6.2. Electrochemical measurements for characterization of $\mathrm{H}_{2} \mathrm{O}_{2}$ synthesis catalysts ......57

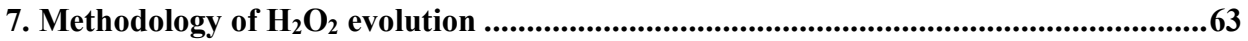

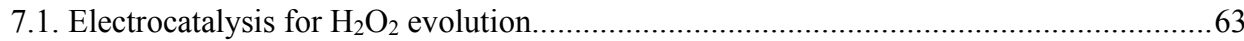

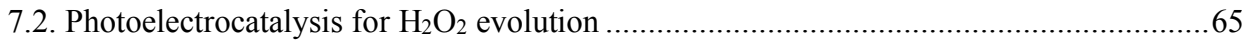

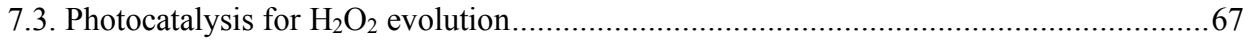

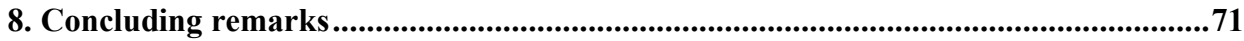

8.1. Advantages of $\mathrm{H}_{2} \mathrm{O}_{2}$ synthesis with organic electronics materials...............................71

8.2. Limitations of $\mathrm{H}_{2} \mathrm{O}_{2}$ synthesis with organic electronics materials and future work .........72

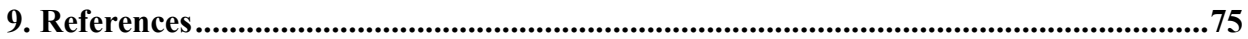




\section{Introduction}

\subsection{Motivation and research background}

Hydrogen peroxide, $\mathrm{H}_{2} \mathrm{O}_{2}$, is a molecule of simple structure, but of high importance in many areas of industry. As an environmentally friendly oxidant, it is widely used for paper manufacturing (bleaching of wood pulp) ${ }^{1}$, as an intermediate in production of polymers (synthesis of polymerization initiators), in food industry (as bleaching agent) ${ }^{2}$, for manufacturing of detergents, and as an ingredient of some cosmetics ${ }^{3}$. In our everyday lives, it is sometimes used for wound treatment ( $3 \%$ solution). Although this particular usage might be controversial ${ }^{4}$, sterilization properties of $\mathrm{H}_{2} \mathrm{O}_{2}$ make it an inexpensive and versatile disinfectant in laboratory and medicine. But probably the most spectacular application of hydrogen peroxide is in the rocket industry, where it can be used as a propellant ${ }^{5}$, mixed with another fuel, or as a single compound. Environmental friendliness of $\mathrm{H}_{2} \mathrm{O}_{2}$ is associated with the fact that the molecule degrades only to $\mathrm{H}_{2} \mathrm{O}$ and $\mathrm{O}_{2}$. Unfortunately, the most common method used for its manufacturing, although well-established and leading to $\mathrm{H}_{2} \mathrm{O}_{2}$ of high purity and concentration, cannot be regarded as non-polluting ${ }^{6}$. The synthesis is based on anthraquinone oxidation, a process which involves hydrogen from fossil fuel sources, organic solvents, noble metal catalysts, and significant energy input. The process generates a nonnegligible amount of waste. Both $\mathrm{H}_{2} \mathrm{O}_{2}$ manufacturers and the scientific research community try to address these issues.

While the industry usually focuses on optimization of the anthraquinone process to reduce its energy consumption and waste generation, academic researchers are exploring different methods of hydrogen peroxide production, such as electrochemical and photochemical syntheses ${ }^{6}$. The main advantage of the latter approaches is the fact that $\mathrm{H}_{2} \mathrm{O}$ and $\mathrm{O}_{2}$ are used as substrates for the synthesis. The required energy input is supplied by electricity or light. This not only makes the whole hydrogen peroxide cycle much more environmentally friendly, but also opens potential avenues for other applications. The abovementioned application of $\mathrm{H}_{2} \mathrm{O}_{2}$ as rocket fuel is related to the fact the molecule contains the highly energetic-O-O- bond. This can be utilized for electricity generation in single-compartment hydrogen peroxide fuel cells ${ }^{7}$, where hydrogen peroxide acts as both reducer and oxidant. Therefore, it is possible to accumulate and store solar energy in a form of hydrogen peroxide and use it for on-demand electricity generation. From the chemical point of view, the only substrates and products of this process are the same: just water and oxygen. Wide abundance and non-toxicity of these two molecules gives us a possibility of on-site hydrogen peroxide production, for instance for a given industrial application. We would not need to synthesize $\mathrm{H}_{2} \mathrm{O}_{2}$ for a given application in 
advance, or to transport it. Having control over the current in the electrochemical process and illumination time and power in the photochemical process, we can precisely generate hydrogen peroxide in a required amount, only when and where it is necessary. Therefore, we can also think of possible applications of $\mathrm{H}_{2} \mathrm{O}_{2}$ technologies in medicine, for stimulation of cells ${ }^{8,9}$ or even cancer treatment ${ }^{10,11}$. Thanks to recent development in iontronics ${ }^{12}$, whenever ion pumps can be implanted, we are capable of precise drug delivery at given time and amount, minimizing side effects of the treatment. Nevertheless, this approach cannot be easily translated to potential $\mathrm{H}_{2} \mathrm{O}_{2}$-based therapies, as this molecule, being electrically neutral, cannot move under the influence of an electric field. With in situ generation of $\mathrm{H}_{2} \mathrm{O}_{2}$, this limitation is not a problem.

\subsection{The aim of the thesis}

The aim of the research efforts summarized in this thesis was to investigate the possibility of using organic electronic materials for more sustainable synthesis of hydrogen peroxide with oxygen and water as the main substrates. The concepts of electrochemical, photoelectrochemical, and photochemical $\mathrm{H}_{2} \mathrm{O}_{2}$ generation are already established, in some cases they are beyond the basic research stage and find technological applications, e.g. in on-site production of diluted, basic solutions of hydrogen peroxide for paper pulp bleaching ${ }^{6}$. The $\mathrm{O}_{2} / \mathrm{H}_{2} \mathrm{O}$ to $\mathrm{H}_{2} \mathrm{O}_{2}$ transformation, apart from energy, requires the presence of a catalyst. So far, in the vast majority of cases, catalytic properties of inorganic materials are utilized for this purpose $^{13}$. However, there are certain caveats related to this approach. First of all, based on some published examples, we can assume that inorganic materials are not inherently selective towards $\mathrm{O}_{2} / \mathrm{H}_{2} \mathrm{O}$ to $\mathrm{H}_{2} \mathrm{O}_{2}$ synthesis ${ }^{13}$. The reaction of $\mathrm{H}_{2} \mathrm{O}_{2}$ reduction to water is a potentially serious loss mechanism. Although there are examples of state-of-the-art materials which are selective and give hydrogen peroxide in high yield, they are usually based on expensive and rare metals ${ }^{14}$. Examples showing sustained accumulation of peroxide with these metallic electrodes are rare. The other problem, especially important in photo- and photoelectrocatalysis, is the light absorption window of inorganic materials. Many of the materials reported as photocatalysts for $\mathrm{H}_{2} \mathrm{O}_{2}$ evolution, such as $\mathrm{TiO}_{2}$ or $\mathrm{ZnO}$, have a wide optical bandgap, therefore they utilize only small part of the solar spectrum ${ }^{15}$. From the point of view of solar energy harvesting, this is not practical. There are of course many inorganic materials of smaller band gap, which absorb also visible light, but usually they are either toxic ${ }^{16}$ or simply lack required catalytic activity. The third issue, flexibility. Thinking of possible, $\mathrm{H}_{2} \mathrm{O}_{2}$-producing biomedical devices, mechanical compatibility of the device with moving tissues is an important requirement, which allows for operation in living organisms. All of these problems can be 
possibly addressed by using organic materials. Even though most of them are insulators, the emerging field of organic electronics provides us with many examples of conductive and semiconductive materials which can be utilized in aqueous redox processes. Organic electronic materials are known of their low price, non-toxicity, potentially high photostability and strong absorption of visible light. What is more, based on initial studies on their photoelectrocatalytic application, we can also expect that they will be selective towards $\mathrm{H}_{2} \mathrm{O}_{2}$ synthesis ${ }^{17}$. This makes them perfect candidates for new catalysts of environmentally friendly hydrogen peroxide synthesis catalysts.

Therefore, the aim of the thesis is to establish the parameter space of how organic electronic materials are capable for electrochemical, photoelectrochemical, and photochemical $\mathrm{H}_{2} \mathrm{O}_{2}$ syntheses. Substantial attention is paid to characterization of longer-term performance and stability. Based on the experimental evidence and gained knowledge about possible advantages and limitations, future prospects of the whole concept of organic electronic $\mathrm{H}_{2} \mathrm{O}_{2}$ energetic cycles can be outlined.

\subsection{Thesis outline}

The first chapter of the thesis presents motivation behind the project. Chapter 2 is a general characterization of electrocatalytic, photoelectrocatalytic, and photocatalytic methods of chemical synthesis. Chapter 3 covers the fundamental chemistry of hydrogen peroxide production by oxygen reduction as well as important information about the reagents. Chapter 4 introduces the organic electronic materials, used as catalysts for the syntheses in our work. Methodology of the device fabrication is detailed in Chapter 5. Characterization methods are discussed in Chapter 6. The following Chapter 7 concerns methodology of $\mathrm{H}_{2} \mathrm{O}_{2}$ evolution and quantification used in our work. Finally, concluding remarks are collected in the final Chapter 8. 



\section{Electro-, photoelectro-, and photocatalysis for chemical synthesis}

\subsection{Electrocatalytic synthesis}

\subsubsection{General characteristics of electrocatalytic synthesis}

Electrocatalytic synthesis can be defined as a method in which the desired product is obtained in an electrochemical process, that is a reaction on a catalyst driven by the passage of electrical current. This term, in many works, is synonymous with electrolysis ${ }^{18}$. In a vast majority of cases, the system consists of a liquid electrolyte and at least two electrodes. By applying a potential difference between them, we force a current, which induces a redox process: a reaction in which atoms change their oxidation states due to a transfer of electrons. When electrons are gained, the oxidation state is decreased and the process is described as reduction. On the other hand, if electrons are lost, the oxidation state increases, resulting in oxidation. In any electrochemical system, these two processes are coupled, as the total number of electrons in the system must be conserved. The oxidation on one of the electrodes can take place only if the reduction happens simultaneously on the other and vice versa. Therefore, even if the aim is to obtain a single product on single electrode, due to the nature of redox reactions, two separate processes at two electrodes are required (although it is sometimes possible to obtain the same product on both). The electrode involved in the reduction is called a cathode. The other one, responsible for oxidation, is called an anode.

\subsubsection{Properties of a good electrocatalyst}

Like in all catalytic processes, we expect the electrocatalyst to be stable, not only mechanically but also chemically. Neither degradation (by self-oxidation/reduction) nor activity loss (by permanent change of the catalyst surface) is desired. The other important feature of a catalyst is its selectivity, in the general case often described as a conversion rate, which says what part of the reacted substrate is converted into the desired product. However, in electrocatalytic synthesis, more frequently, the term faradaic efficiency is used ${ }^{19}$. This is a parameter which correlates the obtained molar amount of the desired product with the maximum theoretical value corresponding to the molar amount of electrons exchanged in the system. Based on Faraday's laws of electrolysis and the Faraday constant (the electric charge of one mole of electrons) we can derive a following formula for faradaic efficiency, FE:

$$
F E=\frac{n_{\text {measured }}}{n_{\text {theoretical }}}=\frac{n \cdot F \cdot z}{Q}
$$


Where:

$n$ : molar amount of the desired product obtained

F: Faraday constant $\left(96485 \mathrm{C} \cdot \mathrm{mol}^{-1}\right)$

$Z$ : number of electrons gained/lost to give one molecule of the product

$Q$ : electrical charge passed in the system (integral of the $\mathrm{I}=\mathrm{f}(\mathrm{t})$ dependence)

The electrocatalyst should also demonstrate high activity - the reaction rate should be as high as possible. This can be increased either by chemical or physical modification of the catalyst.

In most cases, the electrodes, which connect the electric power supply and the redox processes, are themselves electrocatalysts, or these conductors are modified with a coating which serves as a cocatalyst. The reason why materials of good electrical conductivity are used is to minimize the ohmic losses in the system, that is the electrical resistances which increase the required voltage to achieve given current ${ }^{20}$. Ohmic losses are caused also by the electrolyte and electric contacts. In some cases, the actual synthesis does not occur on the electrode/solution interface, but between the substrate and a dissolved mediator. This is a catalytic substance which reacts with the electrode, forming an intermediate product, which by the reaction with the substrate, gives the product and turns back to its initial form. For example, with this approach, using Pt electrode, we can perform the anodic fluorodesulfurization, obtaining a product with two $\mathrm{F}$ atoms as substituents ${ }^{21}$, as shown in Fig. 2.1.

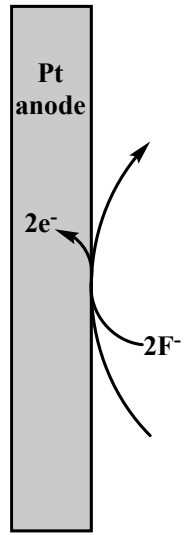<smiles>COc1ccc(I(F)c2ccc(I)cc2)cc1</smiles><smiles>[X]c1ccc(C2(c3ccc([X])cc3)SCCCS2)cc1</smiles>

Fig. 2.1. Anodic fluorodesulfurization with Pt anode and iodoaryl compound as redox mediator. As an electrolyte, mixture of $\mathrm{CH}_{3} \mathrm{CN}$ and $\mathrm{Et}_{3} \mathrm{~N} \cdot 3 \mathrm{HF}$ is used. 
The dissolved substrates might be introduced to the electrolyte either before or during the process, for example, gas by constant purging of the solution ${ }^{13}$, or metal cations by anodic self-oxidation. The obtained products remain dissolved in the reaction mixture, or are released in a form of gas or solid, which usually deposits on the electrode.

\subsubsection{Overpotential of an electrochemical process}

Gibbs free energy is a thermodynamic parameter which allows determination if a chemical process is possible in given conditions. In electrochemistry it is more convenient to use values of standard electrode potentials $\left(\mathrm{E}^{\circ}\right)$, which are associated with the change of standard Gibbs free energy $\left(\Delta G^{\circ}\right)$ by the following relation:

$$
\Delta G^{\circ}=-n \cdot F \cdot E^{\circ}
$$

Where:

$n$ : number of electrons transferred in the reaction

F: Faraday constant $\left(96485 \mathrm{C} \cdot \mathrm{mol}^{-1}\right)$

$E^{\text {: }}$ standard electrode potential

Values of electrode potentials for many chemical processes can be found in the literature, usually given as potentials of half-reactions versus the standard hydrogen electrode. This is very useful in electrocatalysis, as calculation of the electrode potential difference $\Delta \mathrm{E}$ in given conditions informs us about the minimum voltage which needs to be applied to run the electrochemical process. However, the value actually required is always higher, which is caused not only by the ohmic losses mentioned before, but also by the overpotential of electrode. Overpotential is the potential difference between the theoretical, thermodynamic electrode potential and the potential at which the reaction is experimentally observed, that is, at which a small current density is registered ${ }^{19}$. Overpotential corresponds to the kinetic activation barrier of the electrochemical reaction. In electrosynthesis it makes the cathode potential more negative and the anode potential more positive. The excess energy delivered by higher voltage is released as heat.

From the point of view of electrocatalytic synthesis, existence of overpotential is undesired, as it decreases energy efficiency of the process - to get the intended current density, higher voltage needs to be applied. Overpotential is a feature typical of a given electrocatalyst. 
Therefore, a good catalytic system, apart from stability, selectivity and activity, should also work at the lowest possible overpotential.

\subsubsection{Application of electrocatalytic synthesis}

Electrocatalytic synthesis finds many applications in industry. Electrolysis of water is an important method of hydrogen production, used whenever a source of hydrogen is required and the steam reforming of natural gas in not feasible or desirable ${ }^{22}$. If an aqueous solution of $\mathrm{NaCl}$ is taken for electrolysis, as additional products, gaseous chlorine and a solution of $\mathrm{NaOH}$ is obtained $^{23}$. Electrochemical fluorination, electrolysis of organic compounds in liquid HF and $\mathrm{Ni}$ anodes, leads to perfluorinated alcohols, carboxylic acid etc. ${ }^{24}$. Other redox reactions of organic compounds are also possible thanks to electrosynthesis, for example cathodic reduction of nitriles to primary amines ${ }^{25}$.

There are two possible ways of hydrogen peroxide electrosynthesis in water-electrolyte: cathodic reduction of oxygen, dissolved in the electrolyte and anodic oxidation of $\mathrm{H}_{2} \mathrm{O}$ to $\mathrm{H}_{2} \mathrm{O}_{2}{ }^{13}$ :

$$
\begin{gathered}
\mathrm{O}_{2}+2 \mathrm{H}^{+}+2 \mathrm{e}^{-} \rightarrow \mathrm{H}_{2} \mathrm{O}_{2} \text { (electrons delivered BY a cathode) } \\
2 \mathrm{H}_{2} \mathrm{O} \rightarrow \mathrm{H}_{2} \mathrm{O}_{2}+2 \mathrm{H}^{+}+2 \mathrm{e}^{-} \text {(electrons delivered TO an anode) }
\end{gathered}
$$

Based on the number of published articles, the first approach is more widely investigated. As mentioned in the introduction, sometimes it is also applied in industry ${ }^{6}$. Although direct anodic oxidation of $\mathrm{H}_{2} \mathrm{O}$ to $\mathrm{H}_{2} \mathrm{O}_{2}$ is still at basic research state, a similar approach was an industrial method of $\mathrm{H}_{2} \mathrm{O}_{2}$ production in the first half of the twentieth century. The process was based on hydrolysis of ammonium persulfate, $\left(\mathrm{NH}_{4}\right)_{2} \mathrm{~S}_{2} \mathrm{O}_{8}$, which was obtained by the electrolysis of ammonium bisulfate solution in sulfuric $\operatorname{acid}^{26}$ :

$$
\text { Step 1: } \mathrm{SO}_{4}^{2-} \rightarrow \mathrm{S}_{2} \mathrm{O}_{8}^{2-}+2 \mathrm{e}^{-}
$$

Step 2: $\left(\mathrm{NH}_{4}\right) \mathrm{S}_{2} \mathrm{O}_{8}+2 \mathrm{H}_{2} \mathrm{O} \rightarrow \mathrm{H}_{2} \mathrm{O}_{2}+2\left(\mathrm{NH}_{4}\right) \mathrm{HSO}_{4}$

\subsection{Photoelectrocatalytic synthesis}

\subsubsection{General characteristics of photoelectrocatalytic synthesis}

A typical photoelectrocatalytic synthesis shares many properties with a purely electrocatalytic process. The reaction system also consists of at least two electrodes, cathode and anode, responsible for two complementary redox processes, reduction and oxidation. The difference is that at least one of these electrodes is a photoelectrode, that is a device which generates a 
potential difference upon irradiation with light ${ }^{27}$. The remaining electrode is usually a regular electrocatalyst like in an analogous, electrolysis system, e.g. platinum.

In principle a photoelectrode in many respects resembles a photovoltaic cell. The device consists of a semiconducting light absorber, deposited onto a conductive substrate. If photons of an incident light beam are of higher energy than the semiconductor band gap, their absorption causes creation of an exciton. It can be separated into an electron, which occupies the conduction band, and a hole in the valence band. This creates a potential difference and, in favorable conditions, current flow. Like in photovoltaics, the maximum photovoltage generated is fundamentally limited by the bandgap energy. Assuming that we can choose from substrates of different work function, the higher the band gap, the higher the maximum voltage ${ }^{27}$. Nevertheless, aiming for good utilization of sunlight, materials of lower energy gap (below 3 $\mathrm{eV}$ ) are usually tested as photoelectrodes. With regard to photocurrent value, it is related to the efficiency of exciton separation, which depends on the exciton binding energy $\left(\mathrm{E}_{\mathrm{B}}\right)$. The lower the binding energy, the easier the separation of hole and electron ${ }^{28}$. The $E_{B}$ is inversely proportional to the dielectric constant of the material, therefore semiconductors of high dielectric constant are potentially more efficient at photocarrier generation. As organic materials usually have low dielectric constants, efficient operation of the system is usually provided by formation of organic PN heterojunction, made of two different semiconductors ${ }^{29}$, like presented in Fig. 2.2. The energetic offset between the donor $(\mathrm{P})$ and acceptor $(\mathrm{N})$ materials should be sufficient to polarize the exciton into free carriers.

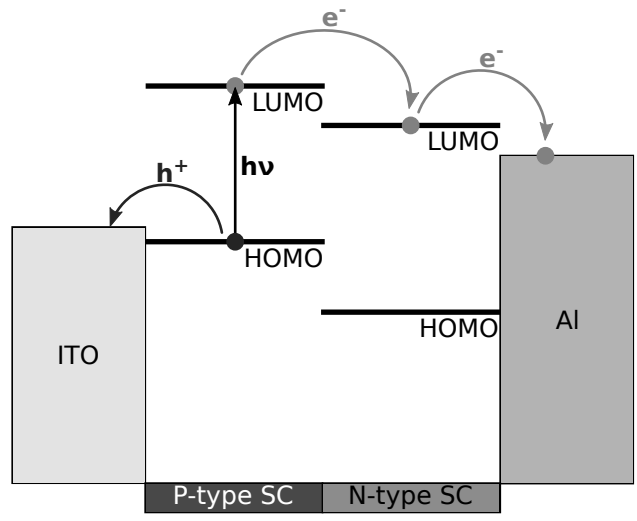

Fig. 2.2. Schematic of operation of an organic PV featuring a PN heterojunction. Thanks to proper band alignment of semiconductors, if the structure is sandwiched between conductors of appropriate work functions, efficient charge separation is possible even for organic materials of low dielectric constant. 


\subsubsection{Comparison of photoelectrodes and photovoltaic cells}

The main difference between a photovoltaic cell and a photoelectrode is that while in the former, the light absorber lies between two layers of electrically connected conductors (e.g. ITO and $\mathrm{Al}$ ), in the latter, a semiconducting system (deposited on a conductor) is rinsed in the electrolyte, where it is involved in a redox process. The conductive substrate is electrically connected with the counter electrode, where the complementary redox process takes place. There are two types of photoelectrodes ${ }^{27}$ :

- Photocathode, where the photogenerated electrons are responsible for a reduction process and photogenerated holes are delivered to a counter electrode;

- Photoanode, where the photogenerated holes are involved in an oxidation process and photogenerated electrons are delivered to a counter electrode.

The general schematic of these two systems is presented in Fig. 2.3.
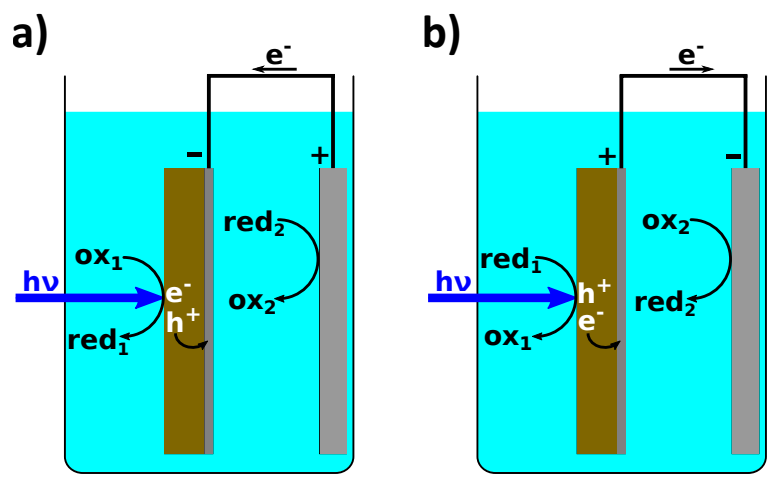

Fig. 2.3. Schematic of the photoelectrochemical systems for redox processes: a) photocathode b) photoanode. The semiconducting system might consist of a single substance or be a multi-layered arrangement of many different materials.

Although this general characterization of photoelectrodes is valid for all systems, the details of their design and operation might be very different. In some cases, the semiconductor is the only material deposited on the conductive substrate and it is directly involved in the redox reaction $^{30}$. But more commonly, a photoelectrode is a multi-layered system. Although it is possible that the semiconductor is effective as both an electrocatalyst (that is, works with low overpotential) and a photocurrent generator, usually the efficiency can be increased by splitting the light-harvesting and the redox processes to two different materials ${ }^{28}$. Thanks to this, the best available catalytic and PV systems can be combined together, utilizing their optimal properties 
for a given purpose. This is especially common in the case of photocathodes used for hydrogen evolution, the process which requires high overpotential on most of semiconductors. Cocatalysts like Pt are necessary for efficient hydrogen evolution. Another advantage of this approach is that the electrocatalytic layer may work as an encapsulation layer, protecting the semiconductors from the electrolyte. Also, metallic catalysts with reflective properties can facilitate better light utilization, by reflecting back the light which would be transmitted by the device otherwise ${ }^{28}$.

\subsubsection{Design and operation of photoelectrodes}

Just like in the case of electrocatalysis, a good photoelectrode has low overpotential, is selective towards the desired process (i.e. operates with high faradaic efficiency) and demonstrates high stability, both chemical and of generated photocurrent ${ }^{28}$. While the main purpose of incorporating a semiconducting system is utilization of the light energy, high conversion efficiency is also desired. In the best-case scenario, the external power supply is not necessary and the system can be exclusively light-driven. However, at the experimental scale, in most cases this is impossible, mainly due to limited photovoltage, which does not allow running energy-demanding processes like e.g. water splitting. Therefore, usually the photoelectrosynthetic process is supported by application of an external bias ${ }^{27}$, provided by a power supply like in electrocatalysis. This way, such an arrangement still allows for utilization of the light irradiation and requires less external energy. There are also other strategies of achieving high photovoltage, for example a tandem cell, containing a photoelectrode made of several PV cells, connected in series as a vertical stack ${ }^{31}$ or the photoelectrochemical cell, made of two photoelectrodes, that is photoanode and photocathode ${ }^{32}$.

\subsubsection{Front-side and back-side illumination}

An important consideration of the photoelectrode operation is the direction of illumination. In principle, a thin-layered device, immersed in the electrolyte, can be operated by using either front-side (electrolyte side) or back-side (substrate side) illumination. Depending on the photoelectrode design, only one way might be available, for example if the substrate is not transparent, only front-side illumination can be used. On the other hand, if the terminal, electrocatalytic layer is made of light-reflective material (e.g. metallic Pt), only back-side illumination through transparent substrate will provide high efficiency. Considering the simple semiconductor/transparent substrate system, if the cell allows for both ways of illumination, the selection should be based on the values of charge carrier diffusion lengths for a given 
semiconductor ${ }^{30}$. As most of the light is absorbed by the material in close vicinity of the illuminated side, light intensity deeper into the semiconductor is lower. Therefore, there is a gradient of photogenerated charge carriers. The irradiation should be performed in a way that a carrier of shorter diffusion length has to be transported a shorter distance. For example, a photoanode with a diffusion length of holes shorter than of electrons. The front-side illumination provides a high number of holes and electrons close to the semiconductor/electrolyte interface. Thanks to long diffusion length of electrons, they can be transported to a conductive substrate. Short diffusion length of holes is not a problem, as they have only short distance to the surface where they are consumed in the anodic process. If the same photoanode is back-side illuminated, most of the holes will be generated close to the substrate/semiconductor interface and due to the short diffusion length, they will be lost by recombination.

\subsubsection{Application of photoelectrocatalysis}

The field of photoelectrocatalysis was launched in 1972 by Fujishima and Honda by the watersplitting photoelectrochemical cell, which consisted of $\mathrm{TiO}_{2}$-based photoanode for water oxidation and platinum counter electrode for hydrogen evolution ${ }^{33}$. Despite enormous interest in this concept and many research efforts, as of 2019, it still has no commercial applications. In contrast to electrocatalytic synthesis, where the obtained chemical is of the main interest, in photoelectrocatalysis the focus is on harvesting and accumulation of solar energy ${ }^{34}$. The obtained products of redox reactions, called solar fuels, are intended to be consumed for electricity generation. The main advantage of this approach, compared with photovoltaics, is the fact that power can be generated independently from the occurrence of sunlight. For example, during the day, the system accumulates energy in a form of hydrogen, which is stored for further use; at night, the accumulated energy is converted to electricity (with an $\mathrm{H}_{2}$ fuel cell) to power street lights. Besides hydrogen, products of $\mathrm{CO}_{2}$ reduction, such as $\mathrm{HCOOH}$ and $\mathrm{CO}$ are also investigated as potential solar fuels ${ }^{35}$. Photoelectrochemical synthesis of hydrogen peroxide is another possibility, although this concept gained attention only recently ${ }^{17,36,37}$.

Apart from light energy harvesting and synthesis of solar fuels, photoelectrocatalysis might be used for deposition of metals on semiconductors, as an alternative method to vacuum deposition by thermal evaporation or sputtering ${ }^{38}$. As the regular electroplating requires a conductive substrate, application of light irradiation allows to run the electrochemical reduction of metal cations also on the surface of semiconductors in a selective, patternable fashion. 


\subsection{Photocatalytic synthesis}

\subsubsection{Definition of photocatalysis}

In a broad sense, a photocatalytic reaction is a chemical transformation, catalyzed by a photoexcited molecule or material. Like in other types of catalysis, either a homogenous or heterogenous process is possible, depending on whether the photocatalyst and reactants are in the same or different phases ${ }^{39}$. An example of a homogenous photoreaction is photo-Fenton oxidation in presence of $\mathrm{H}_{2} \mathrm{O}_{2}, \mathrm{Fe}^{3+}$ and violet light ${ }^{40}$, or hydrogen photoevolution in acidic water solution of noble metal complexes ${ }^{41}$. Although our paper 6 also concerns photocatalytic reactions in a single phase, the following discussion will be focused on heterogenous photocatalysis with semiconductors, as these processes are more prevalent in the scientific literature, especially in the photocatalytic $\mathrm{H}_{2} \mathrm{O}_{2}$ evolution ${ }^{42}$.

\subsubsection{General characteristic of photocatalysis with semiconductors}

Photocatalysis with semiconductors is a redox process which takes place on the surface of a semiconductor in the presence of light. Just like in the case of photoelectrocatalysis and photovoltaics, light absorption leads to formation of an exciton, which separates into hole and electron, occupying the valence and the conduction bands of semiconductor ${ }^{43}$. In contrast to photoelectrodes and PV cells, in a simple photocatalytic system there is no external wiring; the whole phenomenon of charge carrier generation and chemical reaction takes place in the same semiconducting material, in an area spatially confined by the diffusion lengths of electron and hole. In consequence, there is no need of providing conditions for the ionic current flow, neither solvent nor electrolyte is necessary. The process is possible even with gaseous reagents ${ }^{44}$. Schematic of the photocatalyzed redox reaction is shown in Fig. 2.4.

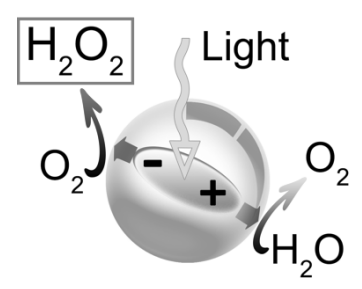

Fig. 2.4. Schematic of a photocatalytic process, in this example case $\mathrm{O}_{2}$ reduction to $\mathrm{H}_{2} \mathrm{O}_{2}$. Reprinted with permission from ${ }^{45}$. Copyright 2018 American Chemical Society.

Since in a photocatalytic experiment current is not registered, calculation of faradaic efficiency is not possible. Determination of the reaction selectivity requires identification and 
quantification of all products of the process. Evaluation of the system efficiency can be based on different figures-of-merit. In general case, having access to proper equipment, it is possible to determine either internal quantum efficiency (IQE) or external quantum efficiency (EQE), using the following formulas ${ }^{46}$ :

$$
\begin{aligned}
& \mathrm{IQE}=\frac{\text { rate of product evolution }}{\text { rate of photon absorption }} \\
& \mathrm{EQE}=\frac{\text { rate of product evolution }}{\text { rate of photon incidence }}
\end{aligned}
$$

\subsubsection{Features of a good photocatalyst}

Apart from simplicity of the photocatalytic system, the advantage of this approach is the possibility of increasing the area of the semiconductor/environment interface. The semiconductor can be used as a dispersion of nanoparticles ${ }^{47}$, which offers a higher number of catalytic active sites compared with planar structure deposited onto a substrate. This might have a positive impact on the efficiency of the photocatalytic process. Apart from high specific surface area, the material should have good wettability ${ }^{48}$ and be of a catalytically-active polymorphic structure. The other factor which impacts the photocatalytic reaction rate is, like in the case of photoelectrocatalysis, the efficiency of exciton separation ${ }^{49}$, as described in the section 2.2.1. If the exciton lifetime is too short, instead of separating, it recombines. The light energy cannot be utilized and it is wasted in the form of heat. There are many ways of addressing this issue. For example, Illiev et al., showed that if commercially available $\mathrm{TiO}_{2}$ nanoparticles are modified by deposition of $\mathrm{Pt}$ and $\mathrm{Ag}$ nanoparticles (Fig. 2.5), the efficiency of oxalic acid photooxidation increases 8 times $^{50}$. While the process of interest still takes place on the $\mathrm{TiO}_{2}$ photocatalyst, the photoexcited electrons are transported from the conduction band to metal nanoparticles, where they are trapped due to existence of Schottky barrier at the semiconductor/metal interface. This not only increases the charge separation efficiency but also, as better ORR catalyst, facilitates the complementary reduction process.

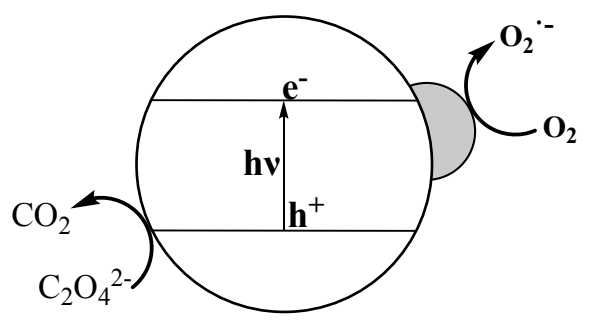

Fig. 2.5. Schematic representation of oxalate photooxidation, catalyzed by the $\mathrm{TiO}_{2} / \mathrm{Pt}$ system ${ }^{50}$. 
The other possibility of increasing the efficiency of exciton separation is, just like in photovoltaic and photoelectrocatalysis, creation of a heterojunction of two semiconductors. With inorganic materials, it can be done even with the same compound, if its two polymorphic structures are employed. This approach was used by Kawahara et al. in preparation of a bilayered $\mathrm{TiO}_{2}$ junction, made of anatase and rutile as photocatalyst for decomposition of $\mathrm{CH}_{3} \mathrm{CHO}^{51}$. The reaction rate of such system is $10-100$ times higher than that of the individual components.

A PN heterojunction is not the only possibility of combining two different materials to increase activity of the photocatalytic system. Although such systems are very common in photovoltaics and photoelectrocatalysis, they require that energy levels of both semiconductors thermodynamically allow to run both reduction and oxidation on single materials. This might be a significant limitation in processes requiring high potential difference, such as $\mathrm{CO}_{2}$ reduction, coupled with water oxidation. As a solution, the Z-scheme type of heterojunction can be employed, for example the $\alpha-\mathrm{Fe}_{2} \mathrm{O}_{3} / \mathrm{g}-\mathrm{C}_{3} \mathrm{~N}_{4}$ system presented by Jiang et al. ${ }^{52}$. In this arrangement, the photocatalyst of the $\mathrm{CO}_{2}$ reduction process, graphite nitride, is not able to oxidize water, therefore photoexcitation leaves hole in its valence band. The electrical neutrality is restored by its recombination with a photoexcited electron, which remains in the hematite after water oxidation. Schematic of the Z-scheme operation, compared with the PN junction, is presented in Fig. 2.6.

$\mathbf{a}$
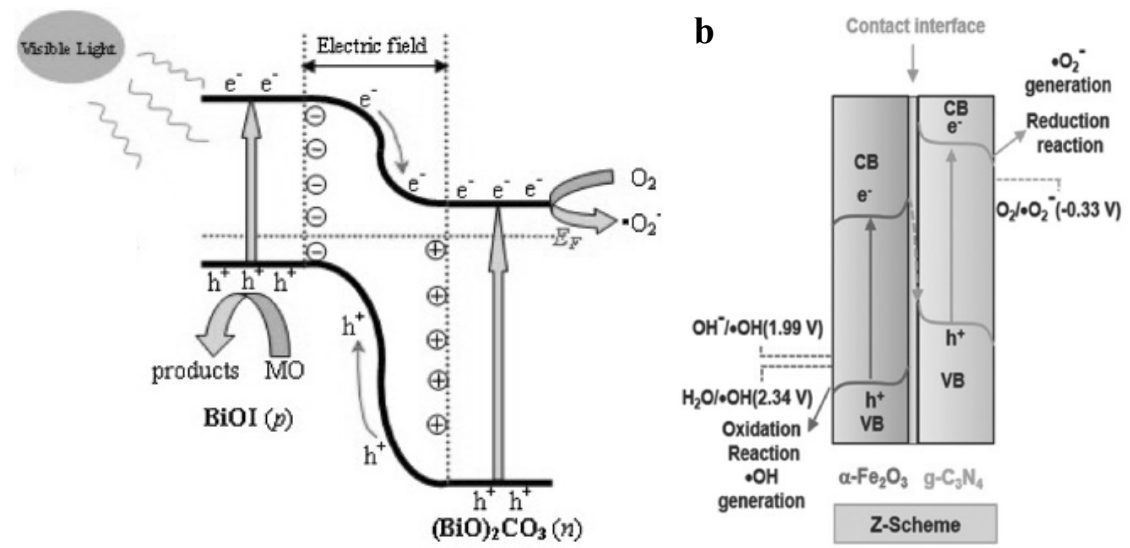

Fig. 2.6. Comparison of a PN heterojunction ${ }^{53}$ (a) and Z-scheme junction ${ }^{52}$ (b). While in the former reduction takes place on the material of lower conduction band energy and oxidation on the material of higher valence band energy, in the Z-scheme it is the other way around. Both figures are reprinted with permission from AAAS. 
It is worth noting that despite such a system offering the possibility of running energydemanding reactions, by principle its quantum efficiency cannot be higher than $50 \%$, as half of the charge carriers recombine at the interface of two semiconductors ${ }^{54}$.

\subsubsection{Challenges in photocatalytic transformations}

Apart from the problem of limited energy efficiency of the Z-scheme, another challenge is a proper selection of materials in a way that their interface allows for the band bending presented in Fig. 2.6.b. Considering that the main purpose of Z-scheme application is usually overcoming the limitation of high oxygen evolution potential, working on the photoreduction processes like $\mathrm{H}_{2}$ evolution or $\mathrm{CO}_{2}$ reduction, the water oxidation issue can be avoided by introduction of a sacrificial electron donor ${ }^{55}$, a compound which has low oxidation potential and does not interfere with the reduction reaction. For better feasibility, usually cheap and non-toxic compounds are used, such as triethylamine, ascorbic acid, and oxalate. This approach has also another advantage, as it solves problem of cross-reactivity, especially pronounced in photochemical water splitting. In a photoelectrocatalytic process, processes of $\mathrm{H}_{2}$ and $\mathrm{O}_{2}$ evolution are spatially separated to two different electrodes, which usually are located in two different compartments, ionically connected in a way described in Chapter 3.2. This prevent $\mathrm{H}_{2}$ and $\mathrm{O}_{2}$ from mixing and recombining to $\mathrm{H}_{2} \mathrm{O}$. In a regular photocatalytic system, with dispersion of water-splitting nanoparticles, due to close vicinity of the reaction centers, the probability of this process is high ${ }^{56}$. What is more, the presence of oxygen has also negative impact on the $\mathrm{H}_{2}$ evolution selectivity, as thermodynamically, the oxygen reduction process is favored over HER. Application of a sacrificial electron donor solves both issues, as it prevents from oxygen evolution and leads to a chemically neutral product of oxidation.

Of course, the ultimate goal is to obtain a photocatalytic system which does not require any additional donors. This strategy is very helpful in development of the materials, but it can be avoided. One of the possible solutions is to design a photochemical system in the form of a planar device, with two different catalysts for $\mathrm{H}_{2}$ and $\mathrm{O}_{2}$ evolution located on the opposite sides. Such a device, which resembles a free-standing photoelectrochemical system, needs to be able to generate high voltage if intended to use without sacrificial electron donor. Due to lack of the wiring, a power supply cannot be connected, therefore application of an external bias, facilitating the water splitting, is impossible. However, high photovoltage can be achieved if vertical stack of multiple semiconductors is used (Fig. 2.7), like in the conceptual artificial leaf presented by Reece et al. ${ }^{57}$ 


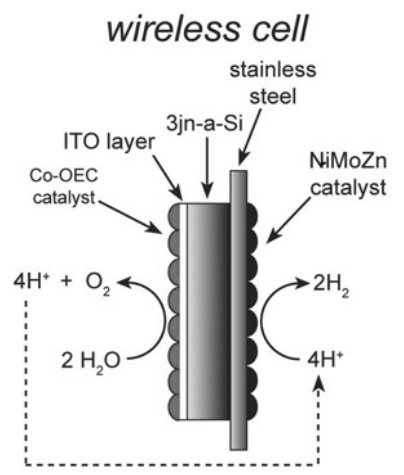

Fig. 2.7. Wireless photochemical cell for water splitting, based on a triple junction of amorphous silicon and electrocatalysts free of noble metals, reported by Reece et al. ${ }^{57}$ Reprinted with permission from AAAS.

\subsubsection{Application of photocatalysis}

Photocatalysis dates back to the first half of the twentieth century, when $\mathrm{ZnO}$ and $\mathrm{TiO}_{2}$ were reported as catalysts for photobleaching of dyes, which is associated with formation of reactive oxygen spices ${ }^{58}$. Photooxidation catalyzed by $\mathrm{TiO}_{2}$ still remains of scientific interest, it also finds real life applications in removal of pollutants by oxidation. For example, titanium dioxide is used in self-cleaning glass ${ }^{48}$ or as a component of a concrete ${ }^{59}$, which if used in building elevations, helps to reduce the content of nitrogen oxides in air. As mentioned before, photocatalytic systems are also intensively investigated in light-driven $\mathrm{H}_{2}$ evolution and $\mathrm{CO}_{2}$ reduction reactions, as possible strategies of solar-energy harvesting and removal of atmospheric $\mathrm{CO}_{2}{ }^{34,35}$. However, these are still at the stage of basic research. Compared with photoelectrocatalysis, photocatalytic $\mathrm{H}_{2} \mathrm{O}_{2}$ evolution is much more common, with first reports of this process, catalyzed by $\mathrm{CdS}^{16}$ and $\mathrm{ZnO}^{60}$ dating back to 1950 s. Nowadays, systems based on graphitic carbon nitrides $\left(\mathrm{g}-\mathrm{C}_{3} \mathrm{~N}_{4}\right)$ are widely explored for this purpose ${ }^{61,62}$, so far, with no commercial applications. 



\section{3. $\mathrm{H}_{2} \mathrm{O}_{2}$ synthesis by $\mathrm{O}_{2}$ reduction}

\subsection{Important chemical and physical properties of $\mathrm{O}_{2}$ and $\mathrm{H}_{2} \mathrm{O}_{2}$}

Table 1. Selected physical and chemical properties of $\mathrm{H}_{2} \mathrm{O}_{2}$ and $\mathrm{H}_{2} \mathrm{O}^{63,64}$.

\begin{tabular}{|c|c|c|}
\hline property & $\mathbf{H}_{\mathbf{2}} \mathbf{O}_{\mathbf{2}}$ & $\mathbf{H}_{\mathbf{2}} \mathbf{O}$ \\
\hline Molar mass $\left(\mathrm{g} \cdot \mathrm{mol}^{-1}\right)$ & 34.01 & 18.016 \\
\hline Melting point $\left({ }^{\circ} \mathrm{C}\right)$ & -0.40 & 0.0 \\
\hline Boiling point $\left({ }^{\circ} \mathrm{C}\right)$ & 150.2 & 100.0 \\
\hline Density $\left(\mathrm{g} \cdot \mathrm{cm}^{-3}\right)$ & 1.45 & 1.0 \\
\hline $\mathrm{pKa}$ & 11.62 & 14 \\
\hline $\mathrm{Viscosity}(\mathrm{cP})^{\circ}$ & 1.249 & 0.89 \\
\hline$\Delta \mathrm{G}^{\circ}\left(\mathrm{kJ} \cdot \mathrm{mol}^{-1}\right)$ & -120.42 & -292.72 \\
\hline $\begin{array}{c}\text { Light absorption cut off }(\mathrm{A} \text { of } 1 \mathrm{~cm} \\
\text { of pure compound }>1 ; \mathrm{nm})\end{array}$ & ap. 340 & 191 \\
\hline \multicolumn{2}{|c}{} \\
\hline
\end{tabular}

Table 1 presents a comparison of some properties of $\mathrm{H}_{2} \mathrm{O}_{2}$ and $\mathrm{H}_{2} \mathrm{O}$. In pure form, hydrogen peroxide is a pale blue liquid with melting point similar to water $\left(-0.43{ }^{\circ} \mathrm{C}\right)$ but of much higher boiling point, estimated as $150.2^{\circ} \mathrm{C}$. The exact value is impossible to determine, as the molecule thermally decomposes when heated to this temperature. Therefore, distillation of $\mathrm{H}_{2} \mathrm{O}_{2}$ solutions, leading to a very pure product, is possible only under reduced pressure ${ }^{65}$. Pure hydrogen peroxide is also sensitive to the presence of some metals and light, especially $\mathrm{UV}^{66}$, which in contrast to $\mathrm{H}_{2} \mathrm{O}$, is absorbed by $\mathrm{H}_{2} \mathrm{O}_{2}{ }^{64}$. High sensitivity of the compound is related to the fact that in standard conditions, it is thermodynamically unstable. The reaction of $\mathrm{H}_{2} \mathrm{O}_{2}$ disproportionation:

$$
2 \mathrm{H}_{2} \mathrm{O}_{2} \rightarrow 2 \mathrm{H}_{2} \mathrm{O}+\mathrm{O}_{2}
$$

Has negative Gibbs free energy $\Delta \mathrm{G}^{\circ}=-172.3 \mathrm{~kJ} \cdot \mathrm{mol}^{-1}$. Elevated temperature favors the process both thermodynamically and kinetically. The decomposition can be also accelerated by basicity of the solution and presence of some other compounds, such as iodide ${ }^{67}$ and catalase enzymes ${ }^{68}$.

To prevent this problem, hydrogen peroxide is usually stored in a cool place in a form of weakly acidic solution with stabilizers ${ }^{69}$, which are compounds forming stable complexes with metals, e.g. phosphates, citrates. Because of the instability and risk of sudden release of huge amount of gas, for regular users hydrogen peroxide is available only as an aqueous solution, usually $30 \%$ for laboratory use and $3 \%$ for pharmacies ${ }^{6}$. If $\mathrm{H}_{2} \mathrm{O}_{2}$ concentration is over $70 \%$, the decomposition converts it completely into gas, as the heat released turns $\mathrm{H}_{2} \mathrm{O}$ into 
steam. This phenomenon allows for using it as a rocket propellant also as a single compound, without additional fuel ${ }^{5}$.

Hydrogen peroxide and the superoxide radical $\left(\mathrm{HO}_{2}^{\circ}\right.$, see Fig. 3.1) are common byproducts of many biochemical processes ${ }^{70}$. As strong oxidants, they are toxic to cells, therefore, for proper functioning of organisms, both $\mathrm{HO}_{2}{ }^{\circ}$ and $\mathrm{H}_{2} \mathrm{O}_{2}$ have to be constantly removed. Living organisms developed two important classes of enzymes: catalases ${ }^{68}$ and superoxide dismutases ${ }^{71}$, for decomposition of these toxins to $\mathrm{H}_{2} \mathrm{O}$ and $\mathrm{O}_{2}$. Whenever equilibrium of production and decomposition of $\mathrm{HO}_{2}{ }^{\circ}$ and $\mathrm{H}_{2} \mathrm{O}_{2}$ is disturbed, this condition is known as oxidative stress, which can damage components of cells. Although this is undesired phenomena, contributing to many diseases, the concept of in vivo $\mathrm{H}_{2} \mathrm{O}_{2}$ generation recently gains research interest, as it might be used e.g. for stimulation of biological response and activation of specific biochemical pathways ${ }^{8}$.

\subsection{Thermodynamics of $\mathrm{O}_{2}$ reduction}

Hydrogen peroxide is not the only possible product of oxygen reduction. Actually, much more prevalent is water, $\mathrm{H}_{2} \mathrm{O}$, the product of $4 \mathrm{e}^{-} \mathrm{O}_{2}$ reduction, while $\mathrm{H}_{2} \mathrm{O}_{2}$ is the product of the $2 \mathrm{e}^{-}$ process $^{72}$. This is an advantageous feature from the point of view of hydrogen peroxide applications, as in most cases, we utilize its oxidizing properties. Oxidation by $\mathrm{H}_{2} \mathrm{O}_{2}$ is in fact a transfer of 2 electrons from the molecule being oxidized (which gets decomposed) to $\mathrm{H}_{2} \mathrm{O}_{2}$, which turns into $\mathrm{H}_{2} \mathrm{O}$. This way, water is the only, oxidant-derived byproduct of the whole process. On the other hand, it makes the $\mathrm{H}_{2} \mathrm{O}_{2}$ synthesis a challenging problem, as we need to avoid the reduction of $\mathrm{H}_{2} \mathrm{O}_{2}$ to $\mathrm{H}_{2} \mathrm{O}$ on the catalyst we use for reduction of $\mathrm{O}_{2}$ to $\mathrm{H}_{2} \mathrm{O}_{2}$. To make the entire reaction cascade even more complicated, there are intermediate products of $1 \mathrm{e}^{-}$and $3 \mathrm{e}^{-}$reduction ${ }^{73}$. All possible $\mathrm{O}_{2}$ reduction processes in water environment, with their corresponding products are collected in Fig. 3.1.

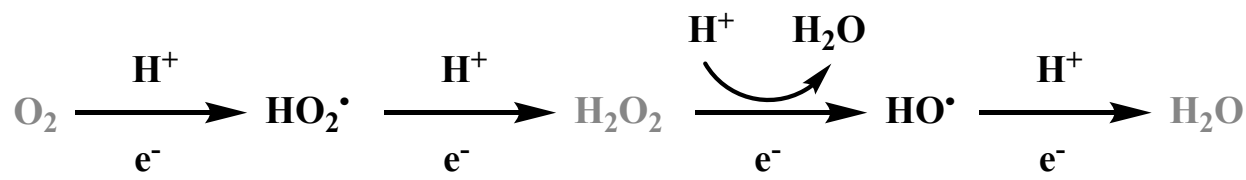

Fig. 3.1. Oxygen reduction reactions pathways. Stable products (possible to separate or accumulate) are marked in red. $\mathrm{HO}_{2}{ }^{-}, \mathrm{H}_{2} \mathrm{O}_{2}$ and $\mathrm{HO}^{*}$, along with products of their deprotonation (e.g. $\mathrm{HO}_{2}^{-} \mathrm{O}_{2}^{-{ }^{-}}$) are known as reactive oxygen species (ROS). 
In electrochemistry, it is convenient to consider the thermodynamics based on standard electrode potentials, $\mathrm{E}^{\circ}$. In standard conditions, to perform a given reduction reaction, the required electrode potential needs to be lower than its corresponding value of $\mathrm{E}^{\circ}$. In a nonselective electrochemical reduction process, where different reactions are possible, thermodynamically more favored are reactions of higher standard electrode potential. Unfortunately, in the discussed case of $\mathrm{H}_{2} \mathrm{O}_{2}$ synthesis, as presented in Table 2, the $\mathrm{E}^{\circ}$ values of both side reactions, $\mathrm{H}_{2} \mathrm{O}_{2}$ to $\mathrm{H}_{2} \mathrm{O}$ and $\mathrm{O}_{2}$ to $\mathrm{H}_{2} \mathrm{O}$, equal to $+1.763 \mathrm{~V}$ and $+1.23 \mathrm{~V}$ respectively, are higher than $+0.67 \mathrm{~V}, \mathrm{E}^{\circ}$ of the $\mathrm{O}_{2}$ to $\mathrm{H}_{2} \mathrm{O}_{2}$ reduction. Therefore, high selectivity of the process cannot be provided by simply applying the right potential.

Nevertheless, the efficient $\mathrm{H}_{2} \mathrm{O}_{2}$ synthesis process is still possible. An electrode potential value is an important thermodynamic parameter which determines if the reaction could take place. However, it does not say how fast this process would be. If due to kinetic limitation, the $\mathrm{O}_{2}$ to $\mathrm{H}_{2} \mathrm{O}_{2}$ process is much faster than both of the undesired side reactions, we can still effectively produce and accumulate $\mathrm{H}_{2} \mathrm{O}_{2}$. There are many examples of industrial chemical processes allowed by thermodynamics but ruled by the reaction kinetics. Usually, the key factor is a proper selection of the reaction catalyst in a way that while the first step is fast and energy efficient, the second one is slow or does not occur at all. The other possibility is a constant removal of an intermediate product. In case of hydrogen peroxide production, it is crucial that $\mathrm{H}_{2} \mathrm{O}_{2}$ molecule is not adsorbed on the reaction catalyst and leaves the proximity of the catalyst/electrolyte interface as soon as it is created. This is important consideration from the point of view of catalyst engineering. While increasing the catalyst's surface area (e.g. by deposition of the catalytically active material onto a porous support) we increase the number of catalytic active sites per geometric area, at the same time we introduce limitations in the efficiency of mass transport. If proper modifications of the reaction system are not introduced (e.g. switching to a flow reactor), it might reduce the total hydrogen peroxide yield by "trapping" $\mathrm{H}_{2} \mathrm{O}_{2}$ molecules in the porous areas where they can be reduced further to $\mathrm{H}_{2} \mathrm{O}$ before being removed from the catalyst/electrolyte interface. 
Table 2. Values of electrode potentials $\left(\mathrm{E}^{\circ}\right)$ at standard conditions $\left(\mathrm{T}=298 \mathrm{~K}, \mathrm{P}=10^{5} \mathrm{~Pa}\right.$, concentration of all reagents equal $1 \mathrm{M}$; values are relative to the standard hydrogen electrode)

\begin{tabular}{|c|l|}
\hline Reaction & \multicolumn{1}{|c|}{$\mathbf{E}^{\circ}$ (vs. SHE) } \\
\hline $\mathrm{O}_{2}+2 \mathrm{H}^{+}+2 \mathrm{e}^{-} \rightarrow \mathrm{H}_{2} \mathrm{O}_{2}$ & $+0.67^{13}$ \\
\hline $\mathrm{O}_{2}+4 \mathrm{H}^{+}+4 \mathrm{e}^{-} \rightarrow 2 \mathrm{H}_{2} \mathrm{O}$ & $+1.23^{13}$ \\
\hline $\mathrm{H}_{2} \mathrm{O}_{2}+2 \mathrm{H}^{+}+2 \mathrm{e}^{-} \rightarrow 2 \mathrm{H}_{2} \mathrm{O}$ & $+1.763^{6}$ \\
\hline $\mathrm{O}_{2}+\mathrm{H}^{+}+\mathrm{e}^{-} \rightarrow \mathrm{HO}_{2}^{-}$ & $+0.10^{73}$ \\
\hline $\mathrm{HO}_{2}^{-}+\mathrm{H}^{+}+\mathrm{e}^{-} \rightarrow \mathrm{H}_{2} \mathrm{O}_{2}$ & $+1.46^{73}$ \\
\hline $\mathrm{H}_{2} \mathrm{O}_{2}+\mathrm{H}^{+}+\mathrm{e}^{-} \rightarrow \mathrm{HO}^{\bullet}+\mathrm{H}_{2} \mathrm{O}$ & $+0.8^{73}$ \\
\hline $\mathrm{HO}+\mathrm{H}^{+}+\mathrm{e}^{-} \rightarrow 2 \mathrm{H}_{2} \mathrm{O}$ & $+2.73^{73}$ \\
\hline $2 \mathrm{H}^{+}+2 \mathrm{e}^{-} \rightarrow \mathrm{H}_{2}$ & 0.0 (by definition) \\
\hline
\end{tabular}

Hydrogen peroxide reduction to water is not the only possible problem in its water-based synthesis. Another issue is oxidation. As mentioned in Chapter 2.1, in an electrochemical (or photoelectrochemical) system, we always have a cathode for a reduction and an anode for an oxidation process. In a best-case scenario of hydrogen peroxide synthesis, we have its generation on both electrodes, that is reduction of oxygen on the cathode and oxidation of water on the anode. This not only gives us high yield of hydrogen peroxide but also simplifies the electrochemical system, which can be made as a single compartment cell. Otherwise, when electrodes are not selective towards desired processes, the issue becomes much more complicated. Let us assume that our system allows for production of $\mathrm{H}_{2} \mathrm{O}_{2}$ only by the cathodic reduction of $\mathrm{O}_{2}$. According to Table 1, the required electrode potential has to be lower than $+0.67 \mathrm{~V}$ vs. SHE. The process must be balanced by an oxidation reaction on the anode, which if not able to oxidize $\mathrm{H}_{2} \mathrm{O}$ to $\mathrm{H}_{2} \mathrm{O}_{2}$, oxidizes $\mathrm{H}_{2} \mathrm{O}$ to $\mathrm{O}_{2}$. This reaction requires the anode potential to be higher than $+1.23 \mathrm{~V}$ vs. SHE. If it is not selective towards $\mathrm{H}_{2} \mathrm{O}$ to $\mathrm{O}_{2}$ oxidation, it will be also active towards the $\mathrm{H}_{2} \mathrm{O}_{2}$ to $\mathrm{O}_{2}$ process, as the $+1.23 \mathrm{~V}$ vs. SHE potential is higher than $+0.67 \mathrm{~V}$ vs. SHE, required for hydrogen peroxide oxidation. Considering the synthesis of $\mathrm{H}_{2} \mathrm{O}_{2}$ by oxidation of water in a system unable to support selective reduction of $\mathrm{O}_{2}$ to $\mathrm{H}_{2} \mathrm{O}_{2}$, we encounter a similar problem. In parallel to the anodic process, we have cathodic reduction, which can be either $\mathrm{O}_{2}$ to $\mathrm{H}_{2} \mathrm{O}$ (which requires potential $<+1.23 \mathrm{~V}$ vs $\mathrm{SHE}$ ) or $\mathrm{H}^{+}$to $\mathrm{H}_{2}$ (which requires potential $<0.0$ vs $\mathrm{SHE}$ ). In both cases, potential is lower than $+1.763 \mathrm{~V}$ vs. SHE required for the $\mathrm{H}_{2} \mathrm{O}_{2}$ to $\mathrm{H}_{2} \mathrm{O}$ reduction, which in the case of non-selective cathode, will dramatically lower the yield of hydrogen peroxide synthesis. 
Despite occurrence of this undesired processes, it is still possible to operate a (photo)electrochemical setup for $\mathrm{H}_{2} \mathrm{O}_{2}$ synthesis with just one, selective electrode. It requires separation of cathodic and anodic compartments ${ }^{74}$. If hydrogen peroxide cannot reach the counter electrode, it will not be reduced/oxidized no matter the potential. The essential condition of operation of double-compartment system is to provide flow of ionic current, just like every electric circuit it has to be closed to work. For this purpose, compartments have to be connected with a salt bridge ${ }^{75}$ or separated with ion selective membrane ${ }^{76}$ or ceramic frit ${ }^{77}$. Schematics of these systems are presented in Fig. 3.2. For efficient operation, these ionic connections have to be of the lowest possible ohmic resistance, what can be achieved by e.g. higher thickness of the membrane ${ }^{78}$. At the same time, the connection has to be very selective for ions and completely prevent catholyte and anolyte from mixing.
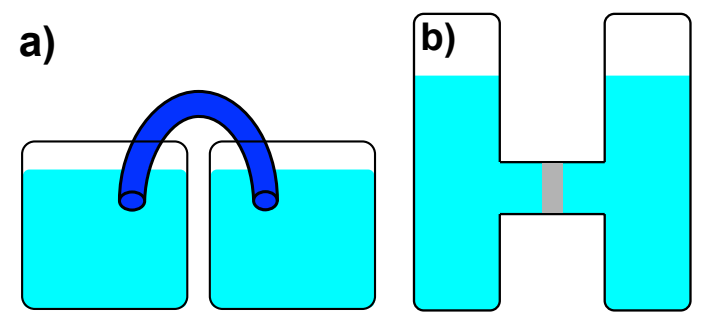

c)

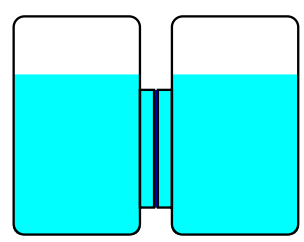

Fig. 3.2. Possible architectures of double-compartment cells: (a) salt-bridge connection, (b) cell with glass frit, (c) cell with ion-selective diaphragm. The most common example of the latter is nafion, a proton-selective membrane of excellent thermal, mechanical, and chemical stability ${ }^{79}$. Because of the cross-section shape resembling the letter $\mathrm{H}$, cells in the b) and c) pictures are called $\mathrm{H}$-cells. For the application in photoelectrochemistry, the photoelectrode compartment has to be transparent for light.

At this point, it is worth mentioning that although being environmentally unfriendly and, at a first glance, complicated, the process of hydrogen peroxide synthesis by anthraquinone oxidation (AO) avoids all these problems, as it is based on a completely different reaction pathway $^{6}$, shown in Fig. 3.3. In contrast to water-based synthesis, where electrons are supplied by an electrically charged catalytic surface and protons are constantly available from water dissociation, in the AO process, hydrogen peroxide is a product of free-radical oxidation of the organic molecule, very selective in the reaction conditions. 


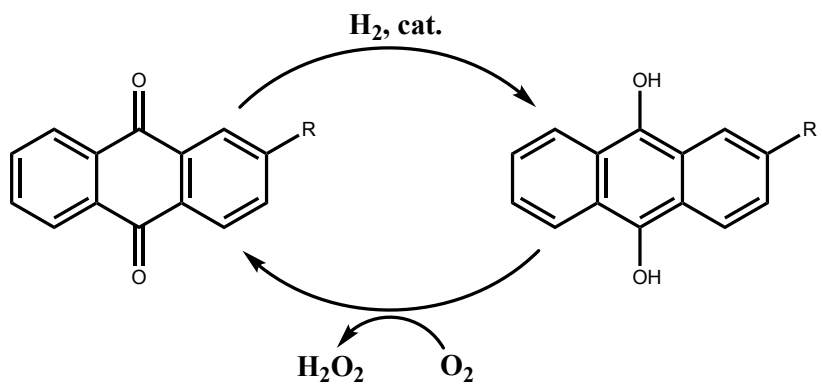

Fig. 3.3. Simplified schematic of the anthraquinone process. Usually as a main substrate, 2ethylanthraquinone is used. A catalyst for the hydrogenation process is based either on palladium or nickel. This step is not completely selective, therefore other products of an anthraquinone derivative reduction are also obtained, leading to consumption of the substrate.

There are also other, technological advantages of the AO process, which can be regarded as synthesis of $\mathrm{H}_{2} \mathrm{O}_{2}$ from $\mathrm{H}_{2}$ and $\mathrm{O}_{2}$, with anthraquinone as catalyst and hydroquinone as the intermediate product. In contrast to $\mathrm{O}_{2}$ reduction in water on solid catalyst, all substrates and products are dissolved, therefore we avoid issue of $\mathrm{H}_{2} \mathrm{O}_{2}$ adsorption and its further side reactions. As we are interested in water-miscible $\mathrm{H}_{2} \mathrm{O}_{2}$, the presence of organic solvent might seem conceptually redundant, but in fact, it is beneficial. Even though hydrogen peroxide concentration in the reaction medium is relatively low, thanks to organic character of the solvent, it is very easy to separate $\mathrm{H}_{2} \mathrm{O}_{2}$ by extraction with water, getting highly concentrated product. This is very important, as concentration of water solution by water evaporation, though simple, due to high heat capacity and vaporization heat of water, is an expensive and energyconsuming process.

\subsection{The oxygen solubility issue}

Solubility of oxygen is a very important parameter, as gaseous oxygen is the main substrate for hydrogen peroxide, and both abovementioned approaches of $\mathrm{H}_{2} \mathrm{O}_{2}$ production are liquid-phase syntheses. Low concentration of the crucial reagent limits the reaction velocity. In the case of the very selective AO process it means that to get the same amount of product, the synthetic setup needs to be heated for a longer time, which is related with energy loss. For water-based $\mathrm{O}_{2}$ reduction, limited solubility of oxygen (approx. $1.2 \mathrm{mM}$ in pure water under $1 \mathrm{~atm} \mathrm{O}_{2}$ pressure ${ }^{80}$ ) might have a negative impact on the reaction selectivity and its final product yield. Let us assume that the catalyst used for hydrogen peroxide synthesis is not fully selective towards our desired process. When upon accumulation of synthesized $\mathrm{H}_{2} \mathrm{O}_{2}$, its concentration 
is similar to the concentration of oxygen, $\mathrm{O}_{2}$ and $\mathrm{H}_{2} \mathrm{O}_{2}$ reductions become competitive processes. Assuming the selectivity ratio as $1: 1$, having equal concentration of $\mathrm{O}_{2}$ and $\mathrm{H}_{2} \mathrm{O}_{2}$, we produce and consume the same amount of $\mathrm{H}_{2} \mathrm{O}_{2}$, which means that its concentration saturates. If in the same solution we increase the oxygen concentration 10 times, statistically for one competing molecule of $\mathrm{H}_{2} \mathrm{O}_{2}$, we have 10 molecules of $\mathrm{O}_{2}$, which corresponds to 10 times higher probability of $\mathrm{O}_{2}$ reduction and still high efficiency of the process. Therefore, high concentration of oxygen in hydrogen peroxide production in water environment is absolutely crucial. The most reasonable approach is to supply it under higher pressure. According to Henry's law ${ }^{81}$ :

$$
C_{g}=H^{C P} \cdot p
$$

Where:

$\mathrm{C}_{\mathrm{g}}$ : Concentration of the gas

$\mathrm{H}^{\mathrm{CP}}$ : Henry's law constant

p: Partial pressure of the gas

Gas solubility is directly proportional to its partial pressure. Although operating at elevated pressure significantly increases the cost of the equipment and makes the basic research difficult, it is a better solution than decreasing the reaction temperature (due to high running cost and impact on the reaction kinetics) or changing the solvent (using of water is a key feature of low cost and environmental friendliness). Of course, to maintain high $\mathrm{O}_{2}$ concentration on the local level (that is in the proximity of the catalyst/electrolyte interface), the solution should be stirred. In some cases, especially in small scale, this is provided by purging of the solution with a stream of $\mathrm{O}_{2}$. 



\section{Organic electronic materials as catalysts for $\mathrm{H}_{2} \mathrm{O}_{2}$ synthesis}

As mentioned in the introduction, there are many possible advantages of using organic electronic materials in catalysis for hydrogen peroxide synthesis. Despite this, to our best knowledge, they were not explored for this purpose before. Therefore, we selected representative examples of two main classes of organic electronic materials: molecular semiconductors and polymers, and investigated their catalytic properties towards $\mathrm{H}_{2} \mathrm{O}_{2}$ production.

\subsection{Organic pigments as molecular semiconductors}

Organic pigments are one of the most important organic compounds, used in many areas of industry as colorants. Although polymers are the main components of such everyday items as clothes, plastic toys or domestic appliances, it is pigments, mostly organic, which make these things colored. An important feature of pigments, which distinguish them from dyes, is that the former are insoluble (even in organic solvents), while the latter are soluble. Nevertheless, in specific conditions, pigments can be dissolved. This allows for their applications in cases when solubility is crucial for deposition of a pigment, but it is undesired later. For example, using reducer and basic solution, indigo can be dissolved in water as its vat from, used for dyeing of jeans clothes and then brought back to their initial, insoluble form by exposure to oxygen ${ }^{82}$.

Currently organic pigments are cheap and easily available, thanks to the progress in organic chemistry. In comparison to some drugs, their production usually involves inexpensive precursors and fewer synthetic steps. Although due to their solid state and insolubility, purification might seem challenging, due to their exceptional thermal stability, organic pigments can be sublimed ${ }^{83,84}$ to yield very pure products.

Insolubility of pigments has important consequences. Thanks to this and to high stability, even if the compound is uptaken by the organism, usually it is non-toxic as it cannot be digested. Therefore, organic pigments are regarded as safe, in contrast to some inorganic pigments containing toxic metals and organic compounds of similar, polycyclic aromatic structure. Apart from thermal stability, low price and non-toxicity, organic pigments are also known of high light fastness and resistance to degradation, also in presence of oxygen and water ${ }^{85,86}$. Their excellent properties make them perfect materials for various applications. However, traditionally they were not regarded as semiconductors, despite first reports on semiconductivity of phthalocyanines as early as $1949^{87}$. Later works proved that similar properties can be exhibited also by other class of organic pigments, such as perylene diimides ${ }^{88}$, 
indigoids $^{82}$, diketopyrrolopyrroles ${ }^{89}$ and quinacridones $^{90}$. Based on the well-established principles of organic electronics, some of these reports might seems surprising, as in contrast to semiconductive polymers, molecules such as indigo or quinacridone, do not have extended system of conjugated $\pi$ bonds, which is regarded as sine qua non of high mobility of charge carriers. Key features of organic pigments which make them semiconductors are their high degree of crystallinity and intermolecular $\pi-\pi$ stacking of aromatic rings, in some cases supported by formation of hydrogen bonds between amine and carbonyl groups. Nevertheless, for efficient operation, the material has to be very pure and deposited in a strictly defined way (rate, temperature of a substrate), often on the specific substrate, what facilitates proper arrangement of the semiconducting molecules ${ }^{82}$.

There are different classes of organic pigments, distinguished based on their chemical structure. Brief characterization of the most important ones, with examples of applications in industry and organic electronics, is as follows:

Rylene dyes: Aromatic diimides, mostly of perylenetetracarboxylic acid (Fig. 4.1). Compounds known of very strong $\pi-\pi$ stacking interaction (due to extensive system of aromatic rings), usually red or brown, with $\lambda_{\max }$ in the $500-600 \mathrm{~nm}$ range and of n-type conductivity. Presence of long alkyl-chain substituents makes them soluble in organic solvents, but as dyes, they tend to aggregate. In organic electronics, perylene diimides are used in PN junctions ${ }^{88,91}$. Their synthetic modification may lead to donor-acceptor type of compounds, with substituents either on nitrogen ${ }^{92}$ or at the aromatic core ${ }^{93}$.

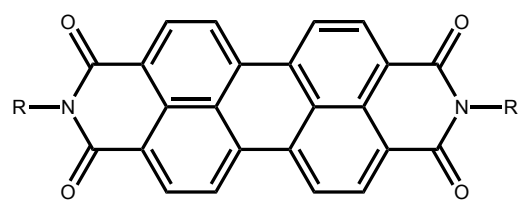

Fig. 4.1. General structure of perylene diimides. Optical properties and the material solubility might be modified by substitutions, both on the $\mathrm{N}$ atoms and the perylene core.

Phthalocyanines: macrocyclic compounds with a ring consisting of $18 \pi$-electrons and two amine groups inside, which might be deprotonated leading to stable complexes with metal cations. Due to strong absorption in the $600-700 \mathrm{~nm}$ range, they are usually blue or green. Substitution, either of the amine group protons or peripheral hydrogen atoms, modifies optical properties of the pigment. Replacement of phthalic acid derivatives with their naphthalic analogous as synthesis precursors leads to naphthalocyanines, compounds with absorption 
shifted to near-infrared region. As p-type materials, just like perylene diimides, they are commonly used as constituents of PN heterojunctions, reaching up to 5\% power conversion efficiency ${ }^{94}$. Fig. 4.2 shows the structure of copper phthalocyanine, the most common phthalocyanine.

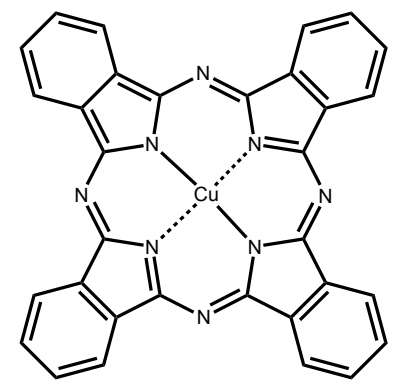

Fig. 4.2. Chemical structure of copper phthalocyanine (also known as $\mathrm{CuPc}$ ).

Indigoids: The most widely spread pigment of this group is indigo (Fig. 4.3.a), which has been in use since ancient times as a blue dyestuff for coloring fabrics ${ }^{82}$. Initially very expensive as a material extracted from natural sources, modern synthetic indigo is easily available and commonly used in the textile industry for the production of denim blue jeans. Its water-soluble derivative, known as indigo carmine, is a non-toxic blue dye, used as food colorant ${ }^{95}$. It can be obtained by direct sulfonation of the pigment. Other indigoids are also commercially available. One of the most important is thioindigo (Fig. 4.3.b), which compared to indigo, has the -NH group replaced with atom of sulfur and is purple in color. Semiconductivity of some indigoids is a recent discovery ${ }^{82}$. These compounds are ambipolar, with relatively high mobility of charge carriers. Possible application of indigo derivatives in photovoltaics and OLEDs is hampered by very efficient photoinduced proton transfer, reversible isomerization of the molecule upon light absorption, leading to dissipation of the excited state into thermal energy. Nevertheless, possibility of photoinduced charge transfer, leading to P3HT photoluminescence quenching, has been shown for dibromoindigo ${ }^{96}$.

a)<smiles>O=C1/C(=C2\Nc3ccccc3C2=O)Nc2ccccc21</smiles>

b)<smiles>O=C1/C(=C2\Sc3ccccc3C2=O)Sc2ccccc21</smiles>

Fig. 4.3. Chemical structure of: (a) indigo, (b) thioindigo. 
Quinacridones: Structure of the most common representative, quinacridone, is shown in Fig. 4.4. It is used in industrial coatings, automotive industry, and in manufacturing of printing ink ${ }^{90}$. Its color varies depending on polymorphic structure, from the most common magenta color of $\alpha$ phase to maroon or red color of $\beta$ and $\gamma$ phases respectively ${ }^{97}$. It shows ambipolar mobility of charge carriers in OFETs $s^{90}$. Other commercially available quinacridones are compounds with $-\mathrm{Cl}$ and $-\mathrm{CH}_{3}$ substituents on the side phenyl rings ${ }^{98}$.<smiles>O=c1c2ccccc2[nH]c2cc3c(=O)c4ccccc4[nH]c3cc12</smiles>

Fig. 4.4. Chemical structure of quinacridone.

Anthraquinones: This group includes many different compounds, consisting of one or two anthraquinone units (Fig. 4.5.a). Single-unit anthraquinones are compounds of relatively low molar absorption coefficient and $\lambda_{\max }$ in 400 - $550 \mathrm{~nm}$ range. Due to solubility, usually they are used as dyes. The most common anthraquinone pigments comprise two anthraquinone units, for example indanthrene (Fig. 4.5.b) or flavanthrone. Some derivatives of these compounds soluble in organic solvents have been tested in organic electronics as fluorescent emitters in OLEDs $^{99}$.

a)<smiles>O=C1c2ccccc2C(=O)c2ccccc21</smiles>

b)<smiles>O=c1c2ccccc2c(=O)c2c1ccc1[nH]c3c(ccc4c(=O)c5ccccc5c(=O)c43)[nH]c12</smiles>

Fig. 4.5. (a) Chemical structure of anthraquinone. Compounds with $-\mathrm{NH}_{2},-\mathrm{OH}$ and $-\mathrm{SO}_{3} \mathrm{H}$ substituents are soluble and used as dyes. (b) Indanthrene (known also as indanthrone) is a blue pigment which is, like indigo, used as a vat dye in textile industry.

Diketopyrrolopyrroles: Known also as DPPs, this is a group of soluble and insoluble compounds based on the dilactam unit presented in Fig. 4.6.a. They are regarded as high- 
performance pigments, which are used in automotive industry and in production of high-quality printing inks ${ }^{100}$. They are also important in organic electronics, with many derivatives tested in OFETs, OLEDs and photovoltaics, frequently as a donor-acceptor type of compounds ${ }^{101}$ (with DPP unit as an acceptor and thiophene(s) ring(s) as a donor). Industrial DPPs used in OFETs show ambipolar carrier mobilities ${ }^{89}$.

a)

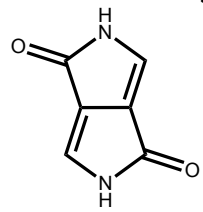

b)

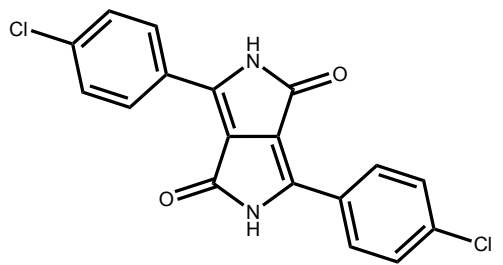

Fig. 4.6. (a) Heterocyclic dilactam which is a constituent of all diketopyrrolopyrroles. (b) Di(pchlorophenyl)-DPP (Pigment Red 254), pigment used in automotive industry in famous Ferrari red coating.

Porphyrins: Group of compounds structurally resembling phthalocyanines (Fig. 4.7), with a continuous cyclic system of $18 \pi$-electrons. They are not as stable as other colorants and therefore not used as industrial pigments. Nevertheless, they are of very high importance in physiology of many organisms. As complexes with some metal cations, porphyrins occur in nature (for example as chlorophyll or heme) and are crucial in processes involving transfer of energy. In organic electronics they are tested in OLEDs as well as in photovoltaics, either as ptype material or as a dye in dye-sensitized solar cells ${ }^{102}$. Porphyrins are also promising photosensitizers in photodynamic therapies of cancer ${ }^{103}$.

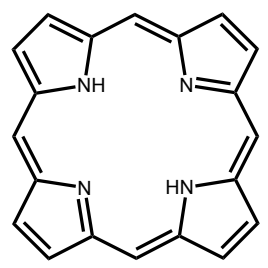

Fig. 4.7. Structure of porphine, the parent compound for porphyrins such as chlorophylls and heme.

In our research we tested $\mathrm{H}_{2} \mathrm{Pc}$ (metal-free phthalocyanine, Fig. 4.8.a), PTCDI (perylene diimide derivative, Fig. 4.8.b) and EPI (epindolidione, a pigment structurally similar to 
quinacridone, shown in Fig. 4.8.c) as well as their water-soluble counterparts as electro-, photoelectro-, and photocatalysts for $\mathrm{H}_{2} \mathrm{O}_{2}$ photoevolution.

a)

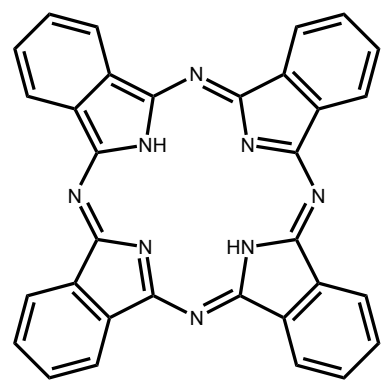

b)<smiles>CN1C(=O)c2ccc3c4ccc5c6c(ccc(c7ccc(c2c37)C1=O)c64)C(=O)N(C)C5=O</smiles>

c)<smiles>O=C1c2ccccc2NC2C(=O)c3ccccc3NC12</smiles>

Fig. 4.8. Chemical structure of $\mathrm{H}_{2} \mathrm{Pc}$ (metal-free phthalocyanine), $\mathrm{PTCDI}$ (perylene diimide derivative) and EPI (epindolidione), organic pigments used in this work.

\subsection{Semiconducting and conducting polymers}

Polymers are historically among the first semiconducting materials, with initial reports on partly conductive aniline derivatives as early as in XIX century. Probably the most famous example is polyacetylene, which is semiconductive in its pristine form, but becomes highly conductive after doping it with iodide ${ }^{104}$. This crucial finding significantly contributed to growing interest in organic electronics and won their discoverers the Nobel Prize in Chemistry in 2000. Despite historical importance, polyacetylene does not have commercial applications, mostly because of its poor mechanical properties and low stability.

The common feature of conducting polymers is a conjugated system of alternating single and double bonds, which are delocalized. It means that they are able to resonate, which is essential for conductivity of the polymer. As $\pi$-bond conjugation is typical of compounds with aromatic rings, except for polyacetylene, all other types of conducting polymers have aromatic rings in their repeat unit. Although a whole gamut of polymer types has been tested, probably the most important are derivatives of thiophene, with many examples of such materials successfully applied in organic solar cells ${ }^{29}$ and field effect transistors ${ }^{105}$. The most widely known polythiophenes are P3HT and PEDOT. 


\subsubsection{P3HT - Poly(3-hexylthiophene-2,5-diyl)}

P3HT, Poly(3-hexylthiophene-2,5-diyl), is a p-type semiconducting polymer of good solution processability, optical stability, and mechanical properties. Although it can be doped to afford a conducting polymer ${ }^{106}$, usually it is used in its pristine, semiconductive form. Its ability to form an efficient PN bulk heterojunction with n-type PCBM (Phenyl-C 61 -butyric acid methyl ester) led to rapid development of solution-processed organic photovoltaics ${ }^{29}$. The repeat unit consists of a thiophene ring, which forms the conjugated system of bonds stretching over the entire polymer chain, but also an n-hexyl substituent which makes the material soluble in organic solvents and facilitates highly ordered molecular arrangement of polymer chains, crucial for high hole mobility. Presence of alkyl chains also makes the material hydrophobic, which is beneficial for its stability in humid environment. Although hydrophobicity is not a desired feature for catalysis in water environment, there are examples of such applications of P3HT ${ }^{107}$.

Depending on the relative orientations of adjacent thiophene units, we distinguish different isomers of P3HT, presented in Fig. 4.9.

a)

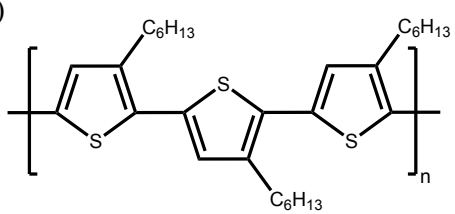

c)

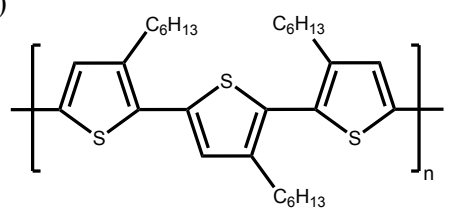

b)

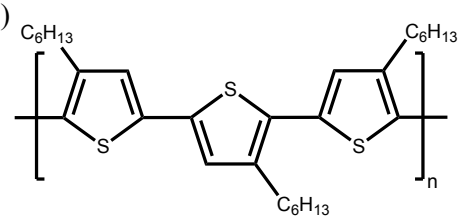

d)

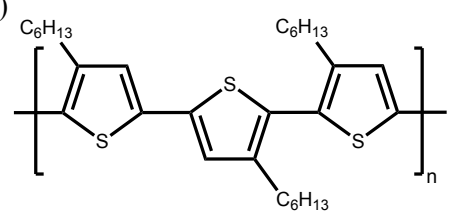

Fig. 4.9. Different structural isomers of regioregular P3HT: a) head-to-tail-head-to-tail, b) tail-totail-head-to-tail, c) head-to-tail-head-to-head, d) tail-to-tail-head-to-head. Apart from these, there is also regiorandom $\mathrm{P} 3 \mathrm{HT}$, with no order of the alkyl chain position.

Due to presence of steric hindrance caused by bulky, n-hexyl substituents in close vicinity, head-to-head or tail-to-tail units are twisted, which negatively impacts their conjugation. Due to that, these polymers have poor hole mobility. Conversely, regioregular head-to-tail-head-totail isomer (ht-ht) have well-conjugated, flat chains, providing high mobility of charge carriers 
and slightly lower band hap ${ }^{108}$. Because of this, in the vast majority of applications, this type of $\mathrm{P} 3 \mathrm{HT}$ is used.

Poly(3-hexylthiophene-2,5-diyl) of the desired ht-ht regioregularity can be obtained by the Grignard Methathesis polymerization, involving in situ formation of organomagnesium derivative from 2,5-dibromo-3-hexylthiophene, followed by polymerization catalyzed by $\mathrm{Ni}$ complexes $^{109}$, as shown in the schematic in Fig. 4.10.

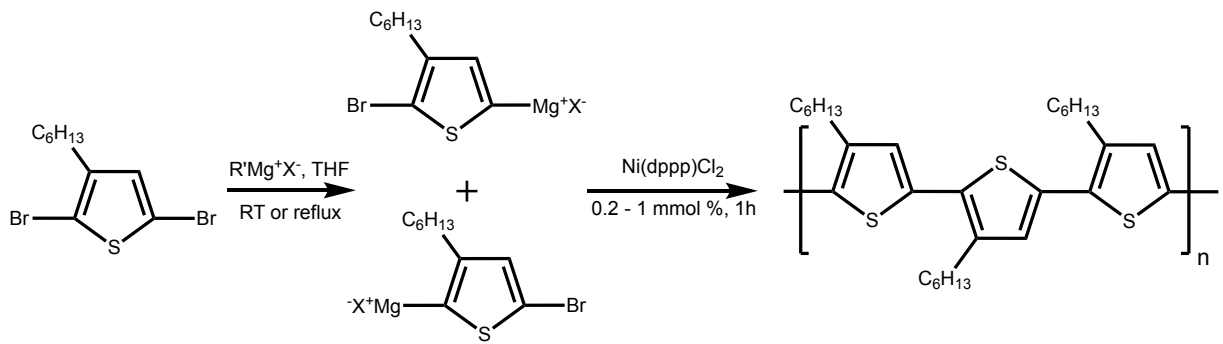

Fig. 4.10. Schematic of the regioregular ht-ht P3HT synthesis.

This is important information from the point of view of P3HT applications is catalysis. Because of the synthetic procedure, the polymer might be contaminated with trace amounts of transition metals, what might significantly impact the efficiency and selectivity of the desired catalytic transformations.

In our research aiming for hydrogen peroxide production, we tested applicability of P3HT in photocatalysis. As of the moment of publishing this thesis, photoelectrocatalytic studies of this material are underway.

\subsubsection{PEDOT - Poly(3,4-ethylenedioxythiophene)}

PEDOT, Poly(3,4-ethylenedioxythiophene), is a polymer of the structure shown in Fig. 4.11. It is probably the most important conducting polymer, of industrial applications such as antistatic coating, hole transporting layer in photovoltaics and OLEDs, electrochromic displays ${ }^{110}$ and in manufacturing of lithium-polymer batteries.

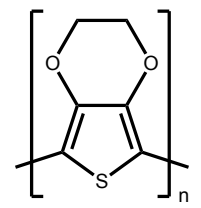

Fig. 4.11. Structure of PEDOT in its pristine, undoped state. 
It is a p-type semiconductor in its pristine state, just like other polythiophenes, but compared with them, it has a key distinguishing feature, that is a presence of ethylenedioxy bridge. This not only increases chemical stability (by preventing oxidation reactions on the 3 and 4 positions of thiophene ring) but also raises HOMO level of the polymer, which lowers the band gap and facilitates oxidative doping.

Depending on the oxidation state, color and transparency of PEDOT varies. While reduced polymer is dark blue, by increasing of the doping level it turns light blue and gains optical transparency ${ }^{111}$. This property is crucial for manufacturing of electrochromic displays, which operate based on electrochromism induced by changing of the voltage.

There are many possible ways to synthesize PEDOT, leading to products of different properties. All of them are based on the oxidation process of EDOT, 3,4ethylenedioxythiophene, which can be performed chemically ${ }^{110}$ (e.g. by iron (III) salts) or electrochemically ${ }^{111}$. Probably the most important formulation of PEDOT is PEDOT:PSS, which is produced by oxidation of EDOT in water mixture of $\mathrm{Fe}_{2}\left(\mathrm{SO}_{4}\right)_{3}$ and $\mathrm{Na}_{2} \mathrm{~S}_{2} \mathrm{O}_{8}$ in the presence of PSS, poly(styrenesulfonate). Despite relatively low polymerization degree of material obtained in this way, it is of high electrical conductivity and can be easily processed from solution ${ }^{110}$. Structure of PEDOT:PSS is shown in Fig. 4.12.

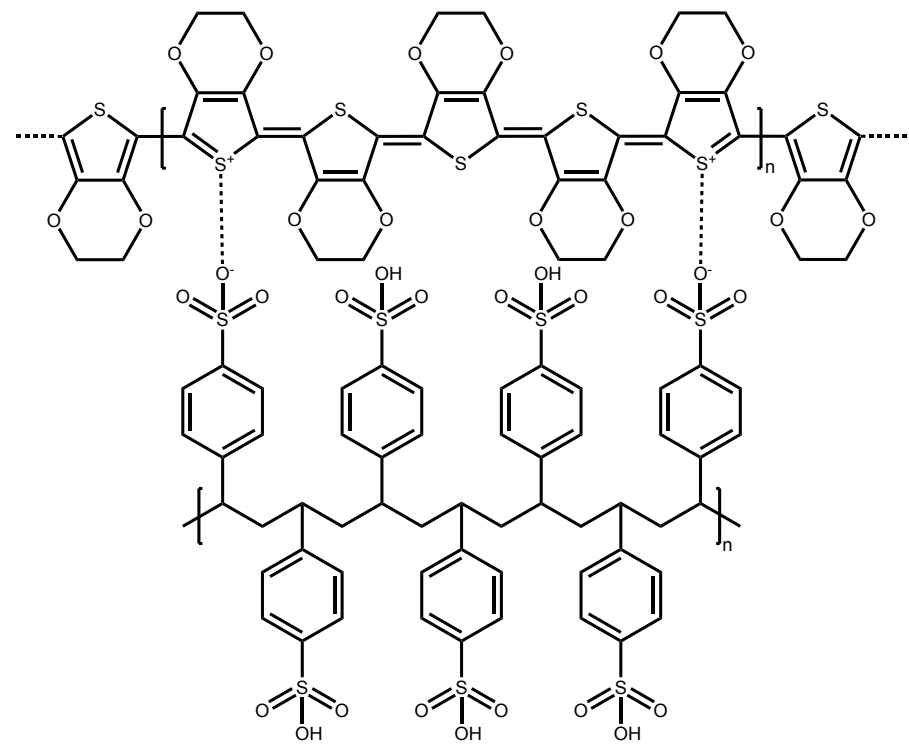

Fig. 4.12. Structure of PEDOT:PSS. Long chains of poly(styrenesulfonate) form a backbone for oligomeric units of PEDOT, giving a very stable structure which cannot be separated by electrophoresis. 
High abundance of negatively charged sulfonic groups in PSS chains is an important feature for doping of the material. Thanks to this, the oxidation state of the PEDOT oligomers might be easily changed without necessity of transporting bulky anions. With PSS as a counterion, only protons (which are of small size and high mobility) have to be delivered/removed upon de-doping/doping process. This is extremely important feature, which makes the PEDOT:PSS not only an electron, but also a proton conductor ${ }^{112}$. Therefore, the variety of possible applications of the polymer is much wider than described above and involves extensive research efforts on PEDOT-based electrochemical transistors and sensors. It also led to establishment of iontronics ${ }^{12}$, which as a bridge between ionic and electronic transport, allows for the effective device operation whenever electronic signal has to be transduced into movement of ions (e.g. ion pumps, stimulating electrodes).

Just like in case of polyaniline ${ }^{113}$, conductivity of PEDOT:PSS films can be increased by so-called secondary doping ${ }^{114}$. This is caused by an introduction of a chemically inert substance to the polymer solution, which favors a proper arrangement of its chains, leading to high conductivity of the material. Even if the secondary dopant is completely removed during the polymer deposition or the following post-treatment, the conductivity enhancement may persist. For PEDOT:PSS, commonly used secondary dopants are for example DMSO, DMF, diethlylene glycol or sorbitol. Their application allows for increasing the conductivity by up to three orders of magnitude, to values over $1000 \mathrm{~S} / \mathrm{cm}^{114}$.

Our study of catalytic activity of PEDOT for synthesis of hydrogen peroxide was based on fabrication of electrodes made of three different types of PEDOT: commercial PEDOT:PSS, chemically polymerized PEDOT:Cl, and finally electropolymerized PEDOT and using them as electrodes in electrolysis of oxygenated water, leading to accumulation of $\mathrm{H}_{2} \mathrm{O}_{2}$ in the cathodic compartment.

\subsubsection{Melanin}

Although the vast majority of polymers used in organic electronics is generally regarded as non-toxic, they are not natural-origin materials. Despite many studies showing their biocompatibility, from the point of view of bioapplications it is also important to investigate naturally occurring polymers. There are not many examples of semiconducting polymers in nature. The most important is probably melanin, occurring in different types ${ }^{115}$ : pheomelanin, neuromelanin, and eumelanin, which of these three is of the highest research interest and physiological importance. 
Eumelanin is a polymer comprising units of 5,6-dihydroxyindole and 5,6dihydroxyindole-2-carboxylic acid, presented in Fig. 4.13. It is widespread in nature as a dark pigment ${ }^{116}$. Despite the presence of carboxylic groups, due to cross-linking, the material is insoluble in water. Its exact structure and ratio of monomer units is not defined and might be different for different organisms. Therefore, eumelanin color varies, from shades of brown to black.

a)

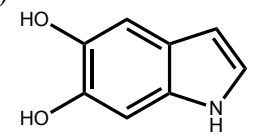

b)

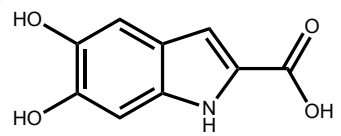

Fig. 4.13. Monomers of melanin: (a) 5,6-dihydroxyindole (DHI) and (b) 5,6-dihydroxyindole-2carboxylic acid (DHICA). The exact monomer ratio and the structure they form is not defined.

The main biological role of eumelanin is protection against UV light, it is highly absorptive in this spectral range. In nature, synthesis of the polymer starts from the amino acid tyrosine, which is oxidized to the DOPA and then dopaquinone, after which different synthetic pathways are possible. The process is usually induced by exposure to sunlight. For the research purpose, eumelanin is usually prepared by ammonia-induced solid-state polymerization of the DHI (Fig. 4.13), which occurs in presence of oxygen ${ }^{117}$. The monomer is dissolved in methanol and can be deposited onto a desired substrate by e.g. spin coating or drop casting.

Eumelanin was the first biopolymer to be investigated as a semiconductor, with the first reports on photoconductivity and dark-DC conductivity in the $1970 \mathrm{~s}^{118-120}$. Although it was demonstrated that these phenomena depend on the hydration state of the material, all hypotheses on the conduction mechanism assumed electron-hole type transport. The observed dependence of conductivity on water content has been explained as local modification of dielectric constant by the uptaken $\mathrm{H}_{2} \mathrm{O}$ molecules. However, recent studies show that eumelanin is predominantly a proton conductor ${ }^{121}$. This property, along with complete biocompatibility of melanin, makes it attractive material for applications in bioelectronics, although low conductivity of the material is still an important problem.

In our work, we obtained thin layers of eumelanin and tested their photocatalytic and photoelectrocatalytic activity towards $\mathrm{H}_{2} \mathrm{O}_{2}$ evolution. 



\section{Fabrication}

In most cases, investigation of catalytic properties of the materials requires preparation of a thin film device. This chapter provides characteristics of all fabrication methods used in our work. Exact experimental details can be found in the included papers.

\subsection{Preparation of thin films by physical vapor deposition (PVD)}

\subsubsection{General characterization of PVD}

The term physical vapor deposition concerns a wide variety of methods of manufacturing of thin films, in which a solid material is transferred to a vapor phase and then condensed back at the desired substrate in a form of thin film ${ }^{122}$. In general, we assume that the obtained layer is of the same chemical composition like the starting material, although in some cases it might be modified, intentionally, or by unwanted side reactions. The two most important techniques are thermal evaporation and sputtering, which are widely used in industry, not only in electronics and optics but also in production of packaging ${ }^{123}$. Other examples include cathodic arc deposition, closed-space sublimation, and pulsed laser deposition. The common feature of all PVD techniques is that the process is performed in vacuum. It is crucial for the efficient deposition which is based on transferring of the material from the source to the substrate. The process can be efficient only if the source-substrate distance is shorter than the mean free path at a given pressure, that is an average distance a moving particle travels before it hits another molecule. Otherwise, atoms (or molecules) of the material collide with a gas present in the environment and scatter. Usually, PVD processes are performed at pressure in the $10^{-3}$ to $10^{-7}$ mbar range, when mean free path is in the $10 \mathrm{~cm}-1 \mathrm{~km}$ range ${ }^{124}$, which is much higher than the source-substrate distance (below $1 \mathrm{~m}$, usually a few $\mathrm{cm}$ ). In some cases, the other advantage of running PVD process in vacuum is the fact that oxygen and water vapor are not present in the environment (or their content is very low), therefore it is possible to work with materials which otherwise would react with oxygen or water in conditions of the process, e.g. thermal evaporation of reactive metals, such as $\mathrm{Mg}$ or $\mathrm{Al}^{122}$.

The main advantage of PVD techniques is that they do not require any solvents or chemicals other than the material itself. This is environmentally friendly and allows to work with sensitive substrates. The major drawback is that they utilize expensive and sometimes bulky equipment what is associated with significant investment expenses. In our studies, we used solely thermal evaporation, therefore it is described in more details below. 


\subsubsection{Thermal evaporation}

Thermal evaporation, performed in a setup called a thermal evaporator (sample picture shown in Fig. 5.1) consists of two simple processes: evaporation of molten material (or sublimation of solid) induced by heating and its condensation on the substrate, which has to be at lower temperature than the source (although in some cases it is also heated, e.g. to give a thin film of different polymorphic structure, or to desorb undesired molecules from the surface). Heating of the material is provided by a current passing through the source it is loaded to, which is of high electric resistance. Usually, the heating source is made of a metal in a form of thin, U-shaped plate (called boat) or coil, containing crucible made of metal or ceramics. Materials used for heating sources must be stable in the temperature range of the process, they must not evaporate, sublime or react with the material. Frequently, they are made of tungsten, molybdenum or tantalum $^{122}$. For better uniformity of the deposited layer, the substrate is usually rotated during the deposition process.
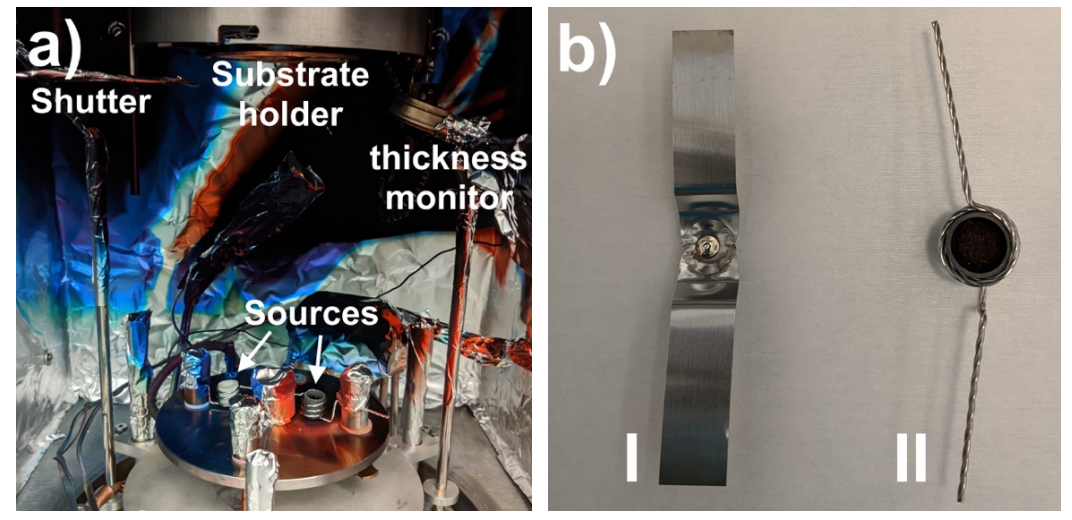

Fig. 5.1. (a) Picture of one of the evaporation systems used in our work (modified Edwards 306 with Moorfield box chamber). Relative position of the quartz crystal monitor to the shutter allows for adjusting the rate before opening the shutter. (b) Sample pictures of heating sources: I - tungsten boat, loaded with silver, II - tungsten coil with ceramic crucible, loaded with organic pigment.

By controlling the current passing through the heating source, we control its temperature. The higher the temperature, the higher the evaporation rate. In general, higher rates facilitate quality of layers by reducing the roughness and minimizing inclusion of gas impurities $^{125}$. 
Thickness of the material can be controlled by a quartz crystal monitor, present in the evaporation chamber. As it can be seen in Fig. 5.1, positions of quartz crystal monitor and the substrate are different. Therefore, the amount of material reaching the thickness monitor differs from the amount reaching the substrate. Fortunately, as long as no changes are introduced to the evaporation system, ratio of the material thickness on the substrate to the material thickness on the quartz crystal balance is constant. This parameter, called tooling factor, has to be determined experimentally before fabrication of samples.

In the evaporation process, the material can be deposited only in the areas of the substrate which are not covered. Therefore, we can control the evaporated pattern by application of so-called shadow masking, which is its negative image cut in a thin metal or plastic foil. This way, conductive traces or electrodes of a given area might be easily fabricated in a single step. Although convenient, this approach has limitations of minimum size of the deposited feature. Due to geometry of the system, part of the material vapor reaches the substrate at the angle different from $90^{\circ}$. Therefore, areas close to the cutouts in the shadow mask do not get the same amount of the material like in the middle, what causes nonuniformity of the coating. This effect, called shadowing ${ }^{126}$, is not a problem when features are big, but becomes a significant issue when their size is comparable to thickness of the mask used. To minimize shadowing, masks should be made of thin materials and mounted as close to the substrate as possible. The same effect is also responsible for nonuniformity of the coating thickness when highly rough substrates are used.

In our research, thermal evaporation has been used for deposition of pigments: epindolidione, $\mathrm{H}_{2} \mathrm{Pc}$, and PTCDI (in papers 1,3,5), layers of chromium/gold (in papers 1,2) and layers of gold (in paper 3). Evaporation of organic pigments has been performed at a faster rate than in some previous works concerning preparations of OFETs, that is at $1-3$ $\AA \cdot \mathrm{s}^{-1}$ rate. Gold has been usually evaporated at $3-5 \AA \cdot \mathrm{s}^{-1}$ rate which is fast enough to get layer of high quality and smoothness, and at the same time, the process is slow enough to be easily controlled by closing the shutter. In case of chromium, due to low thickness of this layer $(1 \mathrm{~nm})$, rate used was never higher than $0.4 \AA \cdot \mathrm{s}^{-1}$. During evaporation, substrates were always rotated and never heated.

\subsection{Preparation of polymer films}

Thermal evaporation is easy to control and reproduce, but it can be used only for materials which evaporate or sublime. Usually, it is not possible in case of polymers, which upon heating, 
degrade before turning to gas phase (apart from a few exceptions e.g. polyaniline ${ }^{127}$ or lowdensity polyethylene ${ }^{128}$ ). Although there are techniques in which thin film of polymer is formed in a vacuum or solvent-free process, usually in research and industry, solution processing is used for deposition. This subchapter describes methods of preparation of polymer thin films used in our work.

\subsubsection{Spin coating}

Spin coating is a method in which the polymer solution is applied on the center of the substrate, which is then rotated at high speed (usually $1000-5000 \mathrm{rpm}$ ), which spreads the solution by centrifugal force ${ }^{129}$. The device used for this process, a spin coater (shown in Fig. 5.2), apart from the rotation velocity, usually allows for control of the rotation acceleration. Upon spreading of the solution, solvent evaporates, resulting in formation of a thin solid film of the dissolved material.
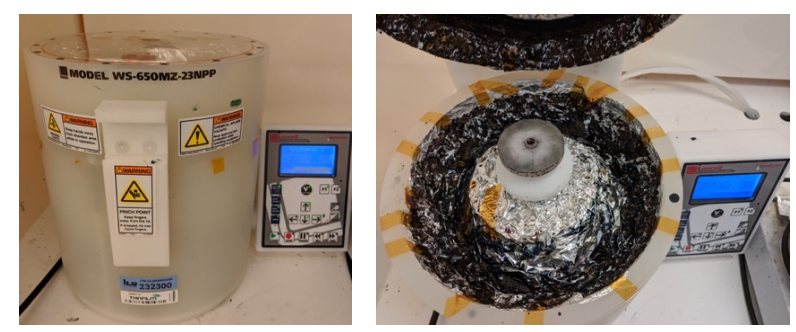

Fig. 5.2. Pictures of the Laurell WS $400 \mathrm{~A}$, spin coater used in our work.

Thickness of the layer depends on many factors, such as viscosity, speed of spinning, and concentration of the polymer. Thickness dependence on these parameters can be described by the following formula ${ }^{130}$ :

$$
\delta \propto \omega^{-1 / 2} \cdot \eta^{1 / 3} \cdot c_{0}
$$

Where:

$\delta$ : thickness

$\omega$ : angular spinning speed

$\eta$ : viscosity of the solution

$\mathrm{c}_{0}$ : material concentration 
Spin coating is a versatile method, which can be used for both polymers and low molecular weight compounds, although layer uniformity is usually better for polymers. However, just like other deposition techniques based on solution processing, it requires using a solvent which is neutral towards the substrate or other materials deposited on it previously. It is also important that the substrate is well-wetted by the solution ${ }^{131}$. The main advantage of spin coating is that it does not require expensive equipment. Its major drawbacks are poor utilization of the material (most of the solution is flung off the substrate) and radial nonuniformity of the thickness layer $^{132}$, which can be thicker in the center. Spin coating is one of the most important methods of device manufacturing in organic electronics, used in preparation of many different types of devices. It is also used in industry in microfabrication of electronic circuits, for deposition of photoresists $^{133}$.

In our work we used spin coating for preparation of P3HT layers on $\mathrm{Si} / \mathrm{Au}$ substrate in paper 5 and as a first step of fabrication of eumelanin layers in paper 4 .

\subsubsection{Drop casting}

Technically very simple method, it is widely used in research, although layer uniformity is usually worse compared with spin coating. The solution of the material is casted by dropping its desired volume on the substrate which is then left for drying. Slow evaporation of solvent (sample covered with a lid with small opening, environment saturated with vapor of solvent) facilitates formation of more uniform layers ${ }^{134}$. Compared with spin coating, material utilization is much better, as the whole volume of the solution used contributes to growth of the layer thickness. Therefore, to get the same thickness like by spin coating, less concentrated solution can be used, which is important in case of materials of poor solubility. Apart from simplicity, the big advantage of drop casting is the fact that quantity of the deposited material is very easy to determine. Therefore, this method has been used in preparation of P3HT layers on plastic substrate in paper 5 .

\subsubsection{Chemical and electrochemical polymerization}

Spin coating and drop casting of polymers are both physical methods in which the material is synthesized and purified before the deposition. However, it is possible to obtain thin layers of material as a result of polymerization. Depending on the conditions, it might lead to product of not only variable thickness and morphology, but also chemical form (different molecular weight or counterion of doped polymer). The main substrate, monomer (or monomers), can be used in various ways: 
- dissolved with rest of the reagents:

- in solid state, after deposition of desired amount of monomer onto a substrate which is then treated in a way leading to polymerization (e.g. heated);

- as vapor, with rest of the reagents deposited on the substrate before the process (vapor phase polymerization, $\left.\mathrm{VPP}^{135}\right)$.

In preparation of thin layers by polymerization, a monomer undergoes oxidation reaction with iron (III) salts (e.g. chloride, tosylate) or ammonium persulfate. The advantage of this approach is fact that it can be easily performed on almost any substrate. The main disadvantage is necessity of removal of the reacted oxidant (e.g. by washing with $\mathrm{HCl}$ ). Therefore, it is difficult to prevent the polymer from contamination, which is especially undesired if it is to be used as catalyst.

However, removal of the oxidant residue is not an issue when the polymerization is performed electrochemically ${ }^{136}$. In this process, a conductive substrate is used as the working electrode in an electrochemical process involving solution of monomer and electrolyte, which is the source of ions as charge carriers and counterions for the polymer (if it is electrochemically doped). As a counter electrode, platinum is usually used. For better precision and reproducibility, it can also be run with a third, reference electrode. The process is controlled by a DC current source (e.g. potentiostat). The electrode potential (or the current) might change during the process, depending on the electrochemical technique and its settings. Usually, we run polymerization using cyclic voltammetry (CV), chronoamperometry (CA), or chronopotentiometry (CP). These are described in Chapter 6.6 concerning characterization of materials. Thickness of the polymer can be easily controlled by changing the process time (or number of cycles while running CV polymerization).

Electrochemical polymerization may give a product of high molecular weight which is insoluble, even if the polymer obtained by chemical polymerization dissolves in the same condition. This leads to well-defined, uniform layers of good adhesion. If the obtained polymer does not deposit on the electrode, by addition of non-solvent, the composition of the precursor might be changed in a way that only the monomer and electrolyte are soluble. The major limitation of electrochemical polymerization is that it can be used only for conductive substrates.

The big advantage of (electro)chemical polymerization is that it is based on the monomer as a starting material. This allows for obtaining films of materials which are not commercially available (or equivalents of commercial polymers of different properties). 
In our work we used chemical and electrochemical polymerization for preparation of PEDOT layers, using EDOT dissolved in organic solvents ( $n$-butanol and acetonitrile respectively) for the work described in paper 2. Chemical polymerization also led to layers of melanin in paper 4 , after spin coating of the reaction precursor onto the substrates.

\subsubsection{Other methods of preparation of polymer films}

Apart from the abovementioned, there are also other techniques of preparation of polymer thin films, either physical or chemical. The former group includes methods based on polymer solution processing, such as dip coating, spray coating, various printing techniques, doctor blading, bar coating, or layer-by-layer technique, useful for polyelectrolytes. RF sputtering is also possible with some polymers ${ }^{137,138}$. As regards to chemical methods, an example of the method important in electronic industry is chemical vapor deposition (CVD) of Parylene C, when the precursor is cracked at elevated temperature in vacuum, yielding the monomer which polymerizes in cold zone of the coater. This gives excellent material for coating of printed circuit boards. Since none of these methods was used in this work, they will not be elaborated here.

\subsection{Other processes in manufacturing of thin layer devices}

An important step of the device preparation is cleaning of the substrate, no matter of which deposition method is used. In all cases, substrates have been ultrasonically cleaned in series of solvents, dried and treated with UV generated ozone or $\mathrm{O}_{2}$ plasma just before the device fabrication. Good care of the material purity must also be taken, as any impurities might significantly lower mobility of charge carriers ${ }^{139}$. Therefore, all pigments have been purified by sublimation before evaporation. All details can be found in the attached papers. 



\section{Characterization}

This chapter concerns characterization techniques and methodology of the $\mathrm{H}_{2} \mathrm{O}_{2}$ evolution experiments. Apart from those listed below, there are many other methods allowing for better understanding of the catalytic systems, such as small-angle-X-ray scattering or isotopic labeling. Only general principles of the methods used in our work will be discussed. Details can be found in the papers included in this thesis.

\subsection{UV-Vis spectroscopy}

UV-Vis spectroscopy, as all spectroscopic methods, is based on an absorption of electromagnetic radiation by an investigated sample. In this case, the radiation range usually used covers part of ultraviolet, the whole visible light and part of near infrared, that is 200 $1100 \mathrm{~nm}$. Upon absorption, molecules undergo electronic transitions, that is their valence electrons are excited to a higher energy level. Because of this phenomena, intensity of the light (that is, number of photons) transmitted by the material is lower than intensity of the incident light $^{140}$. This difference is recorded by a photodetector, part of the UV-Vis spectrometer, the instrument used for this purpose. The amount of the light absorbed is proportional to the number of given molecules. In the case of solutions, for each wavelength this dependence is described by the following formula, known as the Beer-Lambert law:

$$
A=\varepsilon \cdot c \cdot l
$$

Where:

$\varepsilon$ : molar absorption coefficient

c: concentration of the compound

l: optical path length

The logarithm of the $\mathrm{I}_{0} / \mathrm{I}$ quotient, known as absorbance, is an obtained output value. As $\mathrm{A}$ is directly proportional to the material concentration in solution, this is a very useful tool in quantitative analysis. In the case of thin film samples, the terms for molar absorptivity and concentration are replaced by the absorption coefficient, $\alpha$.

$\mathrm{UV}$-vis spectroscopy is also helpful in qualitative analysis. By registering the entire spectrum of absorbance values for given wavelength range, we can identify chemical moieties in the material based on their electronic transitions. In some cases, it allows for identification of the entire chemical compound. Depending on the chemical vicinity of a given moiety, its 
excitation by light may require different energy. Qualitative analysis can be also supported by the fact that during electronic transitions, vibrational transitions (which we normally identify by e.g. FTIR spectroscopy) are also possible. It makes the UV-Vis spectrum more complicated, but the relative intensity of peaks associated with given electronic transition might support qualitative analysis.

In our research we used UV-Vis spectroscopy for qualitative analysis of catalysts degradation during $\mathrm{H}_{2} \mathrm{O}_{2}$ evolution in papers $1,3,4,5$,6. It was also essential in measurements of hydrogen peroxide concentration in all 6 papers. Methodology of $\mathrm{H}_{2} \mathrm{O}_{2}$ is described in a separate section below. Furthermore, UV-Vis spectroscopy was useful in qualitative analysis of dyes aggregation in paper 6 , and to support the hypothesis of polymorphic transition in paper 3.

\subsection{Photoluminescence spectroscopy}

Photoluminescence spectroscopy (PL) in some respects resembles UV-Vis spectroscopy, the instrument also registers the number of photons as a function of a wavelength. However, in this case, these are not photons of the incident beam, unabsorbed by the sample, but the light emitted due to its excitation with an irradiation of higher energy ${ }^{140}$. It allows to get a luminescence spectrum, which like in the case of UV-Vis spectroscopy, depends on the energy of electronic and vibrational states of the material. A characteristic feature of this method is its strong dependence on the environment, surrounding the investigated molecules. Presence of other compounds may lead to emission quenching or enhancement. PL is useful in both qualitative and quantitative analysis, although the dependence of luminescence on the material concentration is not as straightforward like in the case of UV-Vis spectroscopy.

In our work this method was used in papers 5 and 6 for the aggregation study of catalytically active particles (or molecules) present in the reaction mixtures.

\subsection{Dynamic light scattering (DLS)}

DLS is a technique useful in determination of size distribution of particles, dispersed in a colloid $^{141}$. A beam of polarized, monochromatic light (usually a red laser) falls on the sample. When the photons collide with particles present in the solution, they are scattered in all directions. The diffracted light interferes, leading to waves of greater or lower amplitude. Thanks to polarizers and detectors (located in a way that the laser beam does not irradiate them directly) this leads to data which after mathematical processing gives us the size distribution of 
particles. The essential condition of the measurement is proper concentration of the dispersed material and that the light is not absorbed by it.

In the works included in this thesis, DLS was used in papers 5 and 6 for the aggregation study of catalytically-active particles present in the reaction mixtures.

\subsection{Scanning electron microscopy (SEM)}

SEM is an electron microscopy technique in which the sample is scanned with an electron beam. High velocity electrons interact with the sample in different ways. In the most common mode of microscope operation, we utilize the fact that atoms excited by the beam emit electrons, called secondary electrons, which hit the detector (or detectors) ${ }^{142}$. The imaging is possible thanks to the fact that the number of secondary electrons is different for different areas of the scanned specimen and it depends on the topography and chemical composition, among other factors. The technique requires vacuum to avoid collisions of electrons with molecules of gas present in the environment. The specimen has to be electrically conductive, otherwise imaging may be impossible due to charging of the sample. A charged surface repels electrons and leads to distortions in the imaging. Non-conductive samples might be covered with thin layer of conductor, e.g. by sputtering of platinum. The SEM resolution depends on many factors. For metals it can usually be increased by higher voltage of the beam, up to $30 \mathrm{kV}$, leading to images with resolution lower than $1 \mathrm{~nm}^{143}$. On the other hand, in case of semiconductors, too high voltage can lead to surface charging effects or damage of the surface, therefore in this work we usually use $3-6 \mathrm{kV}$.

Working on $\mathrm{H}_{2} \mathrm{O}_{2}$ evolution, we used the SEM for characterization of the morphology of the devices in papers 1, 2 and 3. In case of the latter, the images before and after the experiment was useful in investigation of possible degradation effects of the device performance.

\subsection{Determination of $\mathrm{H}_{2} \mathrm{O}_{2}$ concentration}

There are many ways of $\mathrm{H}_{2} \mathrm{O}_{2}$ quantification ${ }^{144}$, the selection depends on factors such as concentration range, available equipment, and presence of other substances in the solution. In most cases, we utilize redox properties of $\mathrm{H}_{2} \mathrm{O}_{2}$ molecule, which can be both a reducer and an oxidant. A brief characterization of the most common methods is presented below: 
Titration: usually, with a solution of potassium permanganate or iodometric titration (in two steps: I - oxidation of iodide to iodine, II - titration of $\mathrm{I}_{2}$ by thiosulphate). The reaction during these titrations are as follows:

- Titration with $\mathrm{KMnO}_{4}: \mathrm{H}_{2} \mathrm{O}_{2}$ is a reducer:

$$
2 \mathrm{MnO}_{4}^{-}+5 \mathrm{H}_{2} \mathrm{O}_{2}+6 \mathrm{H}^{+} \rightarrow 2 \mathrm{Mn}^{2+}+8 \mathrm{H}_{2} \mathrm{O}+5 \mathrm{O}_{2}
$$

The titration endpoint is when an excess of the $\mathrm{KMnO}_{4}$ turns the titrated solution pink.

- Titration with $\mathrm{S}_{2} \mathrm{O}_{3}{ }^{2-}: \mathrm{H}_{2} \mathrm{O}_{2}$ is an oxidant:

$$
\begin{aligned}
& \mathrm{H}_{2} \mathrm{O}_{2}+2 \mathrm{I}^{-}+2 \mathrm{H}^{+} \rightarrow 2 \mathrm{H}_{2} \mathrm{O}+\mathrm{I}_{2} \\
& \mathrm{I}_{2}+2 \mathrm{~S}_{2} \mathrm{O}_{3}^{2-} \rightarrow 2 \mathrm{I}^{-}+\mathrm{S}_{4} \mathrm{O}_{6}^{2-}
\end{aligned}
$$

The titration endpoint is when the titrated solution, dark blue after addition of starch, decolorizes.

Titration is the most widespread $\mathrm{H}_{2} \mathrm{O}_{2}$ quantification method in the research on hydrogen peroxide synthesis. It does not require any expensive equipment, although its applicability can be limited by non-selectivity of the used titrant e.g. $\mathrm{KMnO}_{4}$ is able to oxidize both $\mathrm{H}_{2} \mathrm{O}_{2}$ and oxalate, if this substance is used as sacrificial electron donor. The detection limit can be low enough to use this method for diluted $\mathrm{H}_{2} \mathrm{O}_{2}$ solutions, especially for iodometric titration.

Direct spectrophotometric measurement: As mentioned in Chapter 3.1, $\mathrm{H}_{2} \mathrm{O}_{2}$ absorbs UV light, which may be used for its quantification, by measuring absorbance at e.g. $250 \mathrm{~nm}^{64}$. The method is fast, convenient and $\mathrm{H}_{2} \mathrm{O}_{2}$ is not consumed, what can be very important if due to low volume of the reaction solution, an aliquot used for an assay has to be returned to the reaction system. The disadvantage of it is high detection limit and the fact that it cannot be used if the solution contains other substances absorbing UV light.

$\underline{\mathrm{H}}_{2} \underline{\mathrm{O}_{2}}$ electrochemical sensors: Instruments consisting of a probe and controller, which operate based on electrochemical oxidation or reduction of $\mathrm{H}_{2} \mathrm{O}_{2}$. The higher $\mathrm{H}_{2} \mathrm{O}_{2}$ content, the higher the resulting current ${ }^{145}$. Such a sensor usually requires calibration in given conditions, but it offers on-line $\mathrm{H}_{2} \mathrm{O}_{2}$ measurement and low detection limit, although it might be sensitive to presence of other, redox-active substances. Some instruments of this type allow for detection of $\mathrm{H}_{2} \mathrm{O}_{2}$ vapor in gas. Standalone, $\mathrm{H}_{2} \mathrm{O}_{2}$-designated instruments are very convenient but used mostly in industry. In research on hydrogen peroxide, electrochemical detection is usually performed with a potentiostat and metal electrodes, especially in a rotating ring-disk electrode studies of the reaction kinetics ${ }^{146}$. The ring-disk methodology was used in paper 2 . 
UV-Vis spectophotometric assays: an aliquot of $\mathrm{H}_{2} \mathrm{O}_{2}$ solution is added to an assay mixture containing a compound which reacts with hydrogen peroxide with the formation of a colored product $^{147}$. The obtained dye can be quantified spectrophotometrically, leading to value of peroxide concentration based on the calibration curve. In many cases to facilitate the assay, it is performed in a presence of horseradish peroxidase (HRP) enzyme as a catalyst of the oxidation by $\mathrm{H}_{2} \mathrm{O}_{2}$. There are many possibilities of using different substances as dye precursors, depending on the required sensitivity and optical transparency. Usually, the assay mixture has to be buffered, due to presence of the enzyme and the fact that color of many dyes depends on the $\mathrm{pH}$. The advantage of this method is its simplicity, speed (measurement of absorbance at single wavelength takes less time than titration), possibility of using plate reader for measurements of absorbance (this allows operation with aliquots of the volume as low as $1 \mu \mathrm{L}$ ) and in many cases, good selectivity towards $\mathrm{H}_{2} \mathrm{O}_{2}$.

This is the method widely used in all of our works. We used a literature procedure ${ }^{148}$ based on the phosphate/citric buffer of $\mathrm{pH}$ 5.5-6, HRP as an enzymatic catalyst and TMB 3,3',5,5'-Tetramethylbenzidine which gives a blue product by the reaction shown in Fig. 6.1.
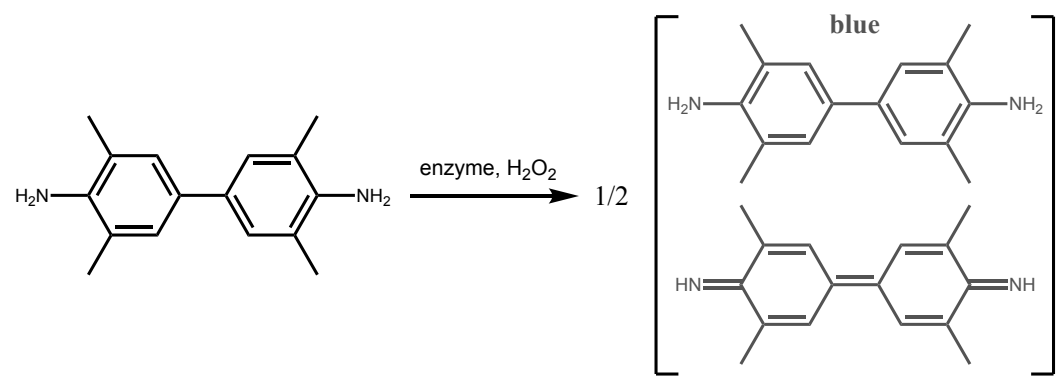

Fig. 6.1. The reaction scheme of the TMB oxidation used for $\mathrm{H}_{2} \mathrm{O}_{2}$ quantification. The product of the reaction forms a blue adduct with a molecule of the unreacted substrate.

Thanks to the fact that $\lambda_{\max }$ of the adduct is above $650 \mathrm{~nm}$ (exact value might vary, depending on the $\mathrm{pH}$; calibration is recommended for every batch of the buffer) we could use this method even for the solutions containing pigments and dyes in paper 5 and 6 . Depending on the aliquot volume, this procedure can be used for detection of $\mathrm{H}_{2} \mathrm{O}_{2}$ in a $1 \mu \mathrm{M}-10 \mathrm{mM}$ range if a plate reader and the 96 wells plate is used. More concentrated solutions have to be diluted before an assay.

Luminescence assays: the principle is very similar to spectophotometric assays, the only difference is that the obtained product of oxidation by $\mathrm{H}_{2} \mathrm{O}_{2}$ is quantified by fluorescence ${ }^{149}$ or 
chemoluminescence ${ }^{150}$. These methods also require buffered solution and are facilitated by the HRP enzyme. If a plate reader is available, exactly the same equipment can be used for all three techniques. The advantage of luminescence methods versus UV-Vis spectroscopy is that they can be even more sensitive, but as the efficiency of light emission strictly depends on the solution composition, separate calibration has to be performed for every single type of sample.

\subsection{Electrochemical characterization}

\subsubsection{General information on electrochemical measurements}

Electrochemistry is a field of physical chemistry which studies chemical reactions induced by electricity. Therefore, it is of high importance in organic electronics and photo(electro)catalysis as an essential tool for characterization of active materials. Even in photocatalysis, where we do not have any electrical circuits and standalone electrodes, it can provide with useful information. In an electrochemical experiment, we induce redox processes on two electrodes ${ }^{19}$. One of them, the working electrode (WE) is the device of interest (or material deposited on a conductive substrate). The second one, counter electrode (CE), enables complementary redox process, as discussed in Chapter 2. Surface area and catalytic activity of the counter electrode should not limit the process on the working electrode, therefore we usually use platinum, e.g. in a form of mesh. The electrochemical system is frequently equipped with a third, reference electrode, to provide a control over the potential of the working electrode. If the system is equipped with just two electrodes, only the potential difference $\mathrm{E}_{\mathrm{WE}} \mathrm{vs}$. $\mathrm{E}_{\mathrm{CE}}$ can be controlled. As the $\mathrm{E}_{\mathrm{CE}}$ is not stable and it strongly depends on the electrolyte (which composition locally changes also during the electrochemical process), any change of the counter electrode potential changes the potential of working electrode. What is more, in the 2-electrode system, the value of $E_{W E}$ is also influenced by an ohmic drop on the electrolyte, which, apart from its composition, depends on the distance between working and counter electrodes. Therefore, for good reliability of measurements, we equip the electrochemical system with the third, reference electrode (RE) and control/register the $\mathrm{E}_{\mathrm{WE}}$ versus this electrode. Stability of the $\mathrm{E}_{\mathrm{RE}}$ is provided by its design and the fact that current does not flow thought it. This assures stability of local electrolyte composition and eliminates the problem of ohmic drop on the electrolyte. Currently, the most commonly used reference electrolyte in water electrolytes is $\mathrm{Ag} / \mathrm{AgCl}$ in $\mathrm{KCl}$ solution.

To summarize this discussion, we can conclude that characterizing the working electrode, we measure the current versus counter electrode and the potential versus reference electrode. If we control the potential, we measure the current, and vice versa, if we control the current, we measure the potential. The way we operate these parameters depends on the 
electrochemical technique in use. Due to the very broad spectrum of possible methods, the discussion will be limited only to the ones used in our work: cyclic voltammetry, linear sweep voltammetry, chronoamperometry, and chronopotentiometry.

In linear sweep voltammetry (LSV) we register the current and control the potential by changing it within a given range (from $\mathrm{E}_{0}$ to $\left.\mathrm{E}_{1}\right)$ at a given rate $(\mathrm{mV} / \mathrm{s})$. As a result, we obtain the $I=f(E)$ dependence. Graphic representations of the potential change in time, along with a sample linear sweep voltammogram are shown in Fig. 6.2.
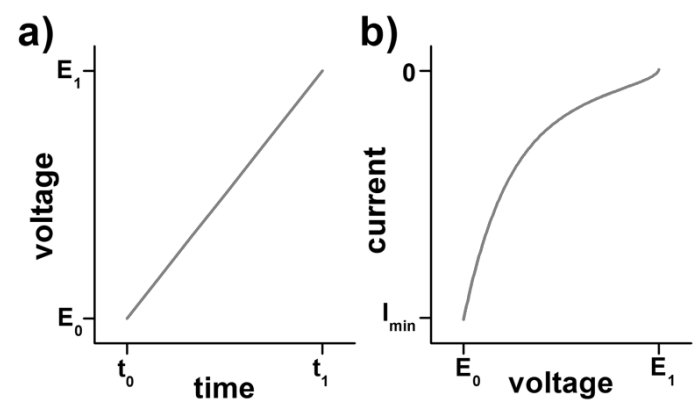

Fig. 6.2. (a) The dependence of the working electrode potential versus time for the linear sweep voltammetry in the $E_{0}$ to $E_{1}$ range. (b) A sample linear sweep voltammogram: $I=f(E)$ dependence, typical of the $\mathrm{O}_{2}$ to $\mathrm{H}_{2} \mathrm{O}_{2}$ reduction process on an organic catalyst (if $\mathrm{E}_{0}<\mathrm{E}_{1}$ ).

Cyclic voltammetry (CV) resembles linear sweep voltammetry, we also register the current and control the potential by changing it within a given range (from $\mathrm{E}_{0}$ to $\left.\mathrm{E}_{1}\right)$ at a given rate $(\mathrm{mV} / \mathrm{s})$. The difference is that we do not stop the measurement once the $E_{1}$ value is reached, but the scanning then goes the other way, that is the potential changes from $E_{1}$ to $E_{0}$ at the same rate as before. As the result, we obtain the $I=f(E)$ dependency. When the redox process results in a product adsorbed on the electrode, the reverse cycle might reverse the process, what can be seen as a current of similar absolute values like in the forward cycle, but of the opposite sign. Registered values of current depend on the reactant concentration and on the scan rate in a way that the higher scan rate, the higher the absolute value of current. This is related with a fact that apart from inducing redox processes, change of electrode potential impacts its electrical double layer (formed by ions adsorbed on the surface) the way that if the "electrode-electrolyte capacitor" is charged in forward cycle, it is discharged in the reverse cycle (or the other way around). Higher scan rate results in shorter charge/discharge time what increases the registered current. Compared with the LSV, cyclic voltammetry allows for better characterization of the electrochemical processes, to assess its reversibility and stability of the system (by comparing 
voltammograms in consecutive cycles), it can be also used in determining of the electrode capacitance. Graphic representations of the potential change in time, along with a sample cyclic voltammograms are shown in Fig. 6.3.
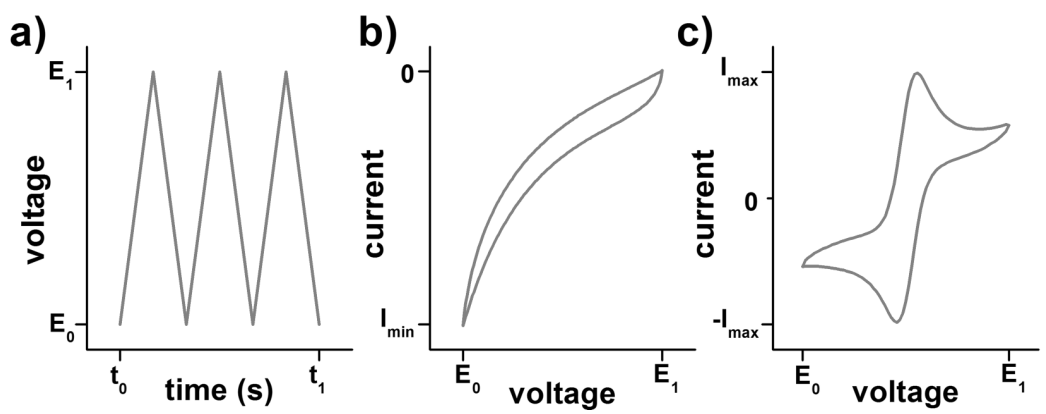

Fig. 6.3. (a) The dependence of the working electrode potential versus time for the cyclic voltammetry in the $\mathrm{E}_{0}$ to $\mathrm{E}_{1}$ range. (b) A sample cyclic voltammogram: $\mathrm{I}=\mathrm{f}(\mathrm{E})$ dependence, typical of the $\mathrm{O}_{2}$ to $\mathrm{H}_{2} \mathrm{O}_{2}$ reduction process on an organic catalyst (if $\mathrm{E}_{0}<\mathrm{E}_{1}$ ). In this case, the product is not adsorbed on the electrode surface, therefore it is constantly formed within the entire $E_{0}-E_{1}-E_{0}$ cycle. We see it as the constantly negative current, impacted only by the changes of the electric double layer on the electrode. (c) A sample cyclic voltammogram, typical for ferrocene dissolved in acetonitrile. In this case, the product of ferrocene oxidation is adsorbed on the electrode surface, therefore in a reverse cycle, as the redox process is reversible, current values change from positive to negative.

Chronoamperometry (CA) is a technique in which the current is registered in time when a constant (or stepped) potential is applied on the electrode. This results in the $I=f(t)$ dependence. Graphic representations of the current change in time, along with a sample chronoamperometric plot are shown in Fig. 6.4.
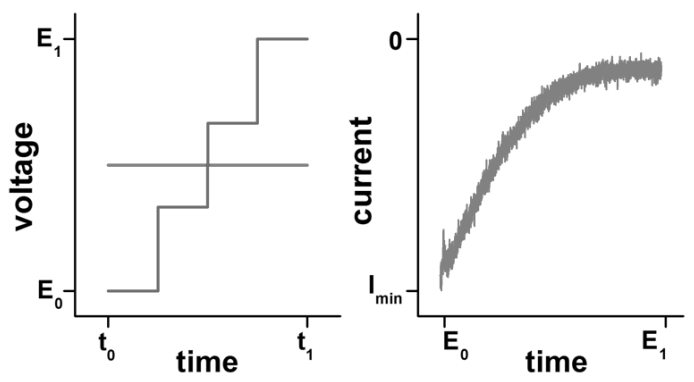

Fig. 6.4. (a) Possible dependencies of the working electrode potential versus time for chronoamperometry. (b) A sample result of the CA measurement, $I=f(t)$ plot. 
Chronopotentiometry (CP) is the other method of chronoanalysis, in which the potential is registered in time after the constant (or stepped) current is applied on the electrode. These conditions are also called galvanostatic. As a result, we get the $E=f(t)$ dependence.

\subsubsection{Electrochemical measurements for characterization of $\mathrm{H}_{2} \mathrm{O}_{2}$ synthesis catalysts}

In most of the papers included in this thesis, a key part of the device characterization was performed with electrochemical techniques. Therefore, a brief summary of these measurements for each paper is presented below. All details and description of the experimental setups can be found in the articles.

In paper 1, we used the cyclic voltammetry to determine occurrence of electrochemical $\mathrm{O}_{2}$ reduction on the $\mathrm{Au} / \mathrm{PTCDI}$ electrode immersed in electrolytes of different $\mathrm{pH}$. Measurements were performed in oxygenated (under purging with $\mathrm{O}_{2}$ ) and deoxygenated (after at least $1 \mathrm{~h}$ of purging with Ar) conditions. As shown in Fig. 6.5, in the presence of oxygen, under bias more negative than $-0.2 \mathrm{~V}$ vs. $\mathrm{Ag} / \mathrm{AgCl}$, a characteristic steep increase of negative value of current can be seen in the entire $1-13 \mathrm{pH}$ range, being the most pronounced at $\mathrm{pH} 1$. In the absence of oxygen, there is no such an effect, we only see a small current associated with reversible reduction of PTCDI.
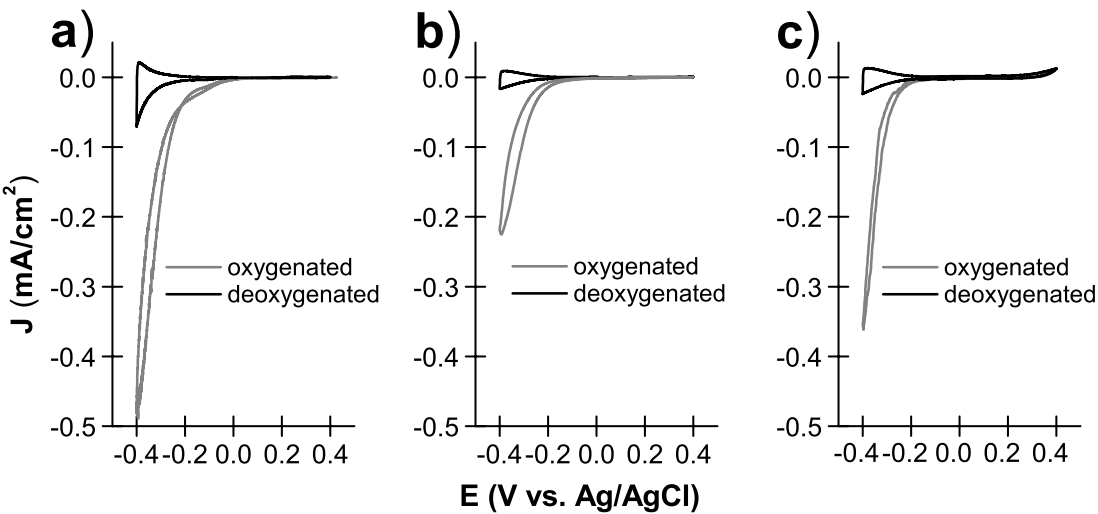

Fig. 6.5. Cyclic voltammetry of $\mathrm{Au} / \mathrm{PTCDI}$ electrodes at $\mathrm{pH} 1$ (a), $\mathrm{pH} 7$ (b) and $\mathrm{pH} 13$ (c) under oxygenated and deoxygenated conditions, proving occurrence of the ORR process.

Electrochemical measurement by itself does not provide information about the product of oxygen reduction. Qualitative identification of $\mathrm{H}_{2} \mathrm{O}_{2}$ was performed as described in Chapter 6.5, after running a chronoamperometric experiment at $-0.4 \mathrm{~V}$ vs. $\mathrm{Ag} / \mathrm{AgCl}$ for $30 \mathrm{~min}$. 
Investigating the catalytic properties of PTCDI, cyclic voltammetry was also used for estimation of the HOMO and LUMO levels of the molecule. Although ultraviolet photoelectron spectroscopy (UPS) ${ }^{151}$ and inverse photoemission spectroscopy (IPES) ${ }^{152}$ are regarded as the correct way to obtain absolute energy level values, electrochemical measurements usually give similar results, but they are much easier to perform ${ }^{153}$. To be able to register oxidation and reduction potentials of the molecule not affected by other processes, the experiment has to be performed in deoxygenated and electrochemically inert electrolyte. For this purpose, we immersed the Au/PTCDI sample and used it as a working electrode in the solution of tetrabutylammonium hexafluorophosphate in acetonitrile $\left(\mathrm{TBAPF}_{6} / \mathrm{CH}_{3} \mathrm{CN}\right)$, which was purged with nitrogen before cyclic voltammetry. The remaining two electrodes of the 3electrode system were $\mathrm{Pt}$ coil and $\mathrm{Ag} / \mathrm{AgCl}$ wire as the counter and reference electrodes respectively. Although PTCDI is not soluble in acetonitrile, its oxidized/reduced forms may dissolve, therefore oxidation and reduction potentials have been investigated in two separate measurements for two separate samples, as shown in Fig. 6.6.

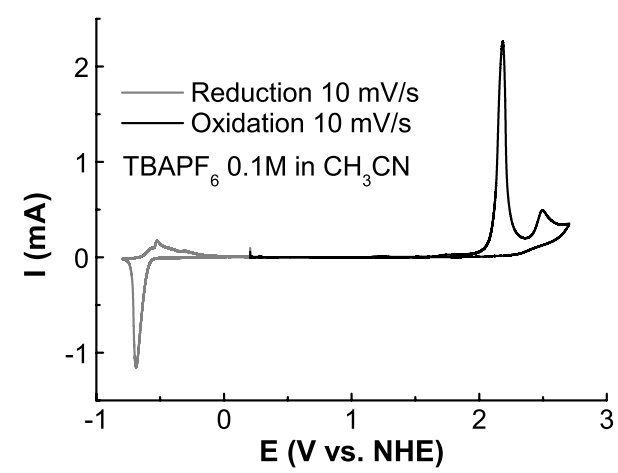

Fig. 6.6. Cyclic voltammetry of $\mathrm{Au} / \mathrm{PTCDI}$ electrodes in deoxygenated $\mathrm{TBAPF}_{6} / \mathrm{CH}_{3} \mathrm{CN}$. As obtained values (E vs. $\mathrm{Ag} / \mathrm{AgCl}$ ) were recalculated and plotted as $\mathrm{E}$ vs. NHE. Scans were performed with 10 $\mathrm{mV} / \mathrm{s}$ rate.

Frontier molecular orbital energy level estimations were calculated according to formulas given by Baran et al. ${ }^{154}$ :

$\mathrm{E}_{\mathrm{HOMO}}=-\left(\mathrm{E}_{\text {onset, ox vs. } \mathrm{NHE}}+4.75\right)(\mathrm{eV})$;

$\mathrm{E}_{\mathrm{LUMO}}=-\left(\mathrm{E}_{\text {onset, }}\right.$ red vs. $\left.\mathrm{NHE}+4.75\right)(\mathrm{eV})$

Giving values of HOMO and LUMO level as $-6.7 \mathrm{eV}$ and $-3.9 \mathrm{eV}$ respectively. 
Paper 2 consists of many different electrochemical measurements, performed with rotating ring-disc electrode and in situ ATR-FTIR among others. These are described in details by Evangelia Mitraka in her $\mathrm{PhD}$ thesis and in paper 2 itself.

In paper 3, concerning photocathodes for $\mathrm{H}_{2} \mathrm{O}_{2}$ evolution (PN/Au/PTCDI and $\mathrm{PN} / \mathrm{Au} / \mathrm{EPI}$ ), electrochemical measurements were performed in presence of a light source, operated in the on-off way during the CV, CA and LSV measurements. As the ability of the employed catalysts of $\mathrm{H}_{2} \mathrm{O}_{2}$ synthesis was proved before, we performed measurements only

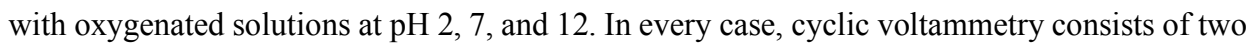
cycles, performed with and without irradiation. The obtained voltammograms (Fig. 6.7) for both types of photocathodes show a lack of current flow without irradiation and strong photocurrents (up to $1100 \mu \mathrm{A} / \mathrm{cm}^{2}$ ) when the light is turned on. In both cases, the higher the $\mathrm{pH}$, the lower the photoresponse.

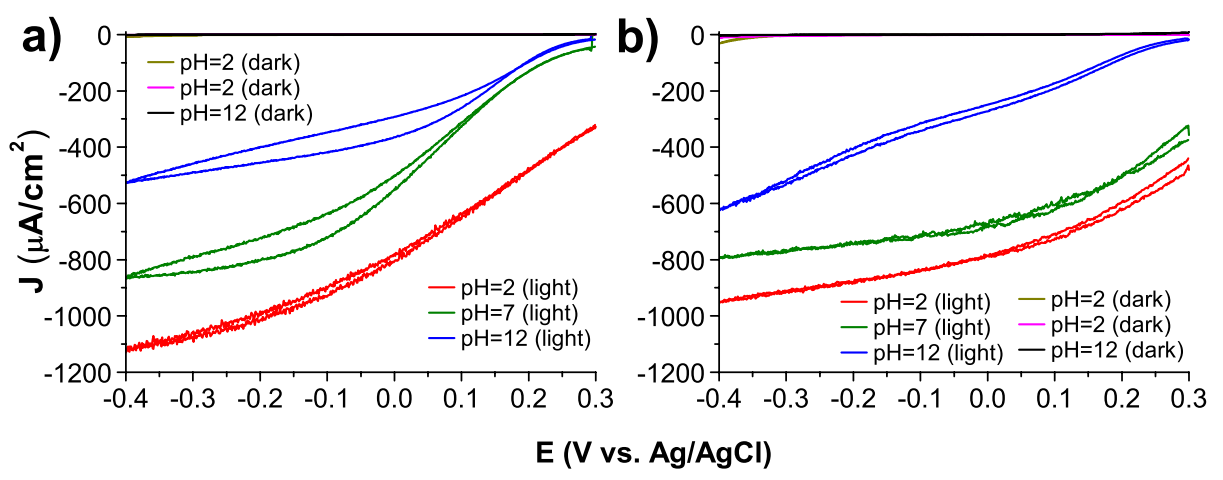

Fig. 6.7. $\mathrm{CV}$ measurements for the PN/Au/PTCDI (a) and PN/Au/EPI (b) photocathodes at pH 2 - 12 with and without irradiation (halogen lamp, $100 \mathrm{~mW} / \mathrm{cm}^{2}$ ).

Chronoamperometric experiments have been performed at $\mathrm{pH} 2$ under pulsed (15 s) irradiation at $0 \mathrm{~V}$ vs. $\mathrm{Ag} / \mathrm{AgCl}$, the same bias which was used in the long experiment of $\mathrm{H}_{2} \mathrm{O}_{2}$ photoelectrogeneration (Fig. 6.8). The purpose of this approach is to show that the current flowing at this bias can be attributed to the light absorption and that the systems do not suffer from occurrence of trap states, which is proved by the lack of transient peaks at the $I=f(t)$ plots. 


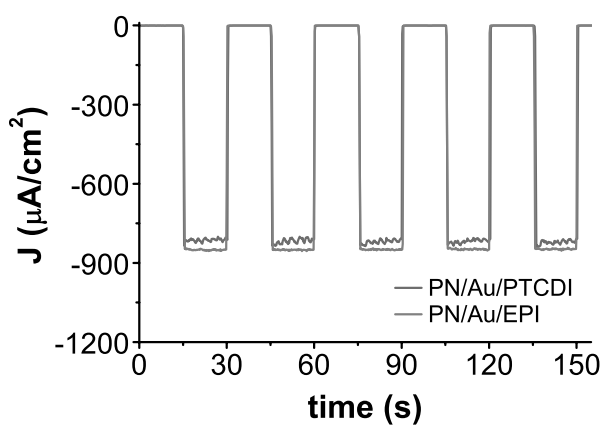

Fig. 6.8. Chronoamperometry of the PN/Au/PTCDI and PN/Au/EPI photocathodes at $\mathrm{pH} 2$ under pulsed (15 s) irradiation.

Finally, the findings were supported by linear sweep voltammetry experiments, in the -0.4 to $+0.8 \mathrm{~V}$ vs. $\mathrm{Ag} / \mathrm{AgCl}$ range for solutions at $\mathrm{pH} \mathrm{2,} \mathrm{7,} \mathrm{and} 12$ (Fig. 6.9). Like in the case of CA measurement, it was performed with pulsed, $15 \mathrm{~s}$ irradiation, showing not only that both photocathodes are free from occurrence of trap states, but also contributing to the discussion on possible mechanism of the oxygen reduction reaction. $\mathrm{H}_{2} \mathrm{O}_{2}$ can be obtained either by direct $\mathrm{O}_{2}$ to $\mathrm{H}_{2} \mathrm{O}_{2}$ reduction or with the superoxide intermediate $\mathrm{HO}_{2}{ }^{\circ}$, which disproportionates to $\mathrm{H}_{2} \mathrm{O}_{2}$ and $\mathrm{O}_{2}$. Assuming that the maximum photovoltage generated by the $\mathrm{PN}$ junction is $550 \mathrm{mV}^{155}$ and that standard electrode potential of the $\mathrm{O}_{2}+\mathrm{H}^{+}+\mathrm{e}^{-}$reaction is $-0.215 \mathrm{~V}$ vs. $\mathrm{Ag} / \mathrm{AgCl}$ at $\mathrm{pH}$ $2^{73}$, this reaction would not be possible under a bias more positive than $0.35 \mathrm{~V}$ vs. $\mathrm{Ag} / \mathrm{AgCl}$. However, LSV plots show that the reaction onsets are $0.61 \mathrm{~V}$ and $0.68 \mathrm{~V}$ vs. $\mathrm{Ag} / \mathrm{AgCl}$ for the $\mathrm{PN} / \mathrm{Au} / \mathrm{PTCDI}$ and PN/Au/EPI photocathodes respectively. Therefore, the superoxide path is very unlikely. This provides evidence that the $2 \mathrm{H}^{+} / 2 \mathrm{e}^{-}$reduction reaction of $\mathrm{O}_{2}$ to $\mathrm{H}_{2} \mathrm{O}_{2}$ is occurring. 


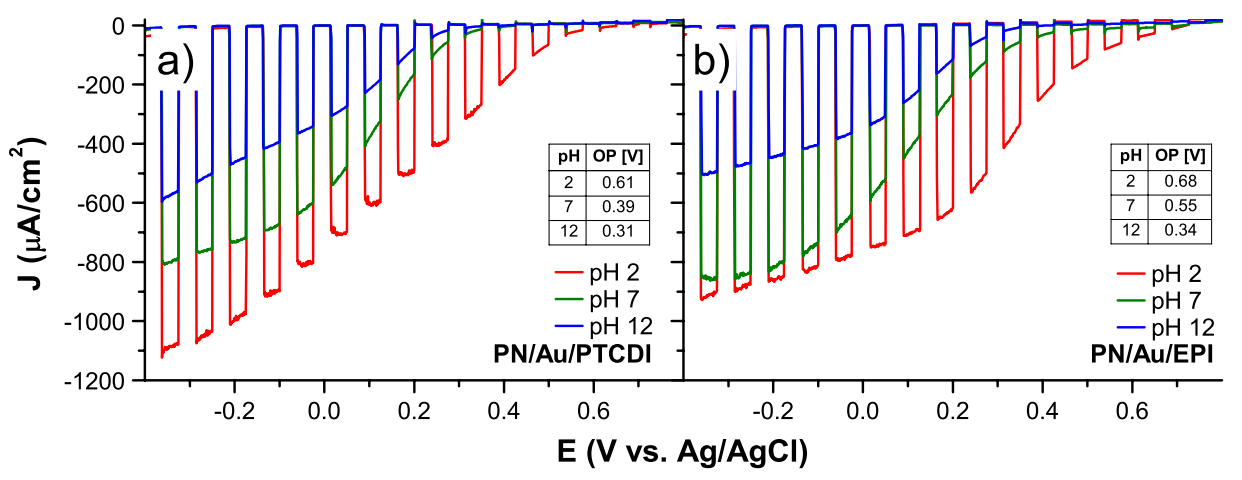

Fig. 6.9. Linear sweep voltammetry of the photocathodes with $15 \mathrm{~s}$ light on/off cycles for (a) $\mathrm{PN} / \mathrm{Au} / \mathrm{PTCDI}$ and (b) PN/Au/EPI. Scans were measured at $\mathrm{pH} \mathrm{2,} \mathrm{7,} \mathrm{and} 12$ with $100 \mathrm{~mW} / \mathrm{cm}^{2}$ irradiation. Values of onset potential (OP) at a given $\mathrm{pH}$ are shown in the inset tables. ${ }^{156}$ Published by The Royal Society of Chemistry.

In paper 4, concerning eumelanin as a photo- and photoelectocatalyst for $\mathrm{H}_{2} \mathrm{O}_{2}$ evolution, a similar approach like in paper 3 has been used. However, in this case, the measurements were performed also with deoxygenated electrolyte. The chronoamperometric experiment at $0 \mathrm{~V}$ vs. $\mathrm{Ag} / \mathrm{AgCl}$ showed that the irradiation induces a faradaic process also for the deoxygenated electrolyte, but it is much more pronounced in presence of oxygen, which is a proof of the ORR process (Fig. 6.10). Using HRP/TMB assay like described in Chapter 6.5, its product has been confirmed as $\mathrm{H}_{2} \mathrm{O}_{2}$.

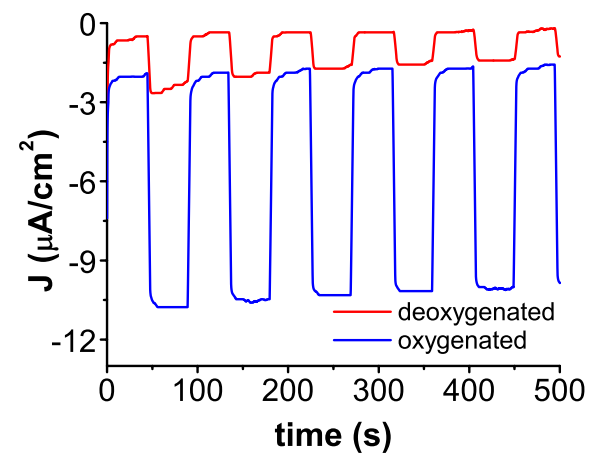

Fig. 6.10. Chronoamperometry of the eumelanin/FTO photocathode under pulsed irradiation at $\mathrm{pH} 1$ and $0 \mathrm{~V}$ vs. $\mathrm{Ag} / \mathrm{AgCl}$. Compared with the work described in paper 3, due to relatively weak photoresponse, stronger light source $\left(255 \mathrm{~mW} / \mathrm{cm}^{2}\right)$ has been used. A duration of the light pulse has been extended to $45 \mathrm{~s}$ due to slower charge carrier dynamics than for the photocathodes in paper 3 . 
In papers 5 and 6 , concerning purely photochemical $\mathrm{H}_{2} \mathrm{O}_{2}$ evolution, electrochemical measurements could not be used in evaluation of the catalyst performance towards $\mathrm{H}_{2} \mathrm{O}_{2}$ generation. Nevertheless, they were useful in estimation of the HOMO and LUMO levels of the materials, which in the case of photocatalysts gives not only information about possibility of the ORR processes but allows also for correlating photostability of the materials with their HOMO levels. For paper 5, we used available literature values, including data for PTCDI collected and published by us before. In paper 6, we used very similar approach like presented above for paper 1 . The difference is that the entire potential range was covered within a single scan. In case of the soluble NDI-G, its solution in acetonitrile has been used, with Pt wire as working electrode. The obtained plots are shown in Fig. 6.11. Values of oxidation and reduction onsets, along with calculated HOMO and LUMO levels, are collected in Table 3.
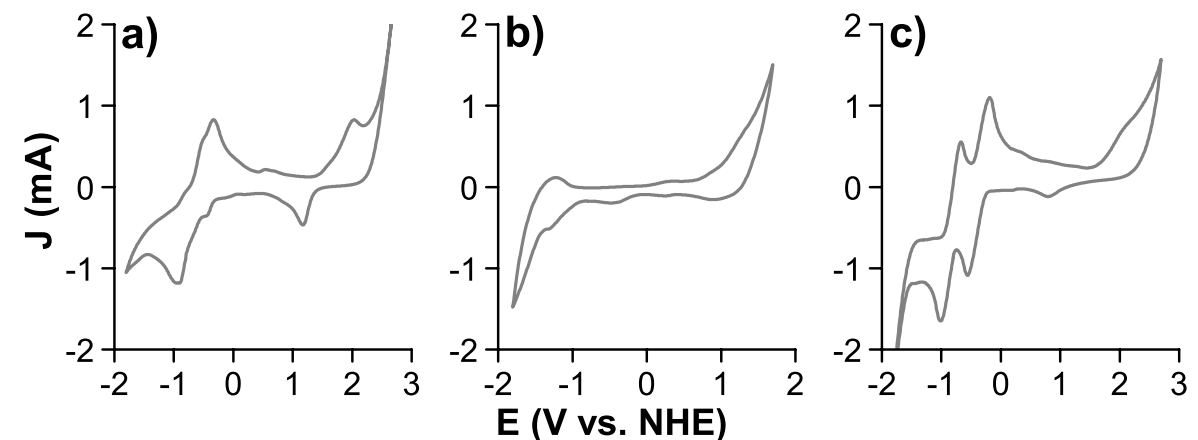

Fig. 6.11. Cyclic voltammetry of the catalytic dyes in deoxygenated $\mathrm{TBAPF}_{6} / \mathrm{CH}_{3} \mathrm{CN}$ a) $\mathrm{PDI}-\mathrm{S}$ b) QNC$\mathrm{S}$ c) NDI-G. As obtained values (E vs. $\mathrm{Ag} / \mathrm{AgCl}$ ) were recalculated and plotted as E vs. NHE. Scans were performed with $100 \mathrm{mV} / \mathrm{s}$ rate, for layers deposited on gold substrates by drop casting of the dye water solution (in case of the PDI-S and QNC-S) or for the dye dissolved in the electrolyte (in the case of NDI-G).

Table 3. Summary of the electrochemical HOMO and LUMO level determination for the dyes used as photocatalysts for $\mathrm{H}_{2} \mathrm{O}_{2}$ evolution in paper 6 .

\begin{tabular}{|c|c|c|c|c|}
\hline dye & $\begin{array}{c}\text { Ox onset vs. } \\
\text { NHE (V) }\end{array}$ & $\begin{array}{c}\text { Red onset vs. } \\
\text { NHE (V) }\end{array}$ & $\begin{array}{c}\text { EHOMO }_{\text {HOV }} \\
(\mathbf{e V}\end{array}$ & $\begin{array}{c}\text { E }_{\text {LUMo }} \\
(\mathbf{e V})\end{array}$ \\
\hline PDI-S & 1.33 & -0.24 & -6.1 & -4.5 \\
\hline QNC-S & 0.83 & -0.79 & -5.6 & -4.0 \\
\hline NDI-G & 1.46 & -0.25 & -6.2 & -4.5 \\
\hline
\end{tabular}




\section{Methodology of $\mathrm{H}_{2} \mathrm{O}_{2}$ evolution}

In our work we investigated catalytic properties of various materials towards hydrogen peroxide production by electro-, photoelectro- and photocatalysis. The reaction setups and employed solutions will be discussed separately for each of these methods. As mentioned in Chapter 3, in general it is possible to produce $\mathrm{H}_{2} \mathrm{O}_{2}$ either by $\mathrm{O}_{2}$ reduction or $\mathrm{H}_{2} \mathrm{O}$ oxidation. Due to thermodynamics of the oxidation process and requirement of high, positive potential of the electrode, the desired transformation would be difficult to achieve with organic catalysts. Therefore, our work is focused only on the oxygen reduction pathway.

\subsection{Electrocatalysis for $\mathrm{H}_{2} \mathrm{O}_{2}$ evolution}

Short summary of the process, performed with Au/PTCDI or PEDOT electrodes: long-term cathodic reduction of oxygen, dissolved in aqueous electrolyte, at constant current, with solution aliquots taken over the course of the experiment to measure $\mathrm{H}_{2} \mathrm{O}_{2}$ concentration and calculate the faradaic efficiency.

In papers 1 and 2, we tested PTCDI and 3 different forms of PEDOT as catalysts, respectively. $\mathrm{H}_{2} \mathrm{O}_{2}$ electroevolution by oxygen reduction was evaluated in acidic, neutral, and basic electrolyte. For the Au/PTCDI electrode, all experiments have been performed with the same sample. This was due to outstanding stability of the Au/PTCDI system. In the case of PEDOT, for each of the experiments we used fresh samples, due to limited mechanical stability of the material and its electrical contact (optimization of these parameters was out of scope of the work). We always used the setup presented in Fig. 7.1, with two separate compartments ionically connected with an agarose $/ \mathrm{Na}_{2} \mathrm{SO}_{4}$ salt bridge.

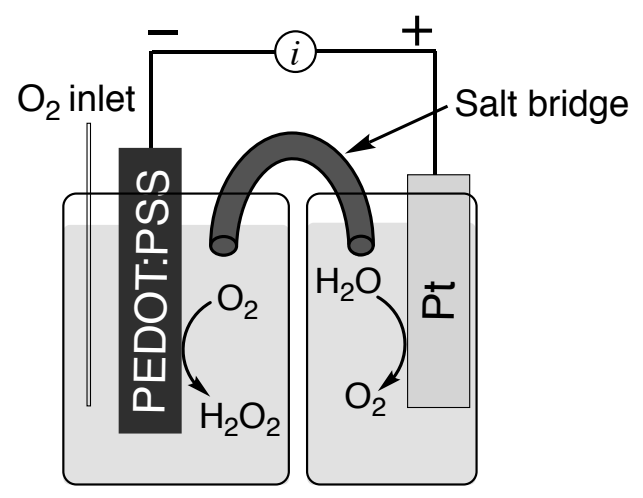

Fig. 7.1. Two-compartment cell used for longer-term electrocatalytic $\mathrm{H}_{2} \mathrm{O}_{2}$ synthesis. The volume of the electrolyte in each compartment was $22-25 \mathrm{ml}$. 
The solution was constantly purged with a flow of oxygen $\left(150 \mathrm{ml} \cdot \mathrm{min}^{-1}\right)$, providing the crucial reagent and also serving to mix the solution. Although in all cases the cathodic compartment was open to the atmosphere, due to purging rate it is assumed that the headspace over the solution consists of $100 \% \mathrm{O}_{2}$ under the 1 bar pressure. As purging was always performed with a stream of dry gas, it caused a partial water evaporation from the solution. The electrolyte level was constantly monitored and if necessary, $0.5-1 \mathrm{ml}$ of pure DI has been added. Taking of the solution aliquots (usually every $2 \mathrm{~h}$, with a night break), due to their low volume $\left(25-200 \mu \mathrm{L}\right.$ ), did not contribute significantly to the decrease of the electrolyte level. $\mathrm{H}_{2} \mathrm{O}_{2}$ concentration has always been determined with the HRP/TMB assay described in Chapter 6.5.

The experiments have been performed with a Keithley 2450 Source Meter in the 2-electrode system, as such an arrangement is more common in industrial electrolyzes than the 3-electrode system. The investigated sample was always employed as working electrode (placed in the cathodic compartment), while platinum mesh was used as a counter electrode (placed in the anodic compartment). As the main focus was on determination of the ORR selectivity and the material stability, we run all experiments using chronopotentiometry instead of chronoamperometry. This made our experiments independent on changes of the electric resistance in the solution, caused mainly by salt bridges. In our experiments, lasting up to $48 \mathrm{~h}$, especially after a few hours we usually saw gradual increase of the voltage values. Replacement of the salt bridge brought the voltage to lower and more stable values. Therefore, for most of the experiments fresh salt bridges have been used. In fully optimized $\mathrm{H}_{2} \mathrm{O}_{2}$ electrolyzes that would not be an issue and the same samples could be probably effectively used in chronoamperometric conditions, giving constant current for a given potential difference.

Measurement of $\mathrm{H}_{2} \mathrm{O}_{2}$ concentration allowed not only to track its increase but also to determine the faradaic efficiency (FE), the parameter defined in Chapter 2.1. In our work it was calculated using the following formula:

$$
F E=\frac{n_{\text {measured }}}{n_{\text {theoretical }}}=\frac{n \cdot F \cdot z}{Q}=\frac{C_{\mathrm{H}_{2} \mathrm{O}_{2}} \cdot V_{\mathrm{H}_{2} \mathrm{O}_{2}} \cdot 96485 \cdot 2}{I \cdot t}
$$

Where:

$\mathrm{n}$ : molar amount of the desired product obtained

$\mathrm{C}_{\mathrm{H} 2 \mathrm{O2}}$ : concentration of the hydrogen peroxide solution

$\mathrm{V}_{\mathrm{H} 2 \mathrm{O2}}$ : volume of the hydrogen peroxide solution

F: Faraday constant $\left(96485 \mathrm{C} \cdot \mathrm{mol}^{-1}\right)$ 
Z: number of electrons gained/lost to give one molecule of the product ( 2 for $\mathrm{H}_{2} \mathrm{O}_{2}$ )

$\mathrm{Q}$ : electrical charge passed in the system (integral of the $I=f(t)$ dependence; in the case of the chronopotentiometric experiment it is equal to the product of current, I and time, $\mathrm{t}$ )

\subsection{Photoelectrocatalysis for $\mathrm{H}_{2} \mathrm{O}_{2}$ evolution}

Short summary of the process, performed with organic PN or eumelanin-based photocathodes: Long-term electrolysis of the oxygenated water electrolyte, under constant illumination, at constant bias ( $0 \mathrm{~V} v \mathrm{~s}$. $\mathrm{Ag} / \mathrm{AgCl})$ with solution aliquots taken over the course of the experiment to measure $\mathrm{H}_{2} \mathrm{O}_{2}$ concentration and calculate the faradaic efficiency.

In papers 3 and 4 we tested photocathodes, based on the $\mathrm{H}_{2} \mathrm{Pc} / \mathrm{PTCDI}$ organic PN junction (PN/Au/PTCDI and PN/Au/EPI) or eumelanin. Although the photocathodes have been tested with solutions of different $\mathrm{pH}$ (PN-based samples at $\mathrm{pH} 2,7,12$; eumelanin-based at $\mathrm{pH}$ 1 and 7), long term experiments have been performed only for acidic solutions, as it gives higher photocurrents. In photoelectrochemical measurements, we used a Redox.me MM PEC HCELL, shown in Fig. 7.2, equipped with a nafion membrane and 3 electrodes: the investigated sample (as a working electrode, with $1 \mathrm{~cm}^{2}$ active area, delimited by the o-ring, exposed to the catholyte), reference electrode $(\mathrm{Ag} / \mathrm{AgCl}$ in water solution of $\mathrm{KCl}$; placed together with working electrode in cathodic compartment) and counter electrode (Pt coil, placed in the anodic compartment). The experiment was controlled by an Ivium technologies Vertex One potentiostat.
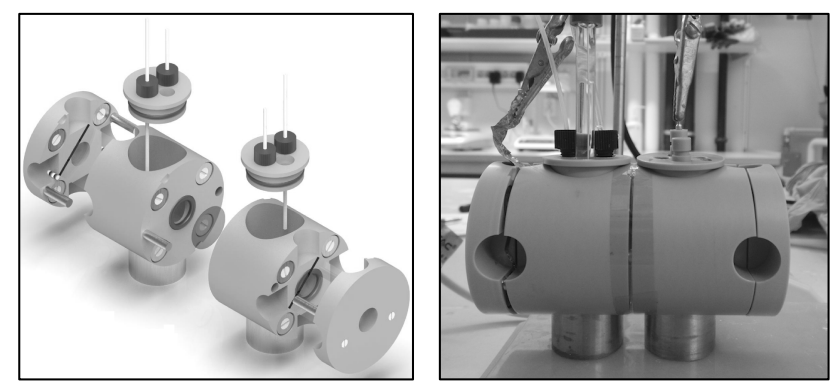

Fig. 7.2. The Redox.me MM PEC H-CELL photoelectrochemical H-cell used in all photoelectrochemical experiments. The cathodic and anodic compartments are separated with nafion, a proton-selective membrane, to prevent from $\mathrm{H}_{2} \mathrm{O}_{2}$ diffusion to the anolyte. Volume of the catholyte is $10-12 \mathrm{ml}^{156}$. Published by The Royal Society of Chemistry. 
The solution was constantly purged with water-saturated oxygen $\left(150 \mathrm{ml} \cdot \mathrm{min}^{-1}\right)$. Compared with electrocatalytic experiments, we pumped the $\mathrm{O}_{2}$ stream through water in a gas bubbler to limit water evaporation. This is also assured by the cell design and the fact that the both compartments are tightly closed. Over the entire time of the experiments, samples were illuminated from the substrate side, i.e. through the ITO/FTO. Selection of the light source depends on the investigated material. In the case of the PN-based photocathodes, a tungsten halogen lamp (with an additional FTO-coated glass filter to limit infrared heating) was used, after its calibration to a light intensity of $100 \mathrm{~mW} / \mathrm{cm}^{2}$ (1.00 sun). Working with eumelaninbased samples we switched to a white LED as a light source, of $255 \mathrm{~mW} / \mathrm{cm}^{2}$ power. All measurements have been performed as long $(6 \mathrm{~h})$ chronoamperometric experiments at $0 \mathrm{~V}$ vs. $\mathrm{Ag} / \mathrm{AgCl}$ bias. An important finding of our work on photocathodes is that when operating at high current density, the process might be limited by oxygen diffusion. Working on papers 1 and 2 and performing all experiments galvanostatically, this was impossible to observe, but for the PN-based photocathodes, the generated photocurrent (which is very important for the final $\mathrm{H}_{2} \mathrm{O}_{2}$ yield) might be limited if the solution is not well-mixed, as shown in Fig. 7.3 below. Therefore, for all experiments with the PN-based samples, the H-cell was magnetically stirred. This was not necessary in case of the eumelanin-based photocathode, as the stirring provided by $\mathrm{O}_{2}$ purging was strong enough for the system generating much lower photocurrent.

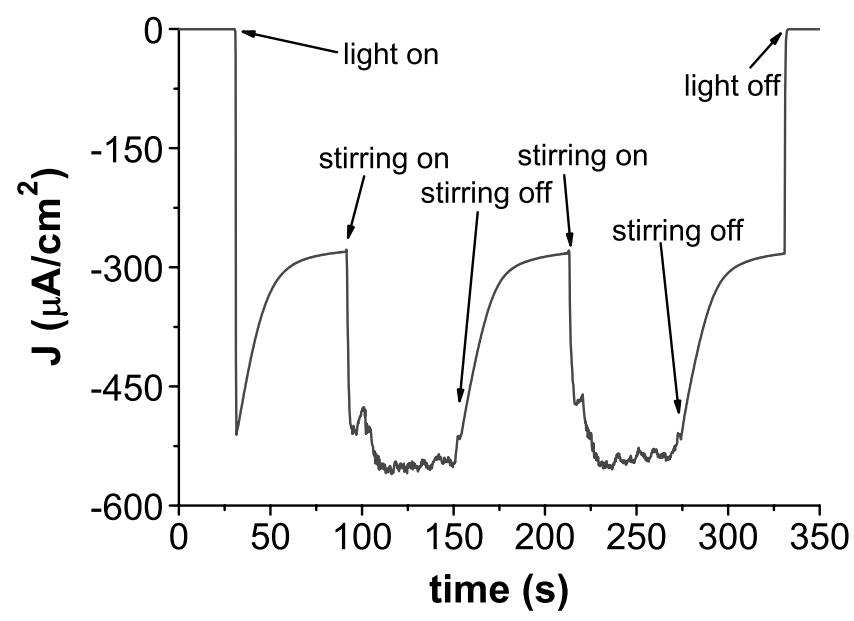

Fig. 7.3. $\mathrm{H}_{2} \mathrm{O}_{2}$ photoevolution with the $\mathrm{PN} / \mathrm{Au} / \mathrm{PTCDI}$ device at $\mathrm{pH} 7$ with magnetic stirring switched on/off in $60 \mathrm{~s}$ cycles. The experiment shows crucial role of the oxygen diffusion on the photocurrent value, especially prominent for well-performing systems. For currents below $100 \mu \mathrm{A} / \mathrm{cm}^{2}$ stirring has no impact on its value ${ }^{156}$. Published by The Royal Society of Chemistry. 
It is assumed that taking of the solution aliquots (every 1.5 - $2 \mathrm{~h}$ for PN-based photocathodes; illumination and stirring were interrupted for a short time), due to their low volume (25 - $100 \mu \mathrm{L}$ ), did not contribute significantly to the decrease in the electrolyte level. For the eumelanin sample, the aliquot has been taken only at the end of the experiment. $\mathrm{H}_{2} \mathrm{O}_{2}$ concentration has always been determined with the HRP/TMB assay described in Chapter 6.5.

Just like in the electrocatalytic $\mathrm{H}_{2} \mathrm{O}_{2}$ evolution, using the same methodology, calculation of faradaic efficiency has also been performed for every time point corresponding to the $\mathrm{H}_{2} \mathrm{O}_{2}$ measurement. In this case however, as the current was not stable and defined value, instead of the $\mathrm{I} \cdot \mathrm{t}$ product, we used a value of the total charge passed $\left(\mathrm{Q}_{\mathrm{tot}}\right)$ at the given time of the experiment, that is an integral of the $I=f(t)$ function. Calculations have been performed with Excel software.

\subsection{Photocatalysis for $\mathbf{H}_{2} \mathrm{O}_{2}$ evolution}

Short summary of the process, performed with layers of organic semiconductors or their watersoluble derivatives: Long-term irradiation of the oxygenated water solution of sacrificial electron donor with solution aliquots taken over the course of the experiment to measure $\mathrm{H}_{2} \mathrm{O}_{2}$ concentration. After the experiment, content of the active material is determined for the calculation of the turnover number.

In papers 4, 5, and 6 we investigated the possibility of photocatalytic $\mathrm{H}_{2} \mathrm{O}_{2}$ generation with different photocatalysts. Whenever hydrogen peroxide was generated, it was also associated with the chemical degradation of the material, visible as photobleaching. Therefore, for each new experiment, a fresh sample of photocatalyst was used. We always used the simple setup shown in Fig. 7.4, which consists of the tightly closed vial (4 or $20 \mathrm{ml}$; transparent glass) which contained the reaction solution with photocatalyst and pure oxygen under pressure of 1 bar. Volume of the mixture was from 0.4 to $1 \mathrm{ml}$. In contrast to (photo)electrocatalytic experiments, solutions have been purged with oxygen only before the experiment and again each time after the vial was opened to take an aliquot of the solution. This significantly simplifies the reaction system and solves the possible problem of water evaporation caused by gas purging, which is especially important considering the low volume of the electrolyte and irradiation-induced heating. Even though the setup is equipped with a fan to maintain room temperature, thermal dissipation of light energy is unavoidable. Considering the range of $\mathrm{H}_{2} \mathrm{O}_{2}$ concentrations and $\mathrm{O}_{2}$ volume in the vials, oxygen consumption is neglectable, therefore a constant active supply is not necessary. Nevertheless, as proved by the example of 
photoelectrochemical $\mathrm{H}_{2} \mathrm{O}_{2}$ evolution, stirring induced by a gas stream (or any other form of solution mixing) could have positive effect on the reaction yield. This however was never tested in our initial studies.
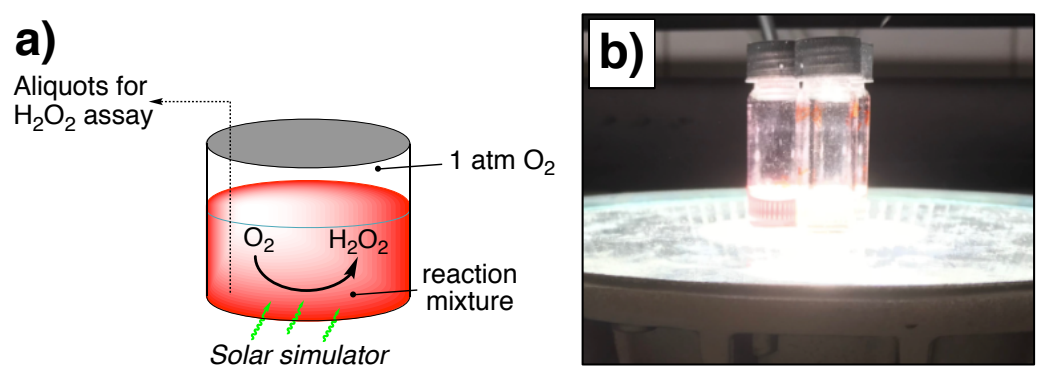

Fig. 7.4. The setup used in photocatalytic $\mathrm{H}_{2} \mathrm{O}_{2}$ evolution, at the example of a dye-catalyzed process: a) schematic, b) picture of the system during the experiment. Depending on the photocatalyst, either a white LED (of $105 \mathrm{~mW} / \mathrm{cm}^{2}$ light power) or violet LED (of $120 \mathrm{~mW} / \mathrm{cm}^{2}$ light power) is used. Thanks to the size of the light beam, it is possible to irradiate up to 4 vials simultaneously.

Apart from water and dissolved oxygen, the solution may contain $\mathrm{HCl}$ or $\mathrm{NaOH}$ (to adjust the $\mathrm{pH}$ ) and sacrificial electron donor, which as an easily oxidizable compound, not only facilitates the reduction of $\mathrm{O}_{2}$ to $\mathrm{H}_{2} \mathrm{O}_{2}$ but also prevents the semiconductor from its autooxidation. The photocatalyst can be employed in different forms:

- As a layer, deposited on a piece of transparent plastic foil of the diameter equal to the diameter of the bottom of the vial, mounted to it with silicone grease. This way eumelanin, P3HT, EPI, and PTCDI have been investigated in papers 4 and 5.

- As a dispersion of colloidally stable particles: EPI in paper 5.

- As a molecular solution of dye: PDI-S, QNC-S and NDI-G in paper 6.

The advantage of using the catalyst in a form of colloidal dispersion or molecular solution is that the theoretical ratio of number of catalytically active sites to the material volume is much higher. In the case of catalytic layer of $100-200 \mathrm{~nm}$ thickness, most of the material cannot participate in $\mathrm{H}_{2} \mathrm{O}_{2}$ photoevolution, as only the part in close vicinity of the solution is active. Therefore, the photoreaction rates with photocatalysts deposited on the substrate are expected to be lower. 
It is worth noting that although the methodology of $\mathrm{H}_{2} \mathrm{O}_{2}$ photocatalytic synthesis is exactly the same for both the semiconductors and the dyes, the mechanism of the process is completely different, as described in paper 6 .

In case of the EPI dispersions, we noticed that the higher the ionic strength, the lower the colloidal stability. Therefore, we decided not to use buffers and adjust the $\mathrm{pH}$ to a desired value with $\mathrm{HCl}$ or $\mathrm{NaOH}$, introducing a smaller amount of ions compared with buffers. The same is valid for solutions of dyes, which tend to aggregate in solutions of high ionic strength.

Due to low volume of the solutions, taking of the aliquots $(5-50 \mu \mathrm{L})$ may have significant impact on the process with the materials in form of layers, changing the ratio of the catalytic area to solution volume. Therefore, only one intermediate aliquot is taken during these experiments. For EPI dispersions and dye solutions, as the catalyst is uniformly spread in the reaction mixture and the light power is sufficiently high, we assume that the $\mathrm{H}_{2} \mathrm{O}_{2}$ photoevolution is independent on the volume of the reaction mixture.

The solution aliquots were taken mainly for the purpose of the $\mathrm{H}_{2} \mathrm{O}_{2}$ assay, always performed with the HRP/TMB method described in Chapter 6.5. In the case of dye solutions, it allowed also measurement of absorbance, photoluminescence, and light scattering during the process, as described in paper 6. Although the aliquot after these assays is not changed and could be returned to the reaction mixture, for the sake of time efficiency, we did not do so. Therefore, the irradiation experiment could be continued while the measurements were performed.

In contrast to electrocatalytic and photoelectrocatalytic experiments, the organic materials we tested always degraded during photocatalytic experiments. Therefore, the important part of their investigation is to determine the degree of the material loss. Considering that all of the used materials are pigments, the most convenient method is UV-Vis spectroscopy. In the best-case scenario, we can simply measure absorbance of the layer/dispersion/solution at the given wavelength before and after the measurement and calculate the molar amount of the remaining catalyst. However, this is hampered by many factors. First of all, nanocrystalline films of organic pigments may undergo light-induced polymorphic transitions. This changes their optical properties, which can be observed as a change of the absorption spectrum features. Therefore, direct measurement of the absorption leads to incorrect results. In case of the EPI dispersions and the dye solutions, the other issue is aggregation of the material. Optical properties of the aggregated mixture might be significantly different. Therefore, to be able to rely on the UV-Vis spectroscopy for determination of the material concentration, the material needs to be turned into a molecular solution. Although this can be done relatively easily in case 
of P3HT (soluble in chloroform) and EPI (soluble in DMSO), it is difficult to perform with PTCDI, insoluble in any conventional solvent. We addressed this issue by dissolution of the material in concentrated $\mathrm{H}_{2} \mathrm{SO}_{4}{ }^{85}$, which is inconvenient to work with, but allows for reliable determination of the PTCDI content. The same approach was also applied in case of the dye solutions. Although the aggregation problem could be probably solved by long sonication at elevated temperature, it was simply easier to evaporate water completely and change the solvent to $\mathrm{H}_{2} \mathrm{SO}_{4}$. Apart from time efficiency, this approach has another advantage. For pigments, in the vast majority of cases, they degrade to products which do not absorb light above $400 \mathrm{~nm}$, which can be seen as a colorless $\mathrm{H}_{2} \mathrm{O}_{2}$ solution and no changes in the normalized spectra of the material dissolved in $\mathrm{H}_{2} \mathrm{SO}_{4}$. However, in the case of dyes, sometimes spectra of water solution of a dye and their degradation product overlap. Therefore, even if a dye remains in its molecular form, its quantification by the absorbance measurement might be impossible. Fortunately, the $\mathrm{H}_{2} \mathrm{SO}_{4}$ dissolution of the solid residue after water evaporation from the reaction mixture, shifts the $\lambda_{\max }$ of dyes by $50-100 \mathrm{~nm}$ towards higher wavelengths. This effect is selective for the dyes and does not occur for their degradation products, what results in consistency of the absorption spectra with the references, obtained for unused materials.

The data collected this way allowed for calculation of the molar amount of degraded material during the reaction. Based on these values, we could directly estimate the relative stability of given material in different conditions ( $\mathrm{pH}$, sacrificial electron donor). To be able to compare the results obtained for different materials, for each of them we calculated the turnover number (TON). This figure-of-merit, frequently used in catalysis ${ }^{157}$, states how many molecules of the substrates are converted by a single molecule of the catalyst before it gets inactivated. In our study we associated the $\mathrm{H}_{2} \mathrm{O}_{2}$ evolution efficiency with degradation of the materials, using the following formula for calculation of the TON:

$$
\text { TON }=\frac{n_{\mathrm{H}_{2} \mathrm{O}_{2} \text { generated }}}{n_{\text {catalyst degraded }}}
$$




\section{Concluding remarks}

The aim of this thesis was to investigate the possibility of using organic electronic materials in environmentally friendly production of hydrogen peroxide, using oxygen and water as primary substrates. Thanks to our efforts, shown in papers $1-6$, we conclude that organic electronic materials: conducting and semiconducting polymers and small-molecule semiconductors of all types (p, n, and ambipolar) can be used in electro-, photoelectro- and photochemical synthesis of $\mathrm{H}_{2} \mathrm{O}_{2}$. There are many advantages of these approaches, but as of now, the existing limitations need to be overcome before they can be an alternative to current industrial processes of hydrogen peroxide production or be applied in medicine.

\subsection{Advantages of $\mathrm{H}_{2} \mathrm{O}_{2}$ synthesis with organic electronic materials}

In the papers 1 and 2 we investigated the possibility of electrocatalytic $\mathrm{H}_{2} \mathrm{O}_{2}$ synthesis, proving that the process works in a wide $\mathrm{pH}$ range and that the catalysts are chemically stable. Just like in current industry practice, this could be a useful alternative to the anthraquinone process whenever diluted water solution of $\mathrm{H}_{2} \mathrm{O}_{2}$ is necessary. It might be also used in accumulation of solar energy, assuming that the electrolyzer is powered by sunlight. In addition, there is a possibility of implanting the materials as electrodes for in vivo generation of hydrogen peroxide.

Our efforts presented in papers 3 and 4 show that efficient photoelectrocatalysis with electrodes based on organic pigments is also possible. As hydrogen peroxide obtained this way might be used for generation of electricity, this can be an interesting approach for electrochemical energy storage. Compared with sunlight-powered electrocatalytic process, where the current generated by the PV needs to be adjusted to the values suitable for the process, the design of the photocathode-based system is much simpler. Although efficiency of the eumelanin photoelectrodes is less promising, our findings contributed to better understanding of the physical chemistry of melanins.

We also demonstrated, in the form of papers 4, 5 and 6, that organic semiconductors (or their water-soluble derivatives) of all types can be applied in photocatalysis for $\mathrm{H}_{2} \mathrm{O}_{2}$ evolution. The advantage of such a method is that the reaction setup is simple and consists only of the material, water, and oxygen. The generation of hydrogen peroxide requires only the addition of light. Even though in the case of the materials we investigated, presence of the sacrificial electron donor is also essential, the approach is still feasible and might be very useful in all fields of medicine and biology, where light-induced in situ $\mathrm{H}_{2} \mathrm{O}_{2}$ synthesis is desired. 
Common features of all the above, apart from environmentally friendly reagents, is that $\mathrm{H}_{2} \mathrm{O}_{2}$ synthesis is catalyzed by organic electronic materials. They have several advantages over inorganic materials, such as:

- good mechanical properties (e.g. flexibility);

- methods of their synthesis and deposition usually do not require high temperatures;

- physical properties, such as band gap, can be modified with chemical synthesis;

- in most cases they are based only on abundant elements: C, O, N, S. Therefore, compared with devices made of e.g. gold, are potentially much cheaper.

\subsection{Limitations of $\mathrm{H}_{2} \mathrm{O}_{2}$ synthesis with organic electronic materials and future work}

Despite advantages listed in the section above, there are also many limitations and problems related with the methods described in this thesis. First of all, some of the materials presented in our papers are not stable in the conditions used for $\mathrm{H}_{2} \mathrm{O}_{2}$ evolution, either mechanically (like PEDOT in some conditions), physically (aggregation of the dyes during the photoreaction) or chemically (degradation of photocatalysts). These problems can be potentially solved, switching to different organic electronic materials, such as other forms of PEDOT, dyes with more water-solubilizing groups incorporated, or materials with lower HOMO and LUMO levels. Selectivity of the $\mathrm{O}_{2}$ to $\mathrm{H}_{2} \mathrm{O}_{2}$ reduction also needs to be improved, especially aiming for an alternative to the anthraquinone process of hydrogen peroxide synthesis. In case of both catalysis and electrocatalysis, faradaic efficiency should be always over $90 \%$ despite accumulation of the product in the solution. For better energy efficiency, we need to look for materials which would lead to $\mathrm{H}_{2} \mathrm{O}_{2}$ (photo)electroevolution with lower overpotentials. To maintain the low cost of the entire devices it is important to avoid any expensive components, also if they are used only as substrates. Therefore, gold and ITO substrates should be replaced with other materials of higher abundance, e.g. copper or aluminum.

The photocathodes shown in the paper 3 need further optimization of not only the photocurrent value but also stability. Possibly, this problem can be solved by implementing other organic pigments, such as metal-containing phthalocyanines. Assuming that it could result also in more efficient tandem architecture, the goal of the photoelectrolyser operating efficiently without necessity of the external bias is also achievable.

The main limitation of the photocatalytic approach, apart from poor stability of the materials, is necessity of using sacrificial electron donors. As the ultimate goal is the stable 
system which reduces $\mathrm{O}_{2}$ to $\mathrm{H}_{2} \mathrm{O}_{2}$ at the cost of water oxidation, we need to look for the materials able to catalyze this process. Aiming for bio-applications of photocatalytic $\mathrm{H}_{2} \mathrm{O}_{2}$ generation, optical transparency of the tissues needs to be taken into consideration ${ }^{158}$, therefore the organic pigments and dyes employed should be of even lower band gap to be able to absorb red light. If it cannot be achieved without providing full resistance to photobleaching, the resulting degradation product should at least not be toxic. 



\section{References}

[1] R. Hage and A. Lienke, Angew. Chemie - Int. Ed., 2005, 45, 206-222.

[2] M. Devic, S. Foyles, Bleaching of Plant Materials, US Pat. 5480788, 1996.

[3] L. Campanella, R. Roversi, M. P. Sammartino and M. Tomassetti, J. Pharm. Biomed. Anal., 1998, 18, 105-116.

[4] T. A. Wilgus, V. K. Bergdall, L. A. Dipietro and T. M. Oberyszyn, Wound Repair Regen., 2005, 13, 513-519.

[5] A. Cervone, L. Torre, L. D’Agostino, A. J. Musker, G. T. Roberts, C. Bramanti and G. Saccoccia, Collect. Tech. Pap. - AIAA/ASME/SAE/ASEE 42nd Jt. Propuls. Conf., 2006, 11, 8786-8796.

[6] J. M. Campos-Martin, G. Blanco-Brieva and J. L. G. Fierro, Angew. Chemie - Int. Ed., 2006, 45, 6962-6984.

[7] E. Miglbauer, P. J. Wójcik and E. D. Głowacki, Chem. Commun., 2018, 54, 1187311876.

[8] J.R. Stone, S. Yang, Antioxidants \& redox signaling, 2006, 8, 244-262.

[9] B. C. Dickinson and C. J. Chang, Nat. Chem. Biol., 2011, 7, 504-511.

[10] M. Chang, M. Wang, M. Wang, M. Shu, B. Ding, C. Li, M. Pang, S. Cui, Z. Hou and J. Lin, Adv. Mater., 2019, 1905271, 1-10.

[11] G. Vilema-Enríquez, A. Arroyo, M. Grijalva, R. I. Amador-Zafra and J. Camacho, Oxid. Med. Cell. Longev., 2016, 1908164, 1-12.

[12] T. Arbring Sjöström, M. Berggren, E. O. Gabrielsson, P. Janson, D. J. Poxson, M. Seitanidou and D. T. Simon, Adv. Mater. Technol., 2018, 3, 1700360, 1-10.

[13] S. C. Perry, D. Pangotra, L. Vieira, L. I. Csepei, V. Sieber, L. Wang, C. Ponce de León and F. C. Walsh, Nat. Rev. Chem., 2019, 3, 442-458.

[14] A. Verdaguer-Casadevall, D. Deiana, M. Karamad, S. Siahrostami, P. Malacrida, T. W. Hansen, J. Rossmeisl, I. Chorkendorff and I. E. L. Stephens, Nano Lett., 2014, 14, 1603-1608.

[15] A. J. Hoffman, E. R. Carraway and M. R. Hoffmann, Environ. Sci. Technol., 1994, 28, $776-785$.

[16] R. E. Stephens, B. Ke, D. Trivich, J. Phys. Chem., 1955, 59, 966-969.

[17] M. Jakešová, D. H. Apaydin, M. Sytnyk, K. Oppelt, W. Heiss, N. S. Sariciftci and E. D. Głowacki, Adv. Funct. Mater., 2016, 26, 5248-5254. 
[18] J. B. Sperry and D. L. Wright, Chem. Soc. Rev., 2006, 35, 605-621.

[19] A. J. Bard and L.R. Faulkner, Electrochemical Methods: Fundamentals and Applications (2nd ed.), John Wiley \& Sons, New York, 2001.

[20] J. Udagawa, P. Aguiar and N. P. Brandon, J. Power Sources, 2007, 166, 127-136.

[21] R. Francke and R. D. Little, Chem. Soc. Rev., 2014, 43, 2492-2521.

[22] M. Carmo, D. L. Fritz, J. Mergel and D. Stolten, Int. J. Hydrogen Energy, 2013, 38, 4901-4934.

[23] J. Fauvarque, Pure Appl. Chem., 1996, 68, 1713-1720.

[24] J. H. Simons and W. J. Harland, JES, 1949, 95, 47-66.

[25] M. Wessling and H. J. Schafer, Chem.Ber., 1991, 124, 2303-2306.

[26] C. W. Jones, Applications of Hydrogen Peroxide and Derivatives, Royal Society of Chemistry, 1999.

[27] Z. Chen, H. N. Dinh and E. Miller, Photoelectrochemical water splitting: standards, experimental methods, and protocols, Springer, New York, Heidelberg, Dordrecht, London, 2013.

[28] L. Steier and S. Holliday, J. Mater. Chem. A, 2018, 6, 21809-21826.

[29] N. S. Sariciftci, L. Smilowitz, A. J. Heeger and F. Wudl, Synth. Met., 1993, 59, 333352.

[30] W. A. Smith, Photoelectrochemical Cell Design, Efficiency, Definitions, Standards, and Protocols in Photoelectrochemical Solar Fuel Production, Springer International Publishing Switzerland, 2016.

[31] B. Liu, Z. Jin, L. Bai, J. Liang, Q. Zhang, C. Liu, Y. Zhao and X. Zhang, J. Mater. Chem. A, 2015, 3, 15583-15590.

[32] Y. H. Lai, K. C. Lin, C. Y. Yen and B. J. Jiang, Faraday Discuss., 2019, 215, 297-312.

[33] A. Fujishima and K. Honda, Nature, 1972, 238, 37-38.

[34] P. Lianos, Appl. Catal. B Environ., 2017, 210, 235-254.

[35] M. Halmann, Nature, 1978, 275, 115-116.

[36] M. K. Węcławski, M. Jakešová, M. Charyton, N. Demitri, B. Koszarna, K. Oppelt, S. Sariciftci, D. T. Gryko and E. D. Głowacki, J. Mater. Chem. A, 2017, 5, 20780-20788.

[37] O. Jung, M. L. Pegis, Z. Wang, G. Banerjee, C. T. Nemes, W. L. Hoffeditz, J. T. Hupp, C. A. Schmuttenmaer, G. W. Brudvig and J. M. Mayer, J. Am. Chem. Soc., 2018, 140, 4079-4084.

[38] M. Dasog, A. I. Carim, S. Yalamanchili, H. A. Atwater and N. S. Lewis, Nano Lett., 2016, 16, 5015-5021. 
[39] C. Gao, J. Wang, H. Xu and Y. Xiong, Chem. Soc. Rev., 2017, 46, 2799-2823.

[40] I. T. Peternel, N. Koprivanac, A. M. L. Božić and H. M. Kušić, J. Hazard. Mater., 2007, 148, 477-484.

[41] A. J. Esswein and D. G. Nocera, Chem. Rev., 2007, 107, 4022-4047.

[42] H. Hou, X. Zeng and X. Zhang, Angew. Chemie Int. Ed., in press (DOI:10.1002/anie.201911609).

[43] N. Serpone and A. V. Emeline, J. Phys. Chem. Lett., 2012, 3, 673-677.

[44] M. Schreck and M. Niederberger, Chem. Mater., 2019, 31, 597-618.

[45] M. Gryszel, M. Sytnyk, M. Jakesova, G. Romanazzi, R. Gabrielsson, W. Heiss and E. D. Głowacki, ACS Appl. Mater. Interfaces, 2018, 10, 13253-13257.

[46] M. Qureshi and K. Takanabe, Chem. Mater., 2017, 29, 158-167.

[47] D. Beydoun, R. Amal, G. Low and S. McEvoy, J. Nanoparticle Res., 1999, 1, 439458 .

[48] T. Adachi, S. S. Latthe, S. W. Gosavi, N. Roy, N. Suzuki, H. Ikari, K. Kato, K. Katsumata, K. Nakata, M. Furudate, T. Inoue, T. Kondo, M. Yuasa, A. Fujishima and C. Terashima, Appl. Surf. Sci., 2018, 458, 917-923.

[49] Z. Pan, J. A. Röhr, Z. Ye, Z. S. Fishman, Q. Zhu, X. Shen and S. Hu, Sustain. Energy Fuels, 2019, 3, 850-864.

[50] V. Iliev, D. Tomova, L. Bilyarska, A. Eliyas and L. Petrov, Appl. Catal. B Environ., 2006, 63, 266-271.

[51] T. Kawahara, Y. Konishi, H. Tada, N. Tohge, J. Nishii and S. Ito, Angew. Chemie, 2002, 41, 2811-2813.

[52] Z. Jiang, W. Wan, H. Li, S. Yuan, H. Zhao and P. K. Wong, Adv. Mater., 2018, 1706108, 1-9.

[53] J. Cao, X. Li, H. Lin, S. Chen and X. Fu, J. Hazard. Mater., 2012, 239-240, 316-324.

[54] X. Xia, M. Song, H. Wang, X. Zhang, N. Sui, Q. Zhang, V. L. Colvin and W. W. Yu, Nanoscale, 2019, 11, 11071-11082.

[55] Y. Pellegrin and F. Odobel, Comptes Rendus Chim., 2017, 20, 283-295.

[56] M. Wang, W. Zhen, B. Tian, J. Ma and G. Lu, Appl. Catal. B Environ., 2018, 236, $240-252$.

[57] S. Y. Reece, J. A. Hamel, K. Sung, T. D. Jarvi, A. J. Esswein, J. J. H. Pijpers and D. G. Nocera, Science, 2011, 334, 645-648. 
[58] J. M. Coronado, F. Fresno, M. D. Hernández-Alonso and R. Portela, Design of advanced photocatalytic materials for energy and environmental applications, Springer, London, Heidelberg, New York, Dordrecht, 2013.

[59] L. Yang, A. Hakki, L. Zheng, M. R. Jones, F. Wang and D. E. Macphee, Cem. Concr. Res., 2019, 116, 57-64.

[60] T. R. Rubin, J. G. Calvert, G. T. Rankin and W. MacNevin, J. Am. Chem. Soc., 1953, 75, 2850-2853.

[61] Y. Shiraishi, S. Kanazawa, Y. Sugano, D. Tsukamoto, H. Sakamoto, S. Ichikawa and T. Hirai, ACS Catal., 2014, 4, 774-780.

[62] R. Wang, X. Zhang, F. Li, D. Cao, M. Pu, D. Han, J. Yang and X. Xiang, J. Energy Chem., 2018, 27, 343-350.

[63] J. A. Dean, Lange's Handbook of Chemistry (15th ed.), McGraw-Hill, 1999.

[64] R. C. Taylor and P. C. Cross, J. Am. Chem. Soc., 1949, 71, 2266-2268.

[65] C. D. Hurd and H. P. Puterbaugh, J. Am. Chem. Soc., 1930, 52, 950-953.

[66] F. Cataldo, Ann. West Univ. Timisoara. Ser. Chem., 2014, 23, 99-110.

[67] M. Huwiler and H. Kohler, Eur. J. Biochem., 1984, 141, 69-74.

[68] J. Williams, J. Gen. Physiol., 1928, 11, 309-337.

[69] P. R. Johnston, 1,2-Diaminocyclohexane Tetraacetic Acid as $\mathrm{H}_{2} \mathrm{O}_{2}$ stabilizer, US Pat. 2961306, 1960.

[70] K. R. Messner and J. A. Imlay, J. Biol. Chem., 1999, 274, 10119-10128.

[71] J. M. McCord and I. Fridovich, J. Biol. Chem., 1969, 244, 6049-6055.

[72] M. L. Pegis, C. F. Wise, D. J. Martin and J. M. Mayer, Chem. Rev., 2018, 118, 23402391.

[73] D. A. Armstrong, R. E. Huie, S. Lymar, W. H. Koppenol, G. Merényi, P. Neta, D. M. Stanbury, S. Steenken and P. Wardman, BioInorg. React. Mech., 2013, 9, 59-61.

[74] L. Cui, P. Ding, M. Zhou and W. Jing, Chem. Eng. J., 2017, 330, 1316-1325.

[75] S. N. Remello, F. Kuttassery, S. Mathew, A. Thomas, D. Yamamoto, Y. Nabetani, K. Sano, H. Tachibana and H. Inoue, Sustain. Energy Fuels, 2018, 2, 1966-1973.

[76] H. W. Kim, M. B. Ross, N. Kornienko, L. Zhang, J. Guo, P. Yang and B. D. McCloskey, Nat. Catal., 2018, 1, 282-290.

[77] S. Siahrostami, A. Verdaguer-Casadevall, M. Karamad, D. Deiana, P. Malacrida, B. Wickman, M. Escudero-Escribano, E. A. Paoli, R. Frydendal, T. W. Hansen, I. Chorkendorff, I. E. L. Stephens and J. Rossmeisl, Nat. Mater., 2013, 12, 1137-1143. 
[78] M. N. Tsampas, A. Pikos, S. Brosda, A. Katsaounis and C. G. Vayenas, Electrochim. Acta, 2006, 51, 2743-2755.

[79] S. R. Samms, S. Wasmus and R. F. Savinell, J. Electrochem. Soc., 1996, 143, 1498 1504.

[80] D. Tromans, Ind. Eng. Chem. Res., 2000, 39, 805-812.

[81] R. Sander, Atmos. Chem. Phys., 2015, 15, 4399-4981.

[82] E. D. Głowacki, G. Voss and N. S. Sariciftci, Adv. Mater., 2013, 25, 6783-6800.

[83] F. H. Chung and R. W. Scott, J. Appl. Crystallogr., 1971, 4, 506-511.

[84] S. J. Palenik, Microscopy Today, 1996, 4, 6-7.

[85] Y. Nagao, Prog. Org. Coatings, 1997, 31, 43-49.

[86] E. D. Głowacki, G. Romanazzi, C. Yumusak, H. Coskun, U. Monkowius, G. Voss, M. Burian, R. T. Lechner, N. Demitri, G. J. Redhammer, N. Sünger, G. P. Suranna and S. Sariciftci, Adv. Funct. Mater., 2015, 25, 776-787.

[87] D.D. Eley, Nature, 1948, 162, 819.

[88] C.W. Tang, Multilayer Organic Photovoltaic Elements, US Pat. 4164431, 1979.

[89] E. D. Głowacki, H. Coskun, M. A. Blood-Forsythe, U. Monkowius, L. Leonat, M. Grzybowski, D. Gryko, M. S. White, A. Aspuru-Guzik and N. S. Sariciftci, Org. Electron., 2014, 15, 3521-3528.

[90] E. D. Głowacki, M. Irimia-Vladu, M. Kaltenbrunner, J. Gąsiorowski, M. S. White, U. Monkowius, G. Romanazzi, G. P. Suranna, P. Mastrorilli, T. Sekitani, S. Bauer, T. Someya, L. Torsi and N. S. Sariciftci, Adv. Mater., 2013, 25, 1563-1569.

[91] E. Kozma and M. Catellani, Dye. Pigment., 2013, 98, 160-179.

[92] P. O. Schwartz, L. Biniek, E. Zaborova, B. Heinrich, M. Brinkmann, N. Leclerc and S. Méry, J. Am. Chem. Soc., 2014, 136, 5981-5992.

[93] M. Park and J. W. Jung, Dye. Pigment., 2017, 143, 301-307.

[94] C. V. Kumar, G. Sfyri, D. Raptis, E. Stathatos and P. Lianos, RSC Adv., 2015, 5, 37863791 .

[95] United States Food and Drug Administration, https://www.fda.gov/industry/coloradditive-inventories/summary-color-additives-use-united-states-foods-drugs-cosmeticsand-medical-devices, (accessed December 2019).

[96] E. D. Głowacki, G. Voss, K. Demirak, M. Havlicek, N. Sünger, A. C. Okur, U. Monkowius, J. Gąsiorowski, L. Leonat and N. S. Sariciftci, Chem. Commun., 2013, 49, 6063-6065.

[97] Z. Hao and A. Iqbal, Chem. Soc. Rev., 1997, 26, 203-213. 
[98] J. Mizuguchi and T. Senju, J. Phys. Chem. B, 2006, 110, 19154-19161.

[99] K. Kotwica, P. Bujak, D. Wamil, M. Materna, L. Skorka, P. A. Gunka, R. Nowakowski, B. Golec, B. Luszczynska, M. Zagorska and A. Pron, Chem. Commun., 2014, 50, 11543-11546.

[100] O. Wallquist and R. Lenz, Macromol. Symp., 2002, 187, 617-629.

[101] C. B. Nielsen, R. S. Ashraf, B. C. Schroeder, P. D’Angelo, S. E. Watkins, K. Song, T. D. Anthopoulos and I. McCulloch, Chem. Commun., 2012, 48, 5832-5834.

[102] M. G. Walter, A. B. Rudine and C. C. Wamser, J. Porphyr. Phthalocyanines, 2010, 14, 759-792.

[103] R. Bonnett, Chem. Soc. Rev., 1995, 24, 19-33.

[104] H. Shirakawa, E. J. Louis, A. G. MacDiarmid, C. K. Chiang and A. J. Heeger, J. Chem. Soc. Chem. Commun., 1977, 578-580.

[105] G. Wang, J. Swensen, D. Moses and A. J. Heeger, J. Appl. Phys., 2003, 93, 6137-6141.

[106] J. Hynynen, D. Kiefer, L. Yu, R. Kroon, R. Munir, A. Amassian, M. Kemerink and C. Müller, Macromolecules, 2017, 50, 8140-8148.

[107] D. Floresyona, F. Goubard, P. H. Aubert, I. Lampre, J. Mathurin, A. Dazzi, S. Ghosh, P. Beaunier, F. Brisset, S. Remita, L. Ramos and H. Remita, Appl. Catal. B Environ., 2017, 209, 23-32.

[108] R. D. McCullough and R. D. Lowe, J. Chem. Soc., Chem. Commun., 1992, 70-72.

[109] R. S. Loewe, S. M. Khersonsky and R. D. McCullough, Adv. Mater., 1999, 11, 250253.

[110] S. Kirchmeyer and K. Reuter, J. Mater. Chem., 2005, 15, 2077-2088.

[111] A. P. Nowak, M. Wilamowska and A. Lisowska-Oleksiak, J. Solid State Electrochem., 2010, 14, 263-270.

[112] M. Kuş and S. Okur, Sens. Actuators: B Chem., 2009, 143, 177-181.

[113] A.G. MacDiarmid and A. J. Epstein, Synth. Met., 1994, 65, 103-116.

[114] J. Nevrela, M. Micjan, M. Novota, S. Kovacova, M. Pavuk, P. Juhasz, J. Kovac, J. Jakabovic and M. Weis, J. Polym. Sci. Part B Polym. Phys., 2015, 53, 1139-1146.

[115] R. L. Haining and C. Achat-Mendes, Neural Regen. Res., 2017, 12, 372-375.

[116] P. Meredith and T. Sarna, Pigment Cell Res., 2006, 19, 572-594.

[117] A. Pezzella, M. Barra, A. Musto, A. Navarra, M. Alfè, P. Manini, S. Parisi, A. Cassinese, V. Criscuolo and M. D'Ischia, Mater. Horizons, 2015, 2, 212-220.

[118] P. R. Crippa, V. Cristofoletti and N. Romeo, BBA - Gen. Subj., 1978, 538, 164-170.

[119] J. E. McGinness, Science, 1972, 177, 896-897. 
[120] J. McGinness, P. Corry and P. Proctor, Science, 1974, 183, 853-855.

[121] J. Wünsche, Y. Deng, P. Kumar, E. Di Mauro, E. Josberger, J. Sayago, A. Pezzella, F. Soavi, F. Cicoira, M. Rolandi and C. Santato, Chem. Mater., 2015, 27, 436-442.

[122] K. S. Sree Harsha, Principles of Vapor Deposition of Thin Films, Elsevier, 2006.

[123] M. Lindner and M. Schmid, Coatings, 2017, 7(1), 9, 1-32.

[124] J. Lutišan and J. Cvengroš, Chem. Eng. J. Biochem. Eng. J., 1995, 56, 39-50.

[125] C. W. Hollars and R. C. Dunn, Rev. Sci. Instrum., 1998, 69, 1747-1752.

[126] W. Colquhoun, R. Sokol, E. Davison and L. Cassimeris, J. Electron Microsc. Tech., 1985, 2, 353-370.

[127] S. Adhikari and P. Banerji, Thin Solid Films, 2010, 518, 5421-5425.

[128] Y. Kanbur, M. Irimia-Vladu, E. D. Głowacki, G. Voss, M. Baumgartner, G.

Schwabegger, L. Leonat, M. Ullah, H. Sarica, S. Erten-Ela, R. Schwödiauer, H. Sitter, Z. Küçükyavuz, S. Bauer and N. S. Sariciftci, Org. Electron., 2012, 13, 1-6.

[129] L. E. Scriven, MRS Proc., 1988, 121, 717-729.

[130] D. W. Schubert and T. Dunkel, Mater. Res. Innov., 2003, 7, 314-321.

[131] S. Roy, K. J. Ansari, S. S. K. Jampa, P. Vutukuri and R. Mukherjee, ACS Appl. Mater. Interfaces, 2012, 4, 1887-1896.

[132] M. D. Tyona, Adv. Mater. Res., 2013, 2, 195-208.

[133] N. Sahu, B. Parija and S. Panigrahi, Indian J. Phys., 2009, 83, 493-502.

[134] R. D. Deegan, O. Bakajin, T. F. Dupont, G. Huber, S. R. Nagel and T. A. Witten, Phys. Rev. E - Stat. Physics, Plasmas, Fluids, Relat. Interdiscip. Top., 2000, 62, 756-765.

[135] A. T. Lawal and G. G. Wallace, Talanta, 2014, 119, 133-143.

[136] R. J. Waltman and J. Bargon, Can. J. Chem., 1986, 64, 76-95.

[137] D. T. Morrison and T. Robertson, Thin Solid Films, 1973, 15, 87-101.

[138] I. Kholodkov, H. Biederman, D. Slavínská, A. Choukourov and M. Trchova, Vacuum, 2003, 70, 505-509.

[139] W. Warta, R. Stehle and N. Karl, Appl. Phys. A Solids Surfaces, 1985, 36, 163-170.

[140] W. Szczepaniak, Metody instrumentalne w analizie chemicznej [Instrumental methods of chemical analysis], Wydawnictwo Naukowe PWN, Warszawa, 2005.

[141] M. Kaszuba, D. McKnight, M. T. Connah, F. K. McNeil-Watson and U. Nobbmann, J. Nanoparticle Res., 2008, 10, 823-829.

[142] D. McMullan, Scanning, 1995, 17, 175-185.

[143] Carl Zeiss Microscopy GmbH, https://www.zeiss.com/microscopy/int/products/ scanning-electron- microscopes/geminisem.html, (accessed December 2019). 
[144] Z. Minczewski, J. Marczenko, Chemia analityczna 2. Chemiczne metody analizy ilościowej[Analytical chemistry 2. Chemical methods of quantitative analysis], Wydawnictwo Naukowe PWN, Warszawa, 2001.

[145] S. Guo, D. Wen, S. Dong and E. Wang, Talanta, 2009, 77, 1510-1517.

[146] F. Jaouen, J. Phys. Chem. C, 2009, 113, 15422-15432.

[147] J. E. Frew, P. Jones and G. Scholes, Anal. Chim. Acta, 1983, 155, 139-150.

[148] B. Li, Y. Du, T. Li and S. Dong, Anal. Chim. Acta, 2009, 651, 234-240.

[149] J. G. Mohanty, J. S. Jaffe, E. S. Schulman and D. G. Raible, J. Immunol. Methods, 1997, 202, 133-141.

[150] A. Navas Díaz, F. García Sanchez and J. A. González García, Anal. Chim. Acta, 1996, 327, 161-165.

[151] S. Braun, W. R. Salaneck and M. Fahlman, Adv. Mater., 2009, 21, 1450-1472.

[152] P. I. Djurovich, E. I. Mayo, S. R. Forrest and M. E. Thompson, Org. Electron., 2009, 10, 515-520.

[153] R. Rybakiewicz, P. Gawrys, D. Tsikritzis, K. Emmanouil, S. Kennou, M. Zagorska and A. Pron, Electrochim. Acta, 2013, 96, 13-17.

[154] D. Baran, A. Balan, S. Celebi, B. Meana Esteban, H. Neugebauer, N. S. Sariciftci and L. Toppare, Chem. Mater., 2010, 22, 2978-2987.

[155] P. Peumans, A. Yakimov, S. R. Forrest, J. Appl. Phys., 2003, 93, 3693-3723.

[156] M. Gryszel, A. Markov, M. Vagin and E. D. Głowacki, J. Mater. Chem. A, 2018, 6, 24709-24716.

[157] N. Serpone and A. V. Emeline, Int. J. Photoenergy, 2002, 4, 93-131.

[158] A. M. Smith, M. C. Mancini and S. Nie, Nat. Nanotechnol., 2009, 4, 710-711. 
THE PAPERS 


\section{Papers}

The papers associated with this thesis have been removed for copyright reasons. For more details about these see:

http://urn.kb.se/resolve?urn=urn:nbn:se:liu:diva-163895 



\section{FACULTY OF SCIENCE AND ENGINEERING}

Linköping Studies in Science and Technology, Dissertation No. 2037, 2020

Department of Science and Technology

Linköping University

SE-581 83 Linköping, Sweden

www.liu.se 